Portland State University

PDXScholar

Winter 3-11-2015

\title{
Intersections of Critical Systems Thinking and Community Based Participatory Research in Developing a Web Site for Autistic Adults
}

Dora Madeline Raymaker

Portland State University

Follow this and additional works at: https://pdxscholar.library.pdx.edu/open_access_etds

Part of the Accessibility Commons, and the Computer Sciences Commons Let us know how access to this document benefits you.

\section{Recommended Citation}

Raymaker, Dora Madeline, "Intersections of Critical Systems Thinking and Community Based Participatory Research in Developing a Web Site for Autistic Adults" (2015). Dissertations and Theses. Paper 2215. https://doi.org/10.15760/etd.2212

This Dissertation is brought to you for free and open access. It has been accepted for inclusion in Dissertations and Theses by an authorized administrator of PDXScholar. Please contact us if we can make this document more accessible: pdxscholar@pdx.edu. 
Intersections of Critical Systems Thinking and Community Based Participatory Research in Developing a Web Site for Autistic Adults

by

Dora Madeline Raymaker

A dissertation submitted in partial fulfillment of the requirements for the degree of

Doctor of Philosophy

in

Systems Science

Dissertation Committee:

Wayne Wakeland, Chair

Christina Nicolaidis, Co-Chair

Katherine McDonald

Laurie Powers

Portland State University

2015 
(C) 2015 Dora Madeline Raymaker 


\begin{abstract}
People with disabilities, including those on the autism spectrum, comprise the world's largest minority and experience significant inequities in Internet use. Existing standards for accessible web sites are necessary but not sufficient without the direct engagement of end users in identifying access needs. Yet little is known about methods for effective engagement, and there are no systematically derived Web accessibility guidelines for autistic end users. Here I explore a hybrid approach to direct engagement using critical systems thinking (CST) and community based participatory research (CBPR) during the co-development of a healthcare-focused web site by the Academic Autism Spectrum Partnership in Research and Education (AASPIRE).

I explore these ideas on three levels: theory, practice, and critical self-reflection. On the theory level, I examine the common philosophical and historical roots of CST and CBPR, ways in which they intersect and complement, and propose the hybrid approach exemplified by AASPIRE. On the practice level, I explore our web site development process and evaluate the accessibility, usability, and acceptability of the web site for autistic end users; from that work, comes a set of recommendations for working with people with disabilities in technology development and a set of accessibility guidelines for autistic end users. On the critical self-reflection level, I inquire into my own experiences as an insider-researcher during the web site development. I then synthesize the levels to evaluate whether or not taking a hybrid CST/CBPR approach to web
\end{abstract}


development was effective, as indicated by the team's ability to function as an emancipatory learning organization (an indicator of effective systems thinking on an organizational level), and the overall usability and accessibility of the web site. The result of the synthesis suggests a hybrid CST/CBPR approach was effective.

Implications of this work include innovations in CST methods for operationalizing its commitment to human emancipation, potential for drawing a more ideologicallyaligned systems thinking literature into the domain of CBPR, a means for individuals wishing to create a more power-balanced learning organization, innovations around including people with disabilities in research and technology development, more accessible web sites for people on the autism spectrum, and a potential small shift of dominant discourse around autism, disability, and the value of insider-researchers over time. 


\section{Acknowledgements}

This dissertation would not exist without the kindness, support, challenge, cruelty, and love of countless friends, foes, and mentors. To those who pushed me into the unknown until a new world-view opened, I thank you. To those who made me angry enough to continue when I had no hope, I thank you. To those who gave me safe ground on which to learn (especially if it was under your desk), I thank you. To those who gave me insight, information, permission to subvert, and knowledge that resistance is possible, I thank you. To those who have patiently explained, in terms both explicit and precise, I thank you.

I thank Wayne Wakeland for making me feel at home in the Systems Science department, for accepting me into the program even when it meant bending a few rules, and for visibly delighting in systems ideas as much as I do. I thank Katherine McDonald for pushing me intellectually and academically, and for being a friend, mentor, collaborator, opportunity-opener, and intrepid conference room-mate. I thank Laurie Powers for giving me a sense of belonging at the Regional Research Institute and for restoring my hope in an academic career, as well as for her countless kindnesses and traversing the road before me. I thank my collaborators in AASPIRE, past and present, without whose hard work and belief in our ability to make a difference none of this work would have happened. I thank my parents, Edward and Catherine Raymaker for their unconditional love, support, and concern, and for teaching me how to learn. 
But especially I thank Christina Nicolaidis, whose contribution to my life as mentor, collaborator, student, ally, champion, person-who-set-me-on-the-path-of-my$\mathrm{PhD}$, and dear, dear friend is bigger than all the words at once. 


\section{Table of Contents}

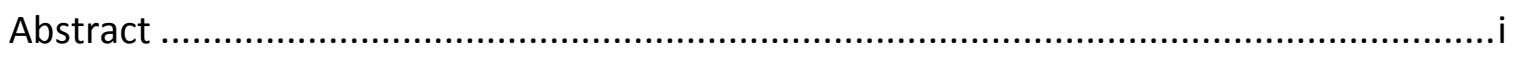

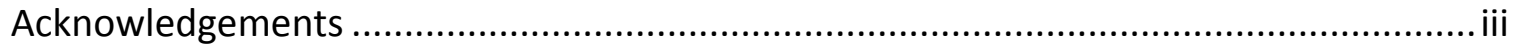

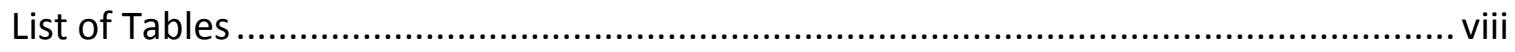

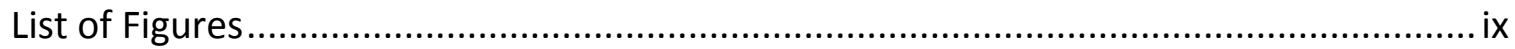

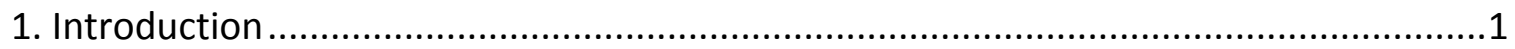

1.1. Motivation, Research Questions, and Data Sources............................................

1.2. The Academic Autistic Spectrum Partnership in Research and Education

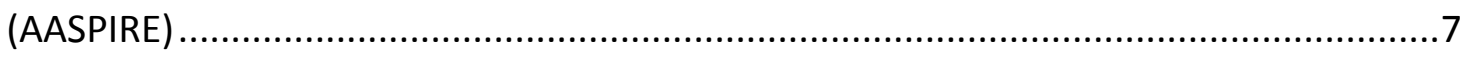

1.3. Learning Organizations \& Knowledge and Power ................................................

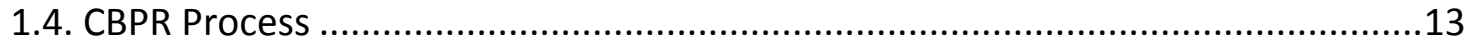

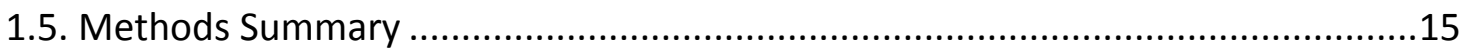

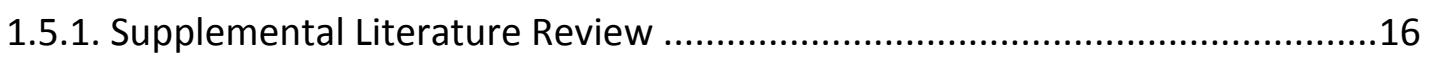

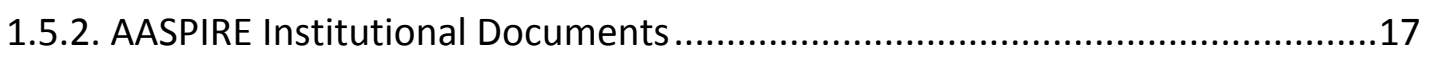

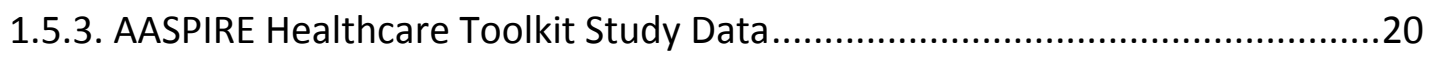

1.5.7. Reflexive Journal / Research Notes .................................................................21

2. Article 1 - Intersections of Critical Systems Thinking and Community Based Participatory Research: A Learning Organization Example with the Autistic Community24

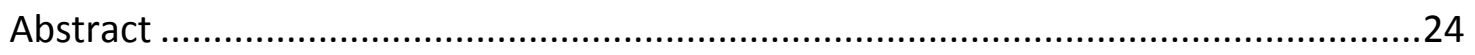

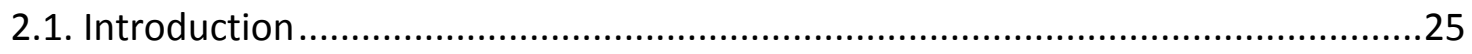

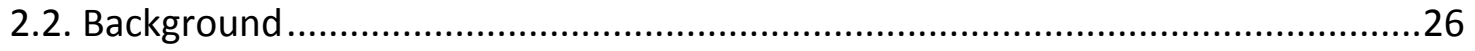

2.3. Intersections and Complements.......................................................................

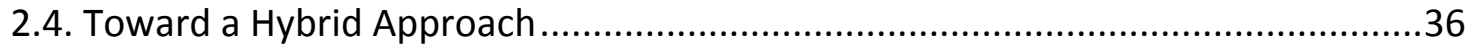

2.5. Example: Academic Autism Spectrum Partnership in Research and Education ....38

2.5.1. AASPIRE and the Learning Organization Model............................................39

2.5.2. Other Organizational Practices .....................................................................43

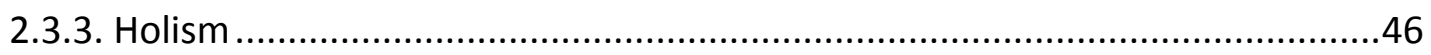

2.6. Conclusion and Future Directions.....................................................................

Acknowledgements ...............................................................................................

3. Article 2 - Community Based Participatory Research Methods in Co-Developing an Accessible Web Site for End Users on the Autism Spectrum .........................................51

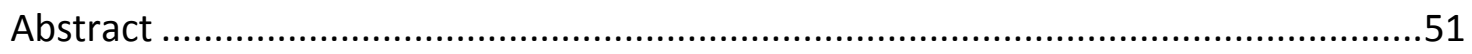




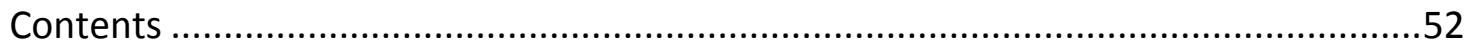

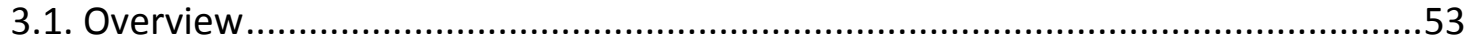



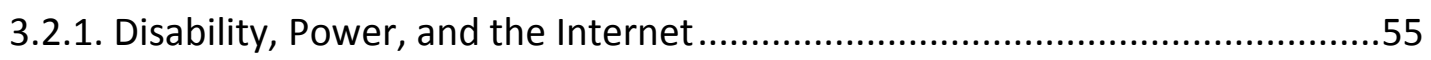

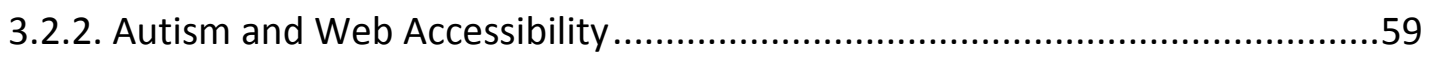

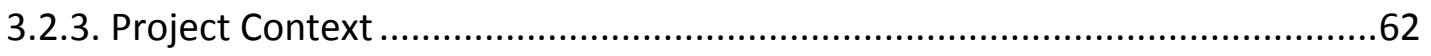

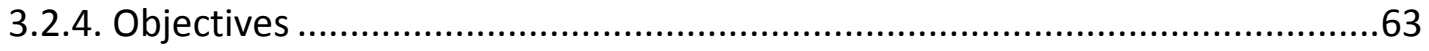

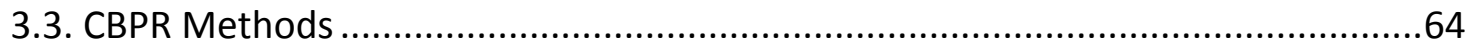

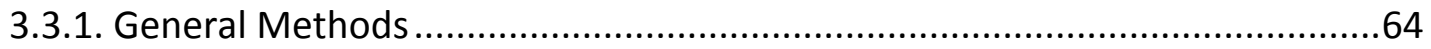

3.3.1.1. Collaboration Methods for Equitable, Iterative Involvement.................64

3.3.1.2. Development Process, Co-Learning, and Power-Sharing........................66

3.3.2. Adaptations for Web Development...........................................................68

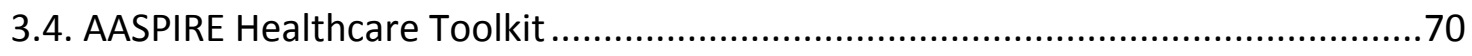

3.4.1. Informational Web Site Development ......................................................72

3.4.1.1. End User Engagement Study 1: Web Site Recommendations ................73

3.4.1.2. Alpha Web Site Development ............................................................76

3.4.1.3. End User Engagement Study 2: Usability...........................................81

3.4.2. Autism Healthcare Accommodations Tool .................................................87

3.4.2.1. End User Engagement Study 3: AHAT Usability and Refinement ............88

3.4.3. Beta Toolkit and Study 4: Evaluation .......................................................91

3.4.3.1. Beta Toolkit...................................................................................91

3.4.3.2. Study 4: Evaluation Methods.................................................................94

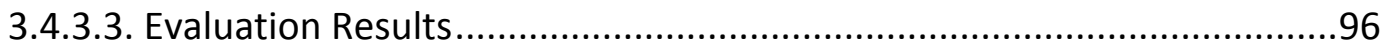

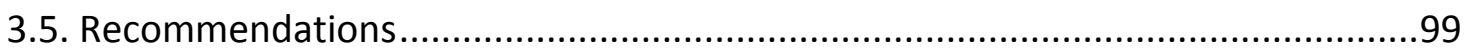

3.5.1. Methods for Community-Engaged Web Development ..............................99

3.5.2. Accessibility Guidelines for End Users on the Autism Spectrum .................103

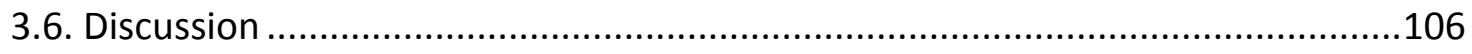

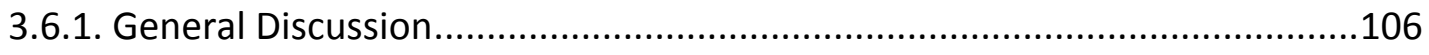

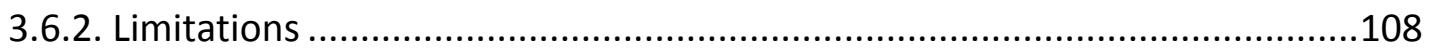

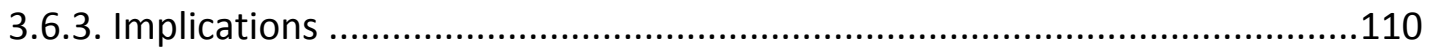

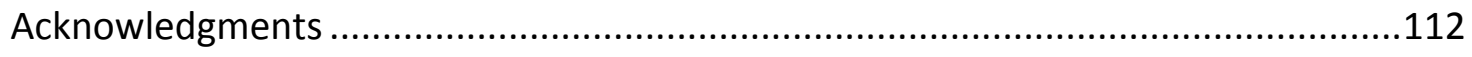


4. Article 3 - Reflections of a Community Based Participatory Researcher from the Intersection of Disability Advocacy, Engineering, and the Academy....

Abstract .114

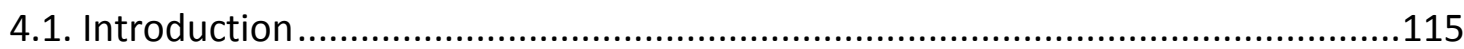

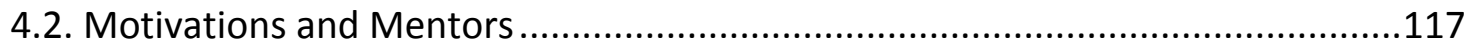

4.3. Adversity from Social Services and the Academy .......................................120

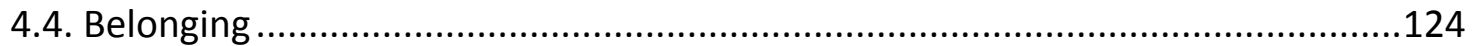

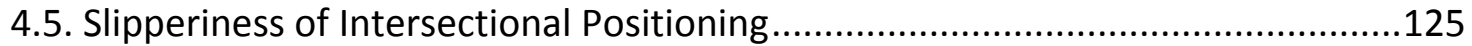

4.6. Opportunity Begets Opportunity (or Privilege Begets Privilege?) .......................127

4.7. Dichotomies of Competency and Inadequacy .............................................128

4.8. Heightened Stakes of Success or Failure ...................................................130

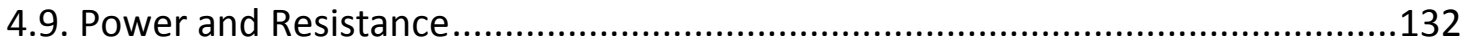

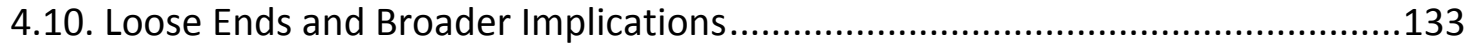

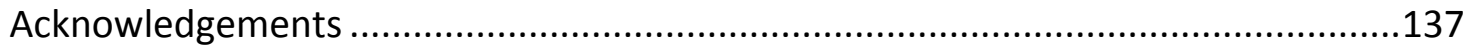

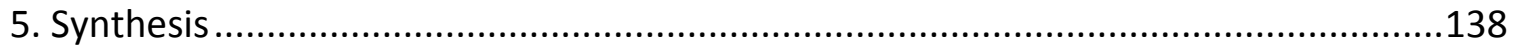

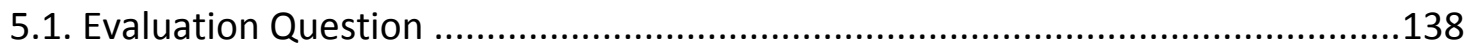

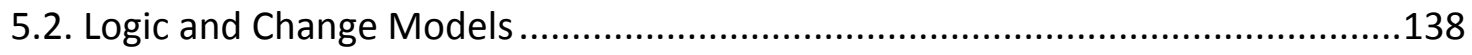

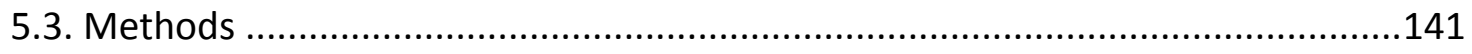

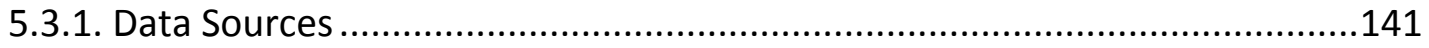

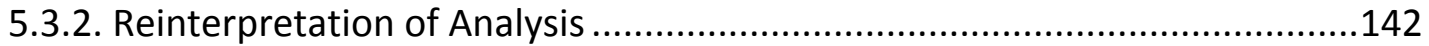

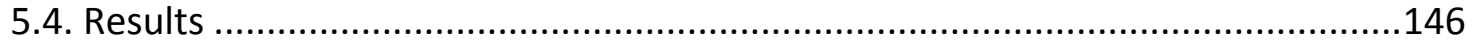

5.4.1. Q1: Did the team operate equitably as a learning organization? ................146

5.4.1.1. The Barriers to Learning and the Five Disciplines ................................146

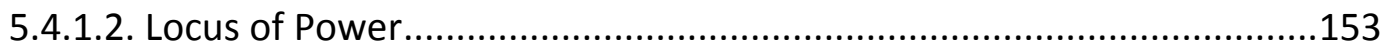

5.4.2. Q2: Was the web site perceived as high-quality by autistic people? ...........157

5.4.3. Synthesis: How did a hybrid CST/CBPR approach impact the quality of the

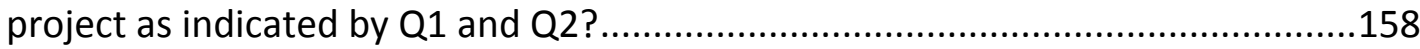

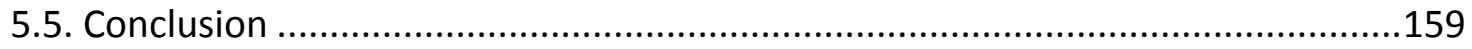

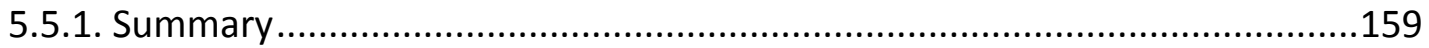

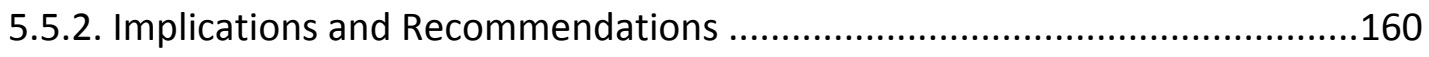

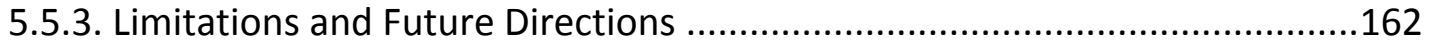

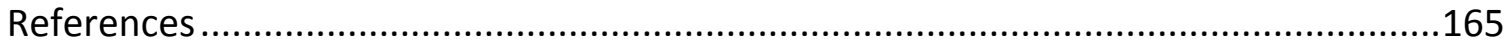




\section{List of Tables}

Table 1 - Data Source Summary .16

Table 2: CBPR's Framework for Critical Reflection (extrapolated from Wallerstein and

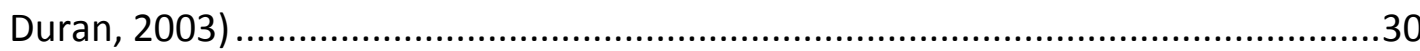

Table 3: Principles of the Web Content Accessibility Guidelines (WCAG) .......................57 Table 4: Nine Principles of Community Based Participatory Research (extrapolated from

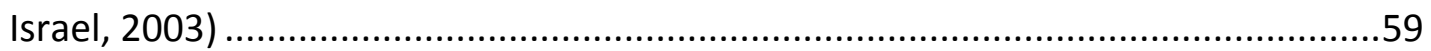

Table 5: Study 1: Recommendations Demographics ................................................75

Table 6: Study 2 Web Site Usability Demographics ......................................................84

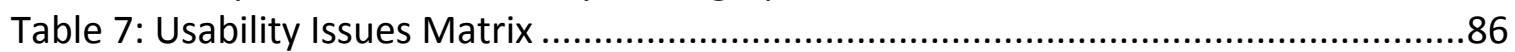

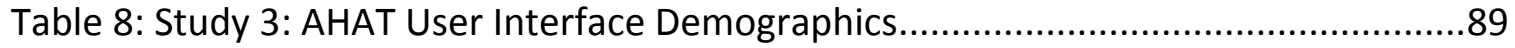

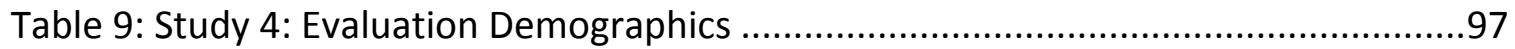

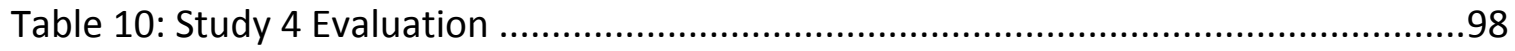

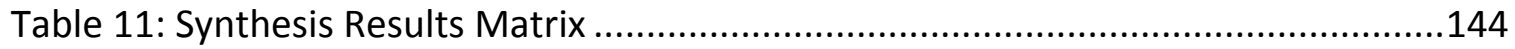




\section{List of Figures}

Figure 1: Conceptual Relationship Between Components .......................................6

Figure 2: Relationship of Data Sources to Articles and Synthesis....................................

Figure 3: End User Engagement and Evaluation Studies ...........................................71

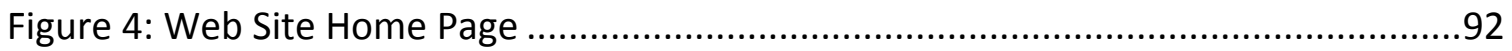

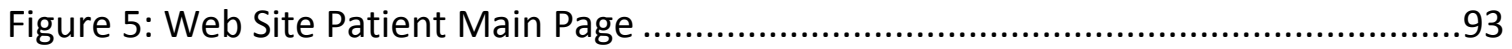

Figure 6: Web Site Patient Detail Page .................................................................93

Figure 7: AHAT User Interface ..................................................................................94

Figure 8: Logic Model for AASPIRE Healthcare Toolkit Web Site Development .............139

Figure 9: Action and Change Models for AASPIRE Healthcare Toolkit Web Site Build ...140 


\section{Introduction}

\subsection{Motivation, Research Questions, and Data Sources}

As we inquire into the rich complexity of our world, it is necessary to develop means of inquiry that can support that richness (Churchman 1979, Hall 1989, Senge 1990, Checkland 1999, Sterman 2000, Ackoff and Sheldon 2003, Ison 2008, Bigirimana 2011). The parts of human social systems in particular relate to each other in denselywoven and nonlinear ways (Churchman 1979, Lendaris 1986, Ackoff and Sheldon 2003) which cannot always be modeled by linear analytical methods (Churchman 1979, Flood and Jackson 1991, Jackson 2006). Indeed, human social problems are frequently classified as "wicked problems:" problems "which are ill-formulated, where the information is confusing, where there are many clients and decision makers with conflicting values, and where the ramifications in the whole system are thoroughly confusing" (Churchman 1967). To address the need for methods of inquiry into wicked problem areas, systems thinking proposes taking a holistic rather than reductionist view, and seeks to develop methodologies capable of managing real-world complexity (Churchman 1979, Lendaris 1986, Hall 1989, Senge 1990, Flood and Jackson 1991, Checkland 1999, Linstone 1999, Sterman 2000, Ackoff and Sheldon 2003, Bigirimana 2011) 
While systems thinking is helpful in understanding real-world social problems-especially lensed through interpretivist or critical epistemologies--it also poses new questions, opens new problem spaces, and draws new criticisms. Who is defining system boundaries? Which world-views are being included or left out of inquiry? How does power interact with knowledge, and how does knowledge interact with the world? How do our mental models affect our notions of the truth, and how can self-reflection examine or influence those models? Before committing resources to a course of action in addressing a complex social problem, it is wise to determine if it is a course of action that should be taken. Critical systems thinking (CST) explores these types of questions via five commitments of critical awareness, social awareness, complementarism at the methodological level, complementarism at the theoretical level, and dedication to human emancipation (Jackson 1990). These commitments are realized through three interrelated intentions: 1) complementarism, 2) emancipation, 3) critical reflection (Flood and Jackson 1991). Critical systems thinking also considers the potential for a new epistemology that is neither positivist nor interpretivist but which "would treat the possibility and boundaries of knowledge with regard to wholeness, as well as how that knowledge can be methodically sought (Fuenmayor 1991)."

Simultaneously with developments in systems thinking, participatory approaches to research--research that includes non-scientists in the process of inquiry--have developed to address similar questions and wicked problem areas. Originating within operations research and systems science, action research makes stakeholders members 
of the research team and incorporates self-reflection into the research process (Lewin 1946, Argyris 1977). Over the years, action research has evolved community-engaged research approaches designed to include marginalized stakeholders, and to address problematic power dynamics and ethical transgressions; examples include participatory action research, community operations research (Midgley 2001), and community based participatory research (CBPR) (Israel, Schulz et al. 2001, Minkler and Wallerstein 2003, St. Denis 2004, Israel, Eng et al. 2005). Community based participatory research, the "flavor" of participatory action research used on this project, distinguishes itself with four characteristics of a focus on community, drawing research into action, equitability of partnership, and an ongoing commitment to the nine principles of CBPR (Nicolaidis and Raymaker 2015).

One wicked problem area that might benefit from approaches like CST and CBPR lies at the intersection of disability and information technology. Perceptions of disability have shifted radically over the past century from a medical model, prevalent until the 1960's (disability is a flaw within an individual to isolate, remedy, and eradicate) (Oliver) to the more recent civil-rights informed and holistic social model of disability (disability is a complex interaction between the individual and the environment, where the dynamic may be either enabling or disabling) (Shapiro 1994, Linton 1998, Charlton 2000). Information technology, too, has seen radical shifts in the past thirty years with the invention of the Internet (TCP/IP and infrastructure) and past twenty years since the invention of the World Wide Web (HTTP/HTML and graphical browser). Since its early 
days as a medium for the wealthy, male, and educated, the "digital divide" has shrunk rapidly (Pew Internet and American Life Project 2013) even as the volume of information and degree of reliance on information technology has risen. Yet, information technology remains inaccessible to many people with disabilities. As of 2011 , only $54 \%$ of adults with a disability were using the Internet, compared with $81 \%$ of adults without a disability (Pew Internet and American Life Project 2011). This is particularly disturbing given the enabling or disabling dynamic of the environment; barriers to Internet technology could conceivably be identified and removed. Contributing to the complexity or "wickedness" of the problem, the Internet exists within our larger social context, which includes the ongoing disempowerment of people who do not fall within normative boundaries of ability (Jaeger 2011). Could approaches like CBPR and CST suggest solutions to the problem of inaccessible information technology for people with disabilities?

This dissertation includes four examinations of CST and CBPR applied to the development of an accessible interactive web-based toolkit for improving healthcare for adults on the autism spectrum. The project uses a hybrid systems thinking / community based participatory research approach to create an emancipatory learning organization (Senge 1990), and involves stakeholders from autistic, academic, parent/professional, and clinical healthcare provider communities. These groups often hold conflicting values, goals, constraints, and power relationships (Kaufman 2007, Ne'eman 2007, 
Wallis 2009), making equitable discourse difficult, even when there is agreement on a particular aim (e.g., improving healthcare outcomes). The four levels of examination are:

1. Theory - What are the intersections and complements of critical systems thinking and community based participatory research, and how might they conjoin to function as a hybrid approach to inquiry?

2. Practice - How might a hybrid CST/CBPR approach function in-use to equitably develop accessible information technology for individuals on the autism spectrum?

3. Critical Self-Reflection - How does my intersectional positioning as an academic researcher, an Autistic woman, and a technology professional play out experientially in the course of such research?

In the dissertation synthesis, I integrate these three levels to answer the evaluation question at the fourth level:

4. Synthesis - How, if at all, did taking a hybrid CST/CBPR approach to developing information technology impact the quality of the project as evidenced by 1) the ability of our team to operate equitably as a learning organization and 2) the perceived quality of the web site product to autistic people?

Figure 1 shows the conceptual relationship between the four components, and Figure 2 shows the relationship between data sources used and the four components. 


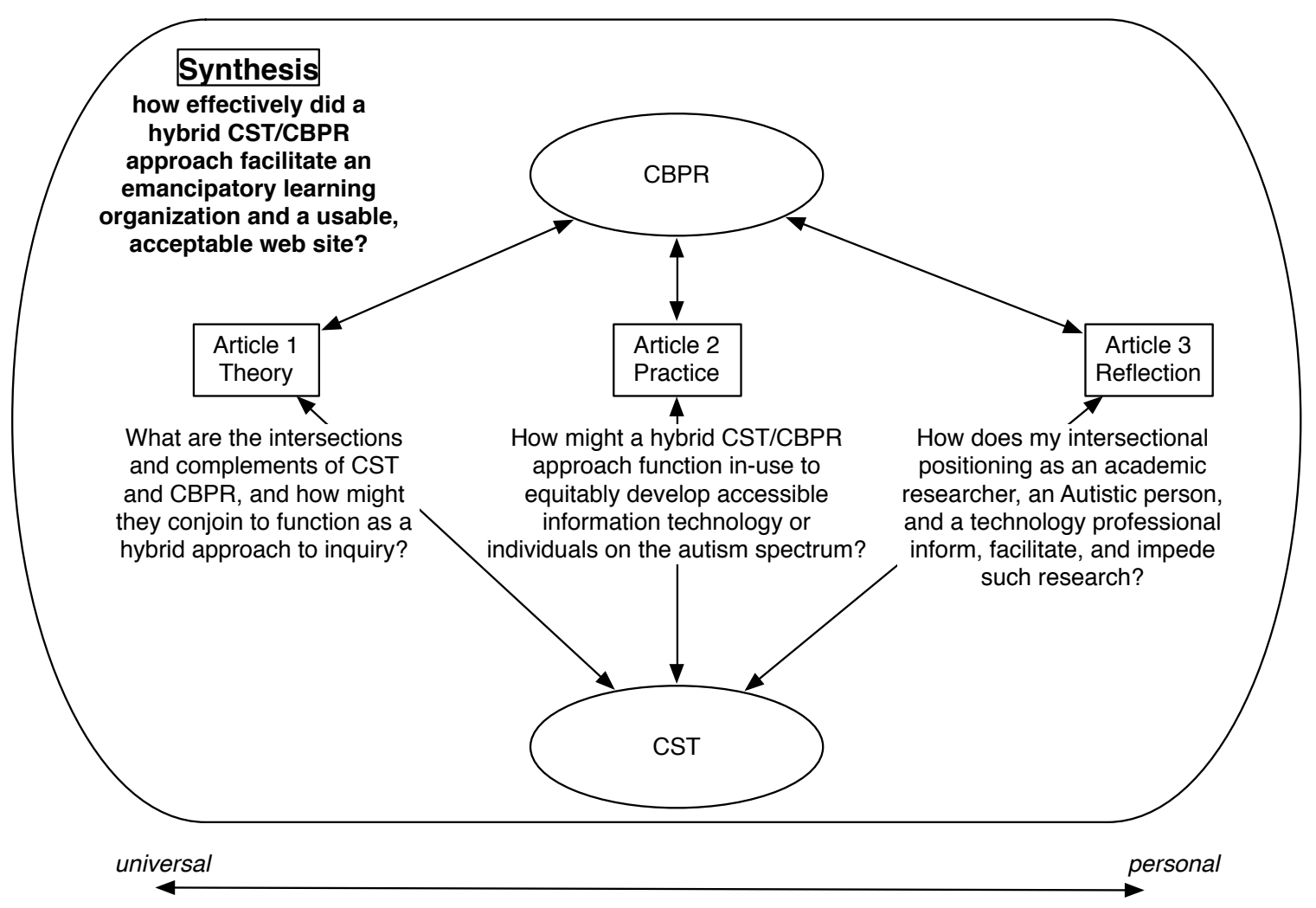

Figure 1: Conceptual Relationship Between Components 


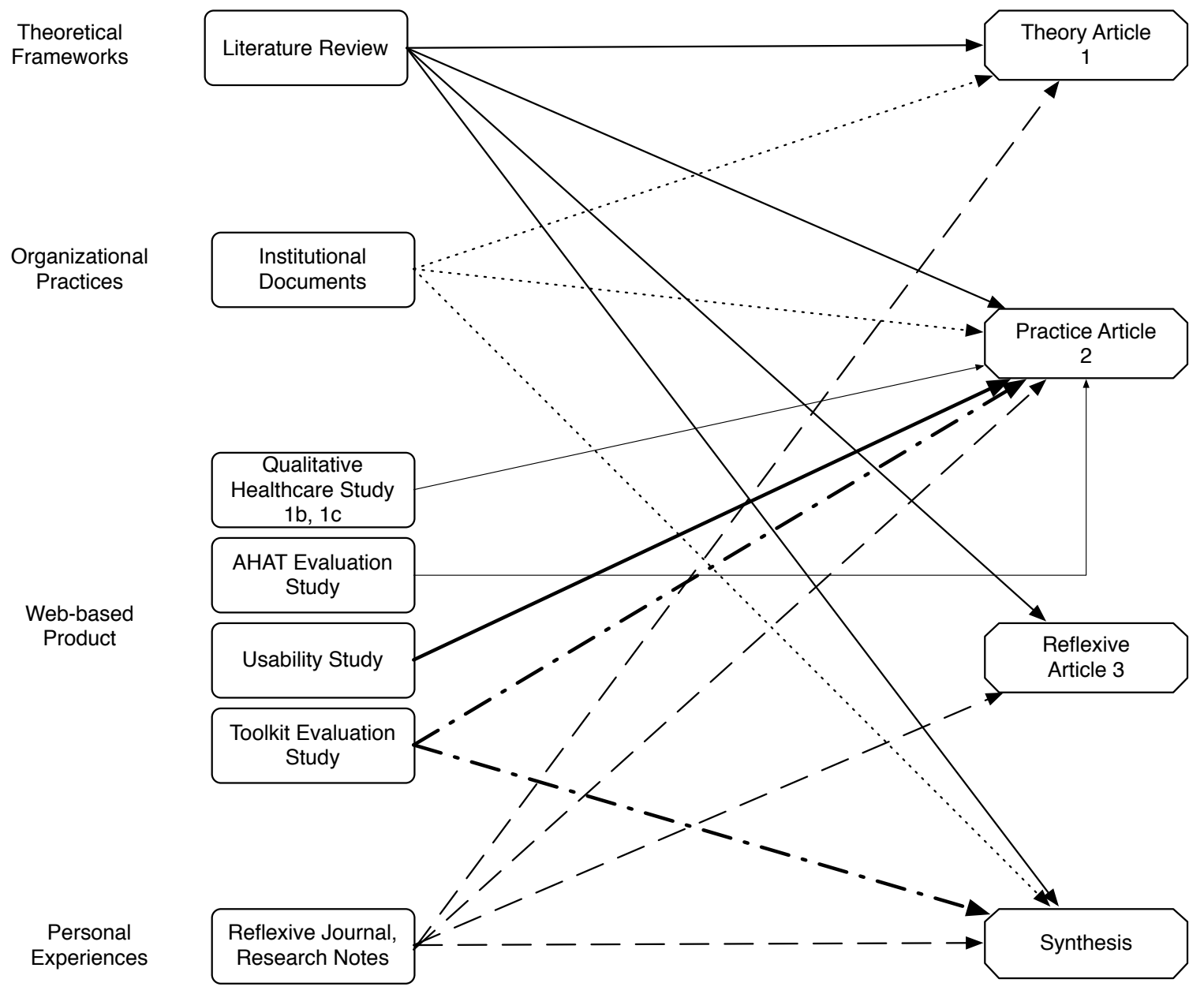

Figure 2: Relationship of Data Sources to Articles and Synthesis

While presented linearly, the four levels are linked, interdependent, and build on each other. Theory informs practice, the lessons learned in practice update theory, neither of these things are possible without critical self-reflection, and all of them influence--and are influenced by--efficacy at the organizational level.

\subsection{The Academic Autistic Spectrum Partnership in Research and Education (AASPIRE)}

I conduced this project in the larger context of the Academic Autistic Spectrum Partnership in Research and Education (AASPIRE). AASPIRE is a community-campus 
partnership that uses a CBPR approach to conduct research with, and relevant to, the Autistic community (Nicolaidis, Raymaker et al. 2011). AASPIRE has been in operation since 2006, when the organization's Co-Directors, Christina Nicolaidis and I, identified a similar pattern of issues regarding power and oppression in both research for the Autistic community and research for more traditional communities defined by race or ethnicity. While AASPIRE has always been committed to the trinity of stakeholder groups represented by academic researchers, autistic persons, and supporters/disability professionals, AASPIRE has been clear from inception that the Autistic community is the non-academic power within our community-campus partnership. Due to Dr. Nicolaidis' positioning as a health services researcher, and the great importance of healthcare quality to the Autistic community, AASPIRE has mostly focused on healthcare in the population of autistic adults.

In the CBPR partnership, I have primarily filled a community role, while Dr. Nicolaidis has primarily filled an academic role. These divisions are not so simple however, as Dr. Nicolaidis is a stakeholder in autism and healthcare as an academic researcher, a clinician, the parent of an autistic son, and a strong ally to the Autistic community. I occupy an intersectional space as a self-advocate within the Autistic community, as an academic researcher, and as an information technology professional (the latter of which places me as an insider-researcher in the sense explored by Holian (Holian and Coghlan 2013)). Particularly as my own academics have progressed, I have found myself frequently serving as a bridge or translator between community, 
academic, and subject matter expert components of the project, sometimes swapping between roles, and other times operating through the lens of multiple perspectives at once.

\subsection{Learning Organizations \& Knowledge and Power}

From my systems science background, I have been heavily influenced by the systems thinking ideas of Senge (Senge 1990) and Sterman (Sterman 2000), particularly by Senge's concept of a "learning organization." I have been actively attempting to develop AASPIRE as a learning organization using Senge's ideas since the group's inception in 2006.

Senge defines a "learning organization" as "an organization that is continually expanding its capacity to create its future." Learning organizations accomplish this via the "five disciplines" of shared vision, reflexive examination of mental models, personal mastery, team learning, and systems thinking (Senge 1990). Because it has defined characteristics (the "five disciplines"), the concept of the learning organization can be thought of as a criteria for determining how well systems thinking has been successfully implemented in a particular setting. In other words, an organization that exhibits success in the five disciplines is capable of "continually expanding its capacity to create its future" (Senge 1990).

The following summary of the "five disciplines" is from Senge's Fifth Discipline (Senge 1990). 
Personal Mastery - Essentially, the pursuit of individual excellence. Personal Mastery is facilitated by curiosity and desire to excel, by using the gap between the actual and ideal (creative tension) to motivate and learn, by being honest with one's self, by practice, and by ruthless clarity of vision. Barriers to Personal Mastery include lack of drive, inability to manage creative tension (and succumbing to emotional tension), failure to set high self-expectations, and impatience.

Mental Models - The conscious recognition of the internal representations used by people to understand the world, and the ability to consciously modify those representations. Mental Models are facilitated by openness and honesty, by balancing inquiry (what do you think?) and advocacy (this is what I think), and by practice including of methods such as "the left hand column" and exploring scenarios. Barriers to Mental Models include manipulation, bias, leaps of abstraction, lack of examining motivations, "analysis paralysis" (too much inquiry), and ego wars (too much advocacy).

Shared Vision - The willing and consensual holding of a collective set of values and goals; genuine commitment. Shared Vision is facilitated by strong leaders, mutually held desires and inspiration, freedom of choice on buy-in, and a workable means to achieve the vision. Barriers to Shared Vision include individuals having a vision forced upon them, rigidity in the face of a changing group need or desire, and lack of communication.

Team Learning - The ability of teams to engage in dialogue (explorations) and discussion (decisions), and create a free flow of ideas, discoveries and insights. Team 
Learning is facilitated by openness and trust, by having strong facilitators and technology for participation, competence with examining defensive routines and managing mental models, and practice. Barriers to Team Learning include lack of trust, lack of practice in working as a learning unit, difficulty dealing with conflict, uneven participation, and unexamined defensive routines.

Systems Thinking - The practice and mastery of the other four disciplines plus the ability to see those four parts operating as a whole. Systems Thinking also means taking into account the effects of time and feedback, and recognizing patterns. Systems Thinking helps to combat what Senge calls organizational "learning disabilities," which can also impede its ability to be implemented.

Point of clarification: Senge's choice of title for these items, and his characterization of learning disabilities in children as "tragic" (Senge 1990) is evidence of stigma against people with disabilities in the academy and society. My learning disabilities are no more "tragic" than my curly hair--perhaps the range of styles available to me are different than for someone with straight locks, but they are of no less value. Therefore, through the remainder of this dissertation, I will use Sterman's terminology for this concept, "barriers to learning" (Sterman 1994). (Note: Sterman identifies different items from Senge as his barriers, although they are connected, and perhaps inclusive as Sterman's are more general.)

The barriers to learning identified by Senge are:

1. seeing one's position in isolation from the big picture 
2. blaming individuals or externalities for systems problems

3. mistaking reactivity for proactivity

4. fixating on isolated events instead of seeking patterns

5. not recognizing change because it happens too slowly

6. not understanding nonlinear effects (e.g., feedback, the role of time)

7. leading in a top-down, willfully ignorant or opaque manner to obscure issues

A learning organization is an organization which, through the practice of the five disciplines, adapts and grows into effectiveness and excellence (Senge 1990).

While nice in theory, critics of the learning organization concept note that it fails to take power and the relationship between knowledge and power into account. (Cavaleri 2005, Caldwell 2012) Caldwell in particular notes, "[Senge] never really addresses the central issue of the relationship between power and learning, knowledge and expertise, learning and leadership. For Senge change is driven by learning, not by authority. But who will openly sacrifice knowledge as power for knowledge as learning (Caldwell 2012) ?"

Indeed, there is a deep relationship between power and knowledge, and between knowledge and normative or marginalizing practices (Foucault 1980, Gaventa 2004, Lukes 2005). It is not possible to address learning within an organization (or elsewhere) without attending to power balances and imbalances, including in the definition of what is worth learning in the first place (Lukes 2005). 
In response to the question of "who will openly sacrifice knowledge as power for knowledge as learning," the answer might be dedicated CBPR practitioners, for that (i.e., co-learning) is one of the very foundational principles of CBPR.

\subsection{CBPR Process}

In keeping with the nine principles of CBPR (discussed in depth later; see Table 4) the development of this dissertation, in those areas which intersect directly with AASPIRE's work, necessarily follows our CBPR process. Our process in general involves a number of methods for working together that equalizes power (e.g., team meetings in text chat, elist communication, multiple formats for input, a lot of structure, a decisionmaking process that bypasses voting, co-created policies and procedures, frequent check-ins and adjustments, etc.). More information on how AASPIRE operates generally can be found in the remainder of this manuscript, as well as in AASPIRE's published process paper (Nicolaidis, Raymaker et al. 2011). For this dissertation in particular:

1. At each major stage of the project (proposal, individual paper development, synthesis development, final document), our entire team, which includes our community partners, was informed of progress on the dissertation as a whole and given an opportunity for providing oversight and feedback. A "cliff notes" (in the team's words) version of the dissertation progress was provided to the group at each stage. 
2. Co-authorship was offered to the full team on the practice paper, which involves the joint work of the group. The paper development followed our jointly-defined internal policies for co-authoring academic publications.

3. Manuscript review was offered to the team on the theory and reflection papers and team acknowledged in the Acknowledgements section of each paper.

4. Attention was paid at all stages to the potential impact of dissertation framing and findings on the Autistic community, and with respect to the representation of autistic persons within both academia and society at large.

5. A plain-language summary and community policy brief will be created for the papers and synthesis findings.

During the early development of the dissertation proposal, I described the dissertation idea to the full team and provided an opportunity for feedback. We discussed and agreed upon items 1, 2, and 3 above.

At that meeting, we discussed the potential significance and impact of each article for the Autistic community. Prior to the meeting, I created bullets in nontechnical language outlining what I thought the significance might be. During the meeting I asked the group whether or not they felt these things I had identified would be of community benefit, and if they had any items to add. The team agreed with the items on my list, and did not have anything to add.

The group gave no substantive feedback on the dissertation idea itself. Community partners were supportive and felt that the idea was interesting and 
important. One partner provided useful references and expressed that academic work related to debunking disability stereotypes related to autism and self reflection, and exploring possible misconceptions related to insider-researcher bias, were particularly important.

\subsection{Methods Summary}

As shown in Figure 2, I considered multiple data sources during the course of this larger inquiry. While each is presented in detail, as appropriate, in the methods of each examination, a bigger picture may be useful for framing the synthetic evaluation question, and further contextualizing the project as a whole. Also, some details in this summary are not included in the three articles, notably around the analysis of the institutional documents. Six data sources and a supplemental literature review informed this study. The data sources are summarized in Table 1.

\begin{tabular}{|c|c|c|c|c|}
\hline Data Source & Type & Condition & Role in Project & Description \\
\hline $\begin{array}{l}\text { AASPIRE } \\
\text { Institutional } \\
\text { Documents }\end{array}$ & Secondary & $\begin{array}{l}\text { Primarily } \\
\text { identifiable with } \\
\text { one de-identified } \\
\text { document set }\end{array}$ & $\begin{array}{l}\text { Institutional } \\
\text { ethnography; } \\
\text { questions 1, 2, } 4\end{array}$ & $\begin{array}{l}\text { Organizational } \\
\text { documents (e.g. } \\
\text { meeting minutes, } \\
\text { list serve } \\
\text { discussions) }\end{array}$ \\
\hline $\begin{array}{l}\text { Qualitative } \\
\text { Healthcare Study } \\
1 b / 1 c\end{array}$ & $\begin{array}{l}\text { Archival: OHSU } \\
\text { IRB \#5580 }\end{array}$ & $\begin{array}{l}\text { Coded with } \\
\text { unique identifier }\end{array}$ & $\begin{array}{l}\text { Web site end-user } \\
\text { engagement; } \\
\text { question } 2\end{array}$ & $\begin{array}{l}\text { Analyzed } \\
\text { qualitative data, } \\
\text { aggregated } \\
\text { demographics }\end{array}$ \\
\hline $\begin{array}{l}\text { Web Site Usability } \\
\text { Study }\end{array}$ & $\begin{array}{l}\text { Archival: OHSU } \\
\text { IRB \#5580 }\end{array}$ & $\begin{array}{l}\text { Coded with } \\
\text { unique identifier }\end{array}$ & $\begin{array}{l}\text { Web site usability / } \\
\text { acceptability; } \\
\text { question } 2\end{array}$ & $\begin{array}{l}\text { Analyzed } \\
\text { qualitative data, } \\
\text { aggregated } \\
\text { demographics }\end{array}$ \\
\hline $\begin{array}{l}\text { AHAT UI } \\
\text { Evaluation }\end{array}$ & $\begin{array}{l}\text { Archival: OHSU } \\
\text { IRB \#5580 }\end{array}$ & De-identified & $\begin{array}{l}\text { Web site usability / } \\
\text { acceptability; }\end{array}$ & $\begin{array}{l}\text { Analyzed, } \\
\text { aggregated }\end{array}$ \\
\hline
\end{tabular}




\begin{tabular}{|c|c|c|c|c|}
\hline & & & question 2 & quantitative data \\
\hline $\begin{array}{l}\text { AASPIRE } \\
\text { Healthcare Toolkit } \\
\text { Evaluation }\end{array}$ & $\begin{array}{l}\text { Archival: OHSU } \\
\text { IRB \#5580 }\end{array}$ & $\begin{array}{l}\text { Coded with } \\
\text { unique identifier } \\
\text { (qual), de- } \\
\text { identified (quant) }\end{array}$ & $\begin{array}{l}\text { Web site usability / } \\
\text { acceptability; } \\
\text { questions 2, } 4\end{array}$ & $\begin{array}{l}\text { Analyzed } \\
\text { qualitative and } \\
\text { quantitative data, } \\
\text { aggregated } \\
\text { demographics }\end{array}$ \\
\hline Reflexive Journal & Primary & $\begin{array}{l}\text { Identifiable } \\
\text { (note: participant } \\
\text { is self) }\end{array}$ & $\begin{array}{l}\text { Autoethnography; } \\
\text { questions } 1,2,3,4)\end{array}$ & $\begin{array}{l}\text { Raw qualitative } \\
\text { data consisting of } \\
\text { my own notes and } \\
\text { reflections while } \\
\text { conducting this } \\
\text { research }\end{array}$ \\
\hline
\end{tabular}

Table 1 - Data Source Summary

\subsubsection{Supplemental Literature Review}

In addition to reviewing literature on the relevant topics to this dissertation (disability and the Internet, foundational documents and current state-of-the-art on CST and CBPR, etc.), I performed a targeted search on the intersection of CST and CBPR prior to starting article 1. I performed the search via Academic Search Premier, JSTOR, and within the two journals Systemic Practice and Action Research (target journal for article 1) and Progress in Community Health Partnerships (one of the primary publishers of CBPR articles). "Critical systems thinking" and "community based participatory research" together yielded no results. "Community based participatory research" paired with "systems thinking," or "critical systems thinking" paired with either "action research" or "participatory action research," yielded a small number of results (collectively, 12), none of which covered the same areas I was interested in examining in article 1. A number of these papers were used in the background and discussion for article 1. 


\subsubsection{AASPIRE Institutional Documents}

AASPIRE's institutional documents were the source for multiple aspects of the individual and synthetic inquiries. Most importantly, they provided:

1. A means for me to check my memories of events (used especially in article 1 and the synthesis) against an external source;

2. Information pertaining to how the team managed the web site development process covered in article 2;

3. Specific recommendations from the team regarding web site content, usability, and accessibility, covered in article 2;

4. Qualitative examination of the evaluation question in terms of the ability of our team to operate equitably as a learning organization, covered in the synthesis section.

The methodological approach I took to examining the AASPIRE institutional documents was informed by institutional ethnography. An institutional ethnography applies an ethnographic approach to the study of social relations and experiences within an organization. (Campbell 1998) As data sources, it typically uses documentation and artifacts produced by the organization in addition to organization members' experiences and researcher observations. (Campbell 1998, Campbell and Gregor 2004)

The documents and artifacts I used for this analysis were:

- Meeting agendas 
- Meeting handouts and supporting documentation

- Meeting minutes

- Internal processes and procedures that were in place prior to the project, with tracking of how they may have changed during the course of the project

- Internal processes and procedures developed and documented during the course of the project (e.g., processes for soliciting and integrating feedback at various stages of product development)

- Materials produced for the purposes of internal communication about project processes

- All project documentation on our internal web site

- All change logs of edits made to web site content, design, and functionality

- Findings from an internal qualitative evaluation done in year 1 of the project

- My personal notes, reflections, and correspondences during the course of the web development project

- Information about team member participation, attrition, and influence (e.g., by looking at meeting attendance and frequency/depth of posts to our listserve)

- Internal correspondences on our listserve

- Timelines related to project phases and milestones I collected the corpus and read through all of it. I then sorted the documents into those related to the web site development and those related to other aspects of the larger AASPIRE Healthcare Toolkit project that are not covered in this dissertation, the 
latter of which I did not review further. I created a text parser to strip duplicate information out of listserve posts and manually deleted non-relevant posts (e.g., side conversation, posts unrelated to the aspects of the project covered in this dissertation, etc.) to reduce and focus the volume of text.

Although I had intended to use a traditional thematic analysis on the corpus (Miles and Huberman 1994), and I did begin tagging data for themes and metadata (e.g., stakeholder group, project component), I found in practice that the documents had such little richness and detail that a detailed coding scheme held little value. I did tag documents for topics of interest (example tags: accessibility>web_site, content $>$ patient $>$ healthcare $>$ wording, content $>$ patient $>$ healthcare $>$ substantive, evaluation>usability). My process of analysis then became one of arriving at a point in the inquiry where institutional information was needed (the examples of using a hybrid CST/CBPR approach in article 1, changes to how we worked to meet web site development challenges in article 2, etc.), and then reaching into the corpus to find, compile, and/or corroborate that information. With big-picture or event-type information, like the examples in paper 1 , it was a process of "I remember this happening, is it reflected in the artifacts?" With specific information that I had tagged, it was a process of "I need to compile all of the recommendations for site accessibility, let me pull up everything I tagged as accessibility>web_site." I used TAMS Analyzer (Weinstein 2012) for the coding. 
I primarily used member checking (Rossman and Marshall 2010) for verification, including leveraging the fact that two of my committee members are also members of AASPIRE and were present during the AASPIRE Healthcare Toolkit web site development. Article 2 was co-authored by many members of the team, which included findings from the institutional data related to group processes and experiences during the web site development and related to group identification of site accessibility, usability, and content needs. In addition to being involved in the process of writing the article, I specifically asked team members to check if my descriptions of organizational processes and team recommendations were consistent with their memory, and invited them to add any key points I had missed. Co-authors confirmed my assessment of events, and added a few minor points that I had missed in terms of the specific site recommendations.

For the remaining articles and the synthesis, I shared the later drafts of the articles with the group and again asked for any places where my descriptions did not match with their own memories. Individuals on the team concurred with what they read in the articles and synthesis.

In addition to member checking, an audit trail (Rossman and Marshall 2010) is available for others to use, should they want to attempt reproducibility of my results.

\subsubsection{AASPIRE Healthcare Toolkit Study Data}

The AASPIRE Healthcare Toolkit Study data includes data from the qualitative healthcare study $1 b / 1 c$, the web site usability study, and the primarily quantitative 
Autism Healthcare Accommodations tool (AHAT) user interface (UI) evaluation and AASPIRE healthcare toolkit evaluation. This data comprises external information about the acceptability, accessibility, and usability of the AASPIRE Healthcare Toolkit, as well as some preliminary recommendations for web site form and content, collected from research study participants who are not involved in AASPIRE's work as part of the research team. The data was collected during the course of four sub-studies conducted in the context of the larger research project from which the investigations in this dissertation are a small part. Relevant methods related to this data are described in detail in article 2, and include both qualitative and quantitative analyses.

I used the results of the AASPIRE Healthcare Toolkit evaluation detailed in article 2 to answer the synthetic evaluation question with respect to the perceived quality of the web site product to autistic people.

\subsubsection{Reflexive Journal / Research Notes}

During the course of developing this dissertation from initial conceptualization through to completion (January, 2012 through December, 2014), I kept a log which included both reflexive journaling and research notes. I used information in the log as part of the institutional examination described above, as an audit trail for the qualitative portions of the project, to assist in writing the methods sections of the articles and synthesis, and as the primary source of autoethnographic information for article 3.

Prior to writing the narrative for article 3, I re-read the entire log. I copied the reflexive parts from the log and pasted them into a separate document, and then 
rearranged them under themes. Because the data was rich but relatively small in volume, and I tended to return to and retrace many of the same ideas in it, I felt comfortable generating and arranging it by main themes without the usual iterative and reductive tagging process of a thematic analysis. I organized the themes under the events of what happened during the project and into specific points about each theme I felt were important to make. More details are offered in the article.

As with the institutional data analysis, I shared a draft of article 3 with team members who were with me during many of the events described within. Team members did not bring up any inconsistencies in my presentation of our work.

I also shared the article with three peers holding similar intersectional space as white people with disabilities they've had since birth working in academic disabilities research: two female PhDs (not autistic, not involved in AASPIRE), one male graduate student (autistic, a member of AASPIRE). These individuals all strongly identified with what I'd written and felt the themes were important and essential to the experience of being on the intersection of disability/other marginalizing factors and the academy. The graduate student did note differences in experience related to not having had a professional identity prior to entering higher education. Two individuals brought up the experience of exploitation by other academics as one they'd dealt with, as well as being implicit in some sections of my text, but which I hadn't picked up on or called out.

One of AASPIRE's Research Assistants who read the paper commented that the article resonated with her experience as a Latina woman in the academy as well as with 
a body of feminist literature, and several friends--a white transgender woman and two white autistic women, all of whom have professional (but non-academic) identities-described similar feelings and experiences, including in one case a nearly identical narrative of events related to employment and adversity from social workers. One of AASPIRE's community partners, an Autistic white male PhD who also works professionally in computer engineering (though outside of the academy and unrelated to disability research), described strong resonances with my themes, again particularly around adversity from social workers and the academy. Additionally, one reader felt his identity as a Jewish person evoked some similar themes. This indicates that while my experience has some unique characteristics, it is also transferrable to other individuals and groups (Rossman and Marshall 2010). An audit trail is available. 


\title{
2. Article 1 - Intersections of Critical Systems Thinking and Community Based
}

\section{Participatory Research: A Learning Organization Example with the Autistic Community}

\begin{abstract}
Critical systems thinking (CST) and community based participatory research (CBPR) are distinct approaches to inquiry which share a primary commitment to holism and human emancipation, as well as common grounding in critical theory and emancipatory and pragmatic philosophy. This paper explores their intersections and complements on a historical, philosophical, and theoretical level, and then proposes a hybrid approach achieved by applying CBPR's principles and considerations for operationalizing emancipatory practice to traditional systems thinking frameworks and practices. This hybrid approach is illustrated in practice with examples drawn from of the implementation of the learning organization model in an action research setting with the Autistic community. Our experience of being able to actively attend to, and continuously equalize, power relations within an organizational framework that otherwise has great potential for reinforcing power inequity suggests CBPR's principles and considerations for operationalizing emancipatory practice could be useful in CST settings, and CST's vocabulary, methods, and clarity around systems thinking concepts could be valuable to CBPR practioners.
\end{abstract}


Keywords: critical systems thinking, community based participatory research, learning organization, power, autism

\subsection{Introduction}

Critical systems thinking (CST) and community based participatory research (CBPR) are approaches to inquiry which share a primary commitment to holism and human emancipation (Flood and Jackson 1991, Minkler and Wallerstein 2003). With roots in much the same philosophical soil and sharing common intentions (Flood and Jackson 1991, Minkler and Wallerstein 2003), the branches of the two approaches also diverge in focus and attendant methods. In particular, while CST offers, reflective of its connection to the broader systems approach, numerous methods for holistic management practices, as well as for uncovering inequity (Midgley 1992, Ulrich 2005), it still has gaps in practical means for generating emancipatory management practices after inequity is exposed (Córdoba and Midgley 2008, Córdoba 2009, Ulrich and Renolds 2010). Likewise, CBPR has an excellent set of principles and guidelines for implementing emancipatory practice assuming the presence of inequity (Israel, Eng et al. 2005), but has less of a formalized language for managing complexity within daily operations. In this paper, I explore the intersections and complements of the two approaches and propose a hybrid approach. I then share an example of how this hybrid approach functions in-practice in a research setting in which study collaborators and broader stakeholders experience a wide power differential. Specifically, our research group, the 
Academic Autism Spectrum Partnership in Research and Education (AASPIRE), engages autistic individuals, academic researchers, family members and disability support professionals, and primary care healthcare providers as co-researchers and codevelopers during all phases of our work, using collaboration methods derived from a hybrid CST/CBPR approach. Our experience as an emancipatory learning organization suggests that CBPR may provide insights into pragmatic means for implementing emancipatory CST-informed projects, and that the wealth of systems methodologies offered by CST may be beneficial for building more effective CBPR collaboratives.

\subsection{Background}

Systems thinking provides a general, non-reductive approach to investigating phenomena characterized by feedback, unintended and long-term effects, chaotic dynamics, and emergent behaviors (Churchman 1979, Lendaris 1986, Flood and Jackson 1991, Checkland 1999, Ackoff and Sheldon 2003, Midgley 2006, Bigirimana 2011). It takes a holistic perspective, examining relationships between wholes and parts across levels of granularity (Churchman 1979, Lendaris 1986, Flood and Jackson 1991, Checkland 1999, Ackoff and Sheldon 2003, Midgley 2006, Bigirimana 2011). Within systems thinking, three main schools have evolved. Hard systems thinking, the first to emerge in the late 19th century, typically takes a mechanistic world-is-a-system positivist approach to inquiry (Checkland 1999). In the 1970's soft systems thinkers 
challenged the utility of applying mechanistic thinking to complex social phenomena, which led to the world-can-be-understood-systemically interpretivist approach of soft systems thinking (Checkland 1999). As the most recent systems thinking paradigm, critical systems thinking has challenged both hard and soft systems thinking, asserting that: 1) the mechanistic positivism of hard systems thinking is indeed incompatible with social systems inquiry; however, 2) soft systems thinking neglects power relations and therefore is insufficient for social systems inquiry, and further 3) the black-and-white separation of hard versus soft systems thinking is not useful (Flood 1990).

Unpacking the criticism around power relations in particular, proponents of CST argue that without a commitment to human emancipation and critical reflection on power, systems thinking and its methods can be exploited by those in dominant positions--either deliberately or through lack of awareness--to maintain the status quo. This risk is structurally rooted in the assumptions made by hard and soft systems thinking as they both assume the value-neutrality of methods (i.e., value systems are independent from a selected methodology; for example, choice of qualitative or quantitative inquiry is unrelated to the values of the investigators or study participants), and soft systems thinking further assumes power-neutrality between actors (i.e., individuals involved in inquiry are equitably positioned with respect to each other) (Flood 1990). As a concrete example of how this problem plays out in operation, Caldwell (2012) describes how, in absence of attention to power differentials between managers and their employees, management agendas are continuously reinforced at 
the expense of project needs in the guise of shared learning in the learning organization model.

To address its critique of hard and soft systems thinking, critical systems thinking has infused the systems thinking approach with the three intentions of 1) complementarism at the theoretical and methodological level, 2) critical reflection, and 3) dedication to human emancipation (Flood 1990, Jackson 1990, Flood and Jackson 1991, Flood 2013)

Developed on a separate trajectory primarily within the field of public health, Community based participatory research (CBPR) is a type of action research that distinguishes itself through a focus on community, drawing research into action, equitability of partnership, and an ongoing commitment to the nine principles of CBPR (Israel, Schulz et al. 2003, Wallerstein and Duran 2003, Nicolaidis and Raymaker 2015). CBPR is explicitly emancipatory; it was developed in response to the marginalization and exploitation of disempowered communities in research (Israel, Schulz et al. 2003). As a form of action research, it is intrinsically concerned with ensuring research has a direct impact on the lives of the people in the community, and that the impact is one people in the community desire. CBPR's engagement model is one of equitability: community members and scientists are involved in shared decision-making and co-creation at all stages of the research process; lived experience is valued at the same level as learned knowledge; steps are actively taken to equalize and share power. At its foundation are the nine principles of CBPR: 1 ) acknowledge the community as a unit of identity; 2 ) build 
on community strengths and resources; 3 ) facilitate a collaborative, equitable partnership in all phases of the research; 4) foster co-learning and capacity-building; 5) balance knowledge generation and action; 6) attend to both local and ecological perspectives; 7) develop systems via a cyclical and iterative process; 8) disseminate results through both the community and the academy; 9) commit to long-term processes and group sustainability (Israel, Schulz et al. 2003, Wallerstein and Duran 2003).

CBPR also provides an aid for operationalizing its principles and facilitating emancipatory practice in a given setting via a four-point framework of considerations for developing emancipatory processes (Wallerstein and Duran 2003). One, reflect critically on the meaning and application of the concept of "participation." Two, critically examine sources of knowledge with particular attention to the relationship between knowledge and power. Three, critically consider the manifestation of power in other contexts (e.g., other forms of social capital and norms, methods of inquiry, resistance to power, etc.). Four, integrate praxis: continuously create, reflect, and readjust using critical self-reflection, feedback, and double-loop learning during all aspects of the research process. These considerations are listed in Table 2. 


\begin{tabular}{|l|l|l|}
\hline Item & Description & Some Process Questions \\
\hline Participation & $\begin{array}{l}\text { Critical examination of the } \\
\text { meaning, use, and application of } \\
\text { "participation" in the project } \\
\text { context. }\end{array}$ & $\begin{array}{l}\text { Who is participating? Are they representative? Is } \\
\text { their participation equitable and reciprocal? }\end{array}$ \\
\hline $\begin{array}{l}\text { Knowledge } \\
\text { creation }\end{array}$ & $\begin{array}{l}\text { Critical examination of } \\
\text { epistemologies, knowledge sources, } \\
\text { and knowledge/power } \\
\text { relationships. }\end{array}$ & $\begin{array}{l}\text { What information is being privileged / } \\
\text { marginalized? What world-view is being privileged } \\
\text { / marginalized? Is the source legitimate? }\end{array}$ \\
\hline Power & $\begin{array}{l}\text { Critical examination of } \\
\text { manifestations of power in contexts } \\
\text { other than knowledge. }\end{array}$ & $\begin{array}{l}\text { What social norms are being privileged / } \\
\text { marginalized? Which aspects of the scientific } \\
\text { inquiry are being privileged / marginalized? How } \\
\text { is power being resisted? }\end{array}$ \\
\hline Praxis & $\begin{array}{l}\text { Critical use of the reflection/action } \\
\text { cycle of double-loop learning. }\end{array}$ & $\begin{array}{l}\text { How are processes for participation functioning } \\
\text { and do they need to be adjusted? How are } \\
\text { processes for attending to power functioning and } \\
\text { do they need to be adjusted? }\end{array}$ \\
\hline
\end{tabular}

Table 2: CBPR's Framework for Critical Reflection (extrapolated from Wallerstein and Duran, 2003)

Although there are potential synergies between CST and CBPR, if only from their shared emancipatory aims and focus on holistic inquiry, there are few direct links between the two approaches in the current literature. Some theoretical intersections between action research and CST have been explored, concluding that the approaches have compatibilities, connections, and potential synergy, but these explorations do not provide specific ideas for next steps, nor do they mention CBPR (Levin 1994, Flood 2013). The CBPR literature acknowledges the utility of systems thinking methods in its work but does not examine theoretical or philosophical connections to CST or other deeper-level connections between the two approaches; additionally, it typically focuses on the use of systems thinking methods for meeting project aims, rather than for internal management (Trochim, Cabrera et al. 2006, Dick 2010, Trickett 2011, BeLue, Carmack et al. 2012). There are no documented instances in the current literature of 
projects that use a stated hybrid CST/CBPR approach to inquiry. Here I aim to both draw that direct link and deeper examination of the intersections and complements of CST and CBPR, and to provide one example of a project that uses a hybrid approach in its research work.

\subsection{Intersections and Complements}

There are many intersections between CST and CBPR, suggesting the two approaches are compatible. Both are general approaches to social inquiry, methodsagnostic, and use ecological (i.e., systemic) lenses in their approach to identifying, understanding, and intervening in social problems (Flood and Jackson 1991, Minkler and Wallerstein 2003). They share philosophical soil in the critical theory of Habermas and the emancipatory philosophies of Foucault and Marx, as well as an underlying pragmatism (Flood and Jackson 1991, Minkler and Wallerstein 2003). From the common influence of critical theory, reflexivity is an explicit and necessary aspect of both approaches. From their common acceptance of ecological perspectives, both value and privilege holistic, anti-reductionist thinking. Rooted in pragmatism, both focus on, and give precedence to, what is needed for a given situation within a broader context (Flood and Jackson 1991, Minkler and Wallerstein 2003). CST and CBPR both grew, in part, from the need to develop effective ways to manage inquiry in "wicked problem" or "mess" areas in which traditional approaches have failed to have traction (Flood and 
Jackson 1991, Minkler and Wallerstein 2003). Both share a stated emancipatory agenda (Flood and Jackson 1991, Minkler and Wallerstein 2003) which is a key characteristic that differentiates them from some other, similar approaches.

CBPR also shares CST's intention of paradigmatic and methodological complementarism; both approaches are explicitly sensitive to the context-dependent nature of ideologies and techniques (Jackson 1990, Israel, Schulz et al. 2003). CST has made complementarism at the paradigmatic and methodological level the focus of one of its distinguishing intentions (Flood 1990). CBPR not only supports a similar concept to complementarism but extends it to the principles of CBPR themselves, asserting that the selection and application of principles must be made by holistically considering the community of interest, the individuals on the team, the needs of the project, and the value systems involved (Israel, Schulz et al. 2003). This could lead to dropping or changing principles, or to inventing new ones: there are no "right" principles, only the ones that facilitate the desired goal in an emancipatory way from within the project whole. The shapes of partnerships, the methods used in inquiry, and the foundational ethos appropriate to the group are all linked to a broader systems (i.e., environmental) context (Israel, Schulz et al. 2003).

Additionally, both approaches reject the value-neutrality of paradigms and methods (Flood 1990, Israel, Schulz et al. 2003); for example, by acknowledging that the selection of a positivist, traditional reductive approach to research (regardless of method) reflects and reinforces the value systems of the positivist, traditional 
researchers who support such an approach (not that this is always "bad," and indeed may be fully appropriate for some research questions, but if left unexamined it may be neither appropriate nor desirable). Thus for an investigator coming from a CST or a CBPR approach, the context in which world-views and methods are selected includes a critical examination of relevant value systems along with the other aspects of the environment. For example, by intentionally choosing a world view likely to privilege marginalized individuals or groups, or being sensitive to how methods may intersect with power (e.g., some survey or interview methodologies may have been used to evaluate participants for services, or may be culturally inappropriate).

While these intersections exist at the shared foundation of both approaches, the approaches are also complementary, particularly with respect to where each has most fully developed means to operationalize its commitments.

Systems thinking has a history of strong ties to the field of organizational management, with a substantial portion of hard systems thinking developing during World War II in the field of classical operations research, with a later paradigmatic and methodological recasting from positivist/quantitative to interpretivist/qualitative in the 1970's as soft operations research (Churchman 1979, Flood and Jackson 1991, Checkland 1999). As part of the broader systems thinking tradition, and acknowledging the complementarism of methodology within that tradition, CST has the full range of systems thinking methodologies for operationalizing management practice at its disposal. These include methods for holistically-focused management structures, 
practices, and decision-making processes, such as soft systems methodology, double loop learning, the learning organization concept, and others. These are mature, welldefined methods which have been refined over decades of real-world use.

However, as proponents of CST have pointed out, these methods do not have explicit emancipatory aims nor a foot in critical theory (Flood and Jackson 1991), opening them to simply advance the status quo, as with the critique of the learning organization (Cavaleri 2005, Caldwell 2012). CST has challenged organizational leaders and researchers to attend to power and human emancipation within the context of operations research (Flood 1990, Jackson 1990, Flood and Jackson 1991). From this challenge, two CST-informed methods have been developed, Ulrich's critical systems heuristics (CSH) (Ulrich 1995, Ulrich and Renolds 2010) and Midgely's boundary critique (Midgley 1992, Midgley 2001). While effective at uncovering and examining inequities, these methods are more focused on understanding inequities than on how to resolve them; they suggest neither a means to equalize power, nor to prevent power imbalances once found (Córdoba and Midgley 2008, Córdoba 2009, Ulrich and Renolds 2010); Midgely states directly "boundary critique is never enough on its own: it is always necessary for agents to find practical means to deal with problematic issues following boundary critique (Midgley 2001)." There is little guidance in the CST literature, in general, for how to operationalize emancipatory practice, particularly between groups of stakeholders with a wide power differential such as managers and employees. 
CBPR has focused on ways to operationalize human emancipation in a variety of research settings via its principles and its considerations for emancipatory practice. A substantial literature exists on how the tenants of CBPR have been put into practice; for example, see the 2003 special issue on CBPR from the Journal of General Internal Medicine (O'toole, Aaron et al. 2003) and the many examples in Methods in CommunityBased Participatory Research for Health (Israel, Eng et al. 2005). Further, CBPR-focused journals such as Progress in Community Health Partnerships encourage the publication of "process papers" on how the CBPR process itself is implemented, such as our paper on AASPIRE's CBPR process (Nicolaidis, Raymaker et al. 2011, Progress in Community Health Partnerships 2013)

Because of the cultural component of CBPR, however, it can be hard to construct generalizable low-level processes; every CBPR partnership is unique and therefore will require its own internal structure and operating procedures (Nicolaidis and Raymaker 2015). Perhaps this contributes to why, despite the deep presence of systems ideas within CBPR, there is less of a unified language for describing and abstracting them. Further, mature methods that take a systems or ecological approach might be particularly well-suited to CBPR settings.

CST and CBPR are grounded in similar philosophical and ideological soil and share both a systemic world-view and commitments to complementarism and human emancipation. CST is rich in tools for organizational management but has yet to develop strong methodologies for ending or preventing inequity once uncovered. CBPR has 
made the development of tools for ending and preventing inequity a priority and has a rich literature of methods toward those ends, yet has perhaps not plundered the fullness that systems thinking has to offer, both in terms of formalized models and methods and in terms of a clean language for describing and working with complexity. This combination of intersections and complements makes the two approaches wellsuited toward working in combination.

\subsection{Toward a Hybrid Approach}

According to Flood and Jackson, CST's emancipatory intention is "to develop systems thinking and practice beyond its present conservative limitations, and...to formulate new methodologies to tackle problem situations where the operation of power prevents the proper use of the newer soft systems approaches (Flood and Jackson 1991)." Minkler summarizes the defining characteristics of CBPR:

- It is participatory.

- It is cooperative, engaging community members and researchers in a joint process in which both contribute equally.

- It is a co-learning process.

- It involves systems development and local community capacity building.

- It is an empowering process through which participants can increase control over their lives. 
- It achieves a balance between research and action. (Minkler and Wallerstein 2003)

In a sense, application of CBPR's principles and Wallerstein's framework for critical reflection can be seen as a guide for the formulation of those new methodologies called for in CST's emancipatory intention. But the principles and framework are not methods; they are guides for the application of methods in ways that promote human emancipation. This opens the question of whether or not CBPR's guides for emancipatory practice can be applied to existing systems thinking methodologies in order to infuse them with CST's emancipatory aim. This in turn would enable someone coming from a CST approach to use those methods to actively attend to power and promote equitability in practice, rather than simply pointing out where the methods may fall short of emancipatory aims.

This hybrid CBPR/CST approach is what AASPIRE implemented when it first formed in 2006. Grounded in the principles of CBPR and a commitment to reflexive emancipatory processes, we rooted our organizational approach in Senge's learning organization (Senge 1990) with decision-making and other management processes informed by systems thinking. It is my belief that by taking a hybrid CBPR/CST approach we were able to achieve both a more equitable learning organization and a more effective CBPR team than we would have by using either approach individually. 


\subsection{Example: Academic Autism Spectrum Partnership in Research and Education}

The Academic Autism Spectrum Partnership in Research and Education (AASPIRE) is a Community Based Participatory Research collaboration between the Autistic community and academic researchers, based primarily at Portland State University (AASPIRE 2013). We formed the group in 2006 in response to the marginalization and harm that individuals on the autism spectrum experience in research, both as research subjects, and as a population that has been systematically excluded both from broader population studies and from professional roles in research (Nicolaidis, Raymaker et al. 2011, Raymaker 2013, Raymaker and McDonald 2013). AASPIRE's projects to date include a series of healthcare studies culminating in the creation of an online healthcare intervention for adults on the autism spectrum (Nicolaidis, Raymaker et al. 2013, AASPIRE 2014, Nicolaidis, Raymaker et al. in press, Raymaker, Nicolaidis et al. in review), a study on well-being and the Internet, and a collaboration examining health, violence, and disability amongst individuals with developmental disabilities (Nicolaidis, Raymaker et al. 2014). AASPIRE's two founding members, Nicolaidis and myself, brought CBPR and systems thinking with us; Nicolaidis as a CBPR researcher engaged in projects with African American and Latino communities, and myself as a systems scientist with a professional background in operations. As a member of the disempowered population of autistic individuals and a self-advocate involved in policy and systems change, I was particularly interested in 
intersections of research and human emancipation, and with critical perspectives. Thus from its inception, AASPIRE has braided CBPR and systems thinking together.

\subsubsection{AASPIRE and the Learning Organization Model}

Creating a new organization, no matter how small or loosely defined, is not trivial. Coming from the systems field and a professional context of technology operations, I was drawn to Senge's learning organization model (Senge 1990) with its well-defined "five disciplines" for building successful organizations, and its useful grounding in system dynamics. Not wishing to invent a new model for the group, I decided to use the learning organization as the basic framework for AASPIRE. I did not, at that time, know of the criticism that had been levied against it with respect to potential for abuse of power--or, at best, risk of reinforcing the status quo. However, I did continuously ask myself how the practices of shared vision, reflexive examination of mental models, personal mastery, team learning, and systems thinking could be informed by, and facilitate, the emancipatory principles of CBPR.

The first action taken by the partnership was to create a shared vision--a set of values and goals emergent from our collective hopes. That vision, encapsulated in our mission statement (to encourage the inclusion of people on the autism spectrum in matters which directly affect them; to include people on the autism spectrum as equal partners in research about the autism spectrum; to answer research questions that are 
considered relevant by the Autistic community; and to use research findings to effect positive change for people on the spectrum) has been the central tenant of everything we've done since. This shared vision is unambiguously emancipatory; it was guided by our community members, the principles of CBPR, and a shared commitment to ending inequity for a marginalized population in research.

Team learning made a natural fit with CBPR's principles. In particular, CBPR's principle to foster co-learning and capacity building among all partners is essentially a description of team learning through an emancipatory lens. Co-learning means an equitable exchange of knowledge and power; capacity-building includes providing resources and information to enable that exchange. Interestingly, Senge describes lack of trust as a barrier to team learning (Senge 1990), and uneven participation can be a barrier to both team learning (Senge 1990) and equitability (Caldwell 2012). Lack of trust is also a key barrier to CBPR, and a literature exists around means to address it (Israel 2005). In AASPIRE's case, co-learning is facilitated by 1) privileging the communication mode favored by the autistic partners (e.g., written, asynchronous), 2) co-creating operational processes and procedures, and 3) sharing power and building trust (e.g., by providing sufficient information in accessible language about the science (from academics) and about the politics and lived experience (from community members) so everyone is making equally informed decisions, by consistently implementing the decisions made by community members). Unlike some communities which intrinsically distrust academics (a number of leaders in the Autistic community have high levels of 
educational attainment), trust issues in AASPIRE have revolved more around the frictions between deficits-based and strengths-based mental models that often polarize clinicians/professionals/academics/family members and individuals on the spectrum themselves, respectively.

This divide, and the trust issues it evokes, makes mental models a particularly loaded area for our group. In some ways, the political complexity of the mental models involved in our work presents barriers not only to the basic concept of the learning organization but to getting any work done at all. As an extreme example, a leading disability service organization refused to distribute our recruitment fliers because we had privileged the Autistic community's desire for identity-first language (autistic person) over the more oppressive, to many autistic people, person-first language (person with autism) (Sinclair 1999). In other ways, the highly politicized context in which AASPIRE sits has us both especially sensitive to mental models and accustomed to routinely examining them in ourselves and others. Due to this facility, our team was able to understand the perspective of individuals who may not have been exposed to, or who disagree with, emancipatory language and identity politics, and was able to craft an acceptable alternative that did not reinforce the oppressive dominant language (person on the autism spectrum). Understanding and examining mental models is a formidable tool in how we navigate the political land-mines of our work; however, understanding does not mean giving in, and it is important from an emancipatory perspective not to 
allow understanding to slip into conformity. Understanding the world-view of the center is not an excuse to push those with alternate models to the margins.

With respect to personal mastery, emancipatory aims may be particularly important. In my experience, it is difficult to pursue excellence, or to care about creative tension, when basic needs are not being met, or when opportunities are suppressed by institutional or systemic oppression. CBPR attempts to address this through its commitment to capacity building. Because of CBPR's commitment to capacity building, I have been given opportunities to grow professionally that most people with my type of disability would not be given. AASPIRE's CBPR model enabled me to be a co-Principal Investigator (Community $\mathrm{PI}$ ) on its projects with equal power to the academic $\mathrm{PI}$, both within the group and when engaging with outside institutions and academics. This in turn provided sufficient financial stability, social capital, and access to opportunities for learning to bootstrap me into a position where I was able to pursue my own excellence both outside of, and within, the group, as well as to pursue a PhD. Another one of our community partners made connections and developed professional skills that enabled her to find broader employment. In a confidential check-in conducted by internally midproject, one team member noted becoming more active in the Autistic self-advocacy community as a result of working with AASPIRE and another noted increased selfadvocacy skills and an increase in self-esteem as a result of working on the project (McDonald 2012). Individuals with more resources and control over their lives are more 
likely to be in a position to practice self-betterment (e.g. the success of Justin Dart in advocating for disability rights (Shapiro 1994)).

As noted previously, CBPR takes a systems thinking (in the sense described by Senge) approach. While not intrinsically emancipatory, it is harder to shove people to the margins when they are included in a whole of many potential boundary definitions. CBPR's principles around ecological perspectives and long-term commitments are aspects of systems thinking. It becomes more difficult--perhaps appropriately so--to find granular examples of the intersection of "the fifth discipline" in AASPIRE's work as there are few things we do that are not informed in some way by systems thinking. AASPIRE plays a long game in its efforts to create a more emancipatory research program for adults on the autism spectrum, consistent with CBPR's principle to commit to long-term processes and group sustainability and the action research aim of research as a change agent. We do not expect to change dominant discourse with a single research paper, but we do hope to change it with a few decades of work, outreach into affected stakeholder communities, and a mission statement that is ruthlessly committed to bringing the margins to center.

\subsubsection{Other Organizational Practices}

Beyond the learning organization--or, perhaps on a finer-grain within it--systems thinking (writ broadly) combined with the CBPR principles influences AASPIRE's day-to- 
day processes. Most notably are our methods for discourse and decision-making, and our use of feedback. With respect to these items, equitability is our primary concern. Our diverse team includes individuals on at both extremes of dominance (a White, male physician) and marginalization (individuals experiencing multiple marginalizations along dimensions of race, gender, sexuality, and disability status). Additionally, our group includes members who cannot hear, cannot speak, or cannot process synchronous communication well. As CST has rightly stated, there can be no equitable discourse without attention to these types of differentials. By application of CBPR's principles and considerations, our attention to these issues has resulted in the following four key lessons learned.

First, the group must adopt communication processes that privilege those most marginalized (i.e., Autistic collaborators) and, if possible, disadvantage the others. We conduct most of our collaborative work through online, text-based interactions, with choices of both synchronous (group chat) and asynchronous (list serve) modes.

Second, project materials must be translated between stakeholder groups, either by someone holding an intersectional position (like me who can bridge community and scientific language) or by collaboration between stakeholders (e.g., my work with Nicolaidis to bridge with healthcare provider language). This is key to enabling the equal access to the information required to participate in shared decision-making, as well as to ensuring the transparency needed to equalize knowledge-based power. 
Third, shared decision-making processes must account for power. Our decisionmaking process, the Five Finger Method (Nicolaidis, Raymaker et al. 2011), provides one example. A method for consensus-building, decision-makers indicate in whatever way works best for them a degree of acceptance (love it, it's fine), the need for further discussion (and about what), or degree of rejection (don't like it but can live with it, will block it) along with why they reject the idea. This makes each decision a negotiation of consensus instead of a vote; it enables quieter individuals to have a say. The adoption of this method was inspired, in part, by a systems understanding of the issues with equitability and voting (Arrow 1950); it is therefore a way to manage consensus that does not involve ranking or voting.

Lastly, one of the principles of CBPR is to develop systems using a cyclical and iterative process. As part of the action research tradition, AASPIRE has operationalized double-loop learning (Argyris 1977) in its standard operating procedures. At the end of our meetings, we do "CBPR check-ins" when needed or when there is time, or when there is a specific reason (e.g., new process, new phase, new collaborator). Collaborators are also encouraged to provide feedback unsolicited. As one example, one of our Autistic team members spoke up about her difficulty understanding emails and recommended a new format to increase accessibility by chunking information under precise headings with specific instructions, and placing extra details in an optional section (Nicolaidis, Raymaker et al. 2011); we are still successfully using her format six years later. The CBPR literature is clear that the ability to reflect, provide feedback, and 
adjust both actions and value systems/mental models via double-loop learning is not to be taken for granted; these practices require shared power and trust. AASPIRE attempts to do this through our approach to team learning/co-learning, and through the reinforcement of everyone's actions over time. In a cyclical and iterative way, is through our feedback loops that we are able to build and sustain the power-sharing and trust necessary for those loops to reinforce emancipatory aims instead of the status quo.

\subsubsection{Holism}

In my opinion, strategies like those described above for building a learning organization that attends to power cannot be implemented in isolation. They comprise complex feedbacks in themselves. Trust-building is facilitated by proof of commitment to capacity building which facilitates personal excellence which in turn strengthens team learning/co-learning which builds trust, and so on. In addition, team member characteristics--such as willingness to prioritize consensus and shared vision over small points--have played a key role in the success or failure of our learning organization over time. Therefore, the combined CST/CBPR model is one which must be considered and implemented in a holistic manner. Happily, holistic thinking is already embedded in both approaches. 


\subsection{Conclusion and Future Directions}

In conclusion, CST and CBPR are compatible approaches to inquiry (via their shared historical, philosophical, and pragmatic foundations and stated aims) that focus on human emancipation, context/complementarism, critical thinking, and holism. The principles and considerations for the practice of CBPR may be useful for implementing emancipatory practices within CST-focused settings; likewise, the rich set of methods from CST may be useful to CBPR practitioners. AASPIRE has been able to create and sustain an equitable learning organization via its application of CBPR's principles and considerations for emancipatory practice. While not without challenges (e.g., needing to re-build trust and re-negotiate team dynamics when new people join the group, managing the extra time required to maintain equitable practice around project deadlines, managing students whose unique positionality can generate challenges with power-sharing or communication, etc.), the hybrid approach has been satisfying and beneficial to us in practice. Researchers unrelated to AASPIRE have started to call attention to the equitability and success of AASPIRE's model (Jivraj, Sacrey et al. 2014, Pellicano, Dinsmore et al. 2014).

AASPIRE conducts academic research. However, we have used our hybrid CST/CBPR approach to develop a web-based healthcare toolkit (AASPIRE Healthcare toolkit, autismandhealth.org) for both marginalized (Autistic) and dominant (healthcare provider) end users. We were able to collaboratively and equitably manage the full software development cycle from concept and design, to user interface and content 
development, through to final testing with minor adjustments to our processes informed by our feedback mechanisms; we describe the details elsewhere (Raymaker, Nicolaidis et al. in review). This suggests that our hybrid approach is usable outside of academic research settings, for example in a commercial technology setting. It would be interesting to see others test the utility of this approach both in similar research settings and in more commercial or industrial contexts--in all settings where systems thinking methodologies are used.

One shortcoming of AASPIRE's implementation of a hybrid approach--at least in terms of the tidiness of its example--is that at the group's inception, I was familiar with hard and soft systems thinking, but not with CST. Given the group's emancipatory focus, CBPR's foundations in critical theory, and the grounding many of AASPIRE's team members (formally or informally) in feminism and/or critical disability studies, it was inevitable that our approach to systems thinking be infused with critical theory; in retrospect, CST best describes the systems thinking approach we took. However, the union could have been tidier. It will be interesting to see if there are any impacts of this increased level of awareness on the group moving forward, including how we can make use of CST's growing literature of methods (e.g., CSH (Ulrich 1995, Ulrich and Renolds 2010), boundary critique (Midgley 1992, Midgley 2001)); for example, to facilitate more conscious awareness of how feedback could be reinforcing dominant positions within the organization and break such loops, or to better understand mental models around power, which could lead to more effective power-sharing. 
Of relevance to this discussion is Midgely's Community Operations Research (COR), which bears many similarities to CBPR, and also speaks to the commonalities and synergies between CST and other "flavors" of participatory action research conducted with marginalized communities. COR is an effective way to conduct emancipatory research and examples of its use well-documented (Midgley 2001). However it differs from the hybrid CBPR/CST example given here in two main ways. First, CBPR brings with it formally defined principles and considerations. Perhaps this formalism could be useful to some COR projects. Second, and more importantly COR, like a pure CBPR approach, requires community as a key component. Perhaps a hybrid COR/CST approach could function similarly to a hybrid CBPR/CST approach in more commercial or industrial settings, or other situations where community is not feasible or not applicable.

The focus of this paper has been skewed toward what CST might be able to use from CBPR, in part because CST has asked for emancipatory methods and means for generating more equitable practices (Flood and Jackson 1991). CBPR's principles (either the principles themselves or a similar set of emancipatory principles appropriate for a given project context), CBPR's considerations for emancipatory practice, and CBPR's wealth of process literature could provide inspiration for developing those general methods and practices. From the CBPR side, what CST has to offer is perhaps more nuanced. With many systems thinking ideas already incorporated (ecological/holistic perspectives, feedback, context and boundaries, etc.), CBPR could perhaps benefit from a more clear language and set of models for understanding and talking about these 
ideas. Additionally, CBPR has acknowledged the need for, and utility of, systems thinking methodologies within its own approach (Dick 2010, Trickett 2011); with its emancipatory aim, the methodologies of CST may be particularly useful to CBPR practitioners.

In conclusion, the hybrid approach to emancipatory collaborations described here is facilitated by the underlying similarities between CST and CBPR; a useful practice can be generated at their complements. Further exploration into a hybrid approach may yield new methods for emancipatory systemic practice.

\section{Acknowledgements}

Foremost, I thank my AASPIRE team members, past and present, for doing the work, reading this paper, and being there for me. I would also like to acknowledge the valuable input of Christina Nicolaidis, Katherine McDonald, Laurie Powers, and Wayne Wakeland who helped me steer a floundering early draft onto a more effective course.

AASPIRE's work is supported by the National Institute of Mental Health [grant number R34MH092503], by the Oregon Clinical and Translational Research Institute (OCTRI), [grant number UL1 RR024140 from the National Center for Research Resources (NCRR), a component of the National Institutes of Health (NIH), and NIH Roadmap for Medical Research], Portland State University, and the Burton Blatt Institute. 


\section{Article 2 - Community Based Participatory Research Methods in Co-Developing an}

\section{Accessible Web Site for End Users on the Autism Spectrum}

Dora M. Raymaker ${ }^{1,2}$, Christina Nicolaidis ${ }^{1,2}$, W. Cody Boisclair ${ }^{2}$, Katherine E.

McDonald $^{3,2}$, Michael Weiner ${ }^{4,2}$, Steven Kapp ${ }^{5,2}$, Elesia Ashkenazy ${ }^{2}$

${ }^{1}$ Portland State University, ${ }^{2}$ AASPIRE, ${ }^{3}$ Syracuse University, ${ }^{4}$ University of Indiana,

${ }^{5}$ University of California, Los Angeles

keywords: accessibility, Internet use, participatory design, design methods, healthcare, autism

\section{Abstract}

People with disabilities experience disparities in technology engagement, in part due to barriers to access. Existing accessibility standards are necessary but not sufficient without input from end users. However, little is known about effective collaboration with this population. This methodological paper details use of a community based participatory research (CBPR) approach in co-developing an interactive website with people on the autism spectrum.

We used a dynamically adjusted version of our collaborative processes and four end user engagement studies designed to solicit recommendations for site form and content, and assess usability, accessibility, and acceptability. 
Autistic team members identified many accessibility requirements around language and design. Participants in the end user engagement studies identified similar requirements. Participants in the beta site evaluation felt the site was easy to use ( $97 \%$ $\mathrm{N}=120)$ and understand (95\% $\mathrm{N}=117)$, and would recommend it ( $92 \% \mathrm{~N}=105)$. Effective methods for community-engaged web development include respecting expertise, equitable involvement at all stages, adjusting processes dynamically, operationalizing emancipatory aims, and leveraging existing partnerships. The AASPIRE Web Accessibility Guideline summarizes accessibility requirements.

People with disabilities can be co-developers in technology creation; CBPR can provide an effective methodological approach to facilitate. Improved access to technology could improve outcomes for individuals with disabilities.

\section{Contents}

\subsection{OVERVIEW}

\subsection{BACKGROUND}

3.2.1. Disability, Power, and the Internet

3.2.2. Autism and Web Accessibility

3.2.3. Project Context

3.2.4. Objectives

\subsection{CBPR METHODS}

\subsubsection{General Methods}




\subsubsection{Adaptations for Web Development}

\subsection{AASPIRE HEALTHCARE TOOLKIT DEVELOPMENT}

3.4.1 Informational Web Site

3.4.2 Autism Healthcare Accommodations Tool User Interface

\subsubsection{Beta Toolkit and Evaluation}

\subsection{RECOMMENDATIONS}

3.5.1. Methods for Community-Engaged Web Development

\subsubsection{Accessibility Guidelines for End Users on the Autism Spectrum}

\subsection{DISCUSSION}

\subsubsection{General Discussion}

\subsubsection{Limitations}

3.6.3. Implications

\subsection{Overview}

Making web-based technology accessible to people with disabilities is important for creating an equitable Internet (Jaeger 2011, Coleman Institute for Cognitive Disabilities 2013). Existing standards such as the Web Content Accessibility Guidelines (WCAG) alone are necessary but not sufficient for meeting accessibility needs; direct input from individuals with disabilities themselves must also be solicited and integrated (Mirchandani 2003, Federici, Micangeli et al. 2005, Friedman and Bryen 2007, Jaeger 2008, Adam and Kreps 2009, Kelly, Sloan et al. 2009, Brajnik, Yesilada et al. 2011, 
Kennedy, Evans et al. 2011). However, not much is known about methods to effectively include individuals with disabilities in web development, especially those whose disabilities may make them particularly marginalized or frequently left out of Internet or technology policy discussions.

This paper describes the development of an accessible web-based healthcare toolkit by the Academic Autistic Spectrum Partnership in Research and Education (AASPIRE, aaspire.org) using a community based participatory research (CBPR) approach (Israel, Schulz et al. 2003, Wallerstein and Duran 2003, Nicolaidis and Raymaker 2015). We detail our CBPR methods for involving individuals on the autism spectrum in web development, including both our usual methods for equitably working together and the adjustments we made to adapt those methods to fit the specific needs of a web development project.

We then describe the web development project itself. The AASPIRE Healthcare Toolkit (autismandhealth.org) consists of an informational web site and an interactive tool called the Autism Healthcare Accommodations Tool (AHAT), which were developed separately and then integrated into the complete toolkit. As part of the development process, we conducted a series of end user engagement studies to further capture the perspectives of individuals on the autism spectrum. We present the development of the informational web site, attending to accessibility concerns with respect to both the site's content and its user interface design, and the development of the user interface for the 
interactive AHAT tool. Lastly, we present our evaluation of the combined components in the complete AASPIRE Healthcare Toolkit.

We synthesize our experience into two sets of recommendations. First we summarize our CBPR methods into a set of recommendations for others interested in working directly with individuals with disabilities to build accessible web sites or other technologies. Second, we summarize what we learned about making web sites accessible to individuals on the autism spectrum into a set of empirically verified web accessibility guidelines.

We conclude with a discussion of the broader implications of this work both in addressing existing gaps in understanding how to collaborate with people with disabilities to create accessible technology, and in improving the accessibility of the Internet more generally.

\subsection{Background}

\subsubsection{Disability, Power, and the Internet}

At an estimated worldwide population of over a billion (World Health Organization 2011), people with disabilities comprise one of the world's largest and most diverse minorities. Like other minorities, they experience significant inequities in multiple areas of life, including education (United Nations 2006), employment (United Nations 2006, U.S. Department of Labor 2014), health and healthcare (World Health Organization 2013), participation in policy (United Nations Human Rights Council 2011), and engagement with technology (Jaeger 2011, Pew Internet and American Life Project 
2011). In the US, only $51 \%$ of people with disabilities have access to Internet technology compared with $84 \%$ of individuals without disabilities (Pew Internet and American Life Project 2011), and only $64 \%$ of scientists and engineers with a disability are employed compared with $83 \%$ of peers without disabilities (National Science Foundation 2013). These inequities in technology engagement persist despite the existence of technology accessibility standards such as the WCAG (W3C 2013) and policies such as Section 508 of the US Rehabilitation Act (United States Government 2013) and the United Nations Web Accessibility Mandate (United Nations 2013). They also persist despite the fact that many accessibility features are cost-effective and easy to implement. (Jaeger 2011). These disparities both reinforce, and are symptomatic of, people with disabilities having less social, political, and economic power (the ability to effect change or take action) than dominant groups.

In their "information worlds" model, Jaeger and Burnett define three dimensions of information access: physical, intellectual, and social (Jaeger 2011). With respect to the World Wide Web, physical accessibility has received the most focus (Jaeger 2011), and can often be simpler to address. For example, physical accessibility might be implemented by using image alt tags or providing user-controlled font sizes, whereas intellectual accessibility might require translation into a simpler and less abstract vocabulary or social accessibility might require an expert who can write content for individuals who have limited comprehension of language pragmatics. The principles of the WCAG, the most widely-used web accessibility standard, focus primarily on physical 
accessibility and state web sites must be perceivable, operable, understandable, and robust (see Table 3) (W3C 2008, W3C 2013). While there are no standards that specifically address intellectual and social accessibility on the web, a general guideline may be found in the plain language movement. "Plain language" is defined behaviorally by the Center for Plain Language: "Can the people who are the audience for the material quickly and easily find what they need, understand what they find, [and] act appropriately on that understanding" (Center for Plain Language 2013).

\begin{tabular}{|l|l|l|}
\hline Principle & Description & Example \\
\hline Perceivable & Users can detect content & $\begin{array}{l}\text { Providing text descriptions of non-text } \\
\text { elements }\end{array}$ \\
\hline Operable & Users can control the site & Keyboard-only navigation \\
\hline Understandable & Users can comprehend content & Predicable operation of web pages \\
\hline Robust & $\begin{array}{l}\text { Users can run the site on current and future } \\
\text { technologies }\end{array}$ & $\begin{array}{l}\text { Compliance with standards such as } \\
\text { HTML5, CSS3 }\end{array}$ \\
\hline
\end{tabular}

Table 3: Principles of the Web Content Accessibility Guidelines (WCAG)

Accessibility standards are necessary but not sufficient for creating accessible web sites; there is a substantial literature justifying the need for end user engagement in the development of accessible sites (Mirchandani 2003, Federici, Micangeli et al. 2005, Friedman and Bryen 2007, Jaeger 2008, Adam and Kreps 2009, Kelly, Sloan et al. 2009, Brajnik, Yesilada et al. 2011, Kennedy, Evans et al. 2011). Individuals who do not experience a particular disability lack the lived experience (literally, the expertise gained by having had an experience) necessary to understand effective accessibility strategies, or even what functional limitations posed by the disability may require accommodating (Brew-Parrish 1997, Brew-Parrish 2004). The diversity of the experience of disability means that no one set of guidelines will fit all accessibility needs. There is also a strong 
justification for the ethics and efficacy of including individuals with disabilities in disability research, both as participants and as members of the research team (McDonald and Keys 2008, McDonald, Kidney et al. 2009, McDonald 2012, Raymaker and McDonald 2013).

Inclusion of people with disabilities in research and web development, however, is not trivial. Although civil rights movements led by people with disabilities have worked throughout the past century to end segregation and promote inclusion and opportunities (Shapiro 1994, Linton 1998, Charlton 2000, Jaeger 2011), systems change is slow. Ongoing inequities in education and employment result in fewer people with disabilities working in web development. The population can be difficult for outsiders to reach or to understand how to effectively engage. To adequately attend to the complex dynamics of power and marginalization and understand accessibility barriers well enough to create effective accommodations for improving access to web-based technology, a unique methodological approach may be required.

Community based participatory research (CBPR) offers an approach to research which can be used to engage people with disabilities in web development and technology research. CBPR is a branch of emancipatory action research which evolved within health services to address many issues that minority communities experience with research, including exclusion and power inequity (Israel, Schulz et al. 2003, Minkler and Wallerstein 2003, Israel, Eng et al. 2005). Action research is an approach to inquiry where members of the research team are also part of the population of interest, and 
the research is conducted for the purpose of making a change in the world;

emancipatory action research also attempts to increase the power and capacity of people who have been marginalized (Reason and Bradbury 2006). These types of approaches to research developed, in part, to address issues wherein research was not benefiting the people or communities it was being conducted on (Lewin 1946, Minkler and Wallerstein 2003). CBPR focuses on community as a unit of identity, fostering equal partnership between communities and academics, research for the purpose of action, and an ongoing commitment to nine principles of emancipatory practice (see Table 4) (Israel, Schulz et al. 2003, Minkler and Wallerstein 2003, Israel, Eng et al. 2005, Nicolaidis and Raymaker 2015). The process for conducting CBPR can be documented and applied in a systematic way to promote equitable, collaborative inquiry that attends to accommodations and is sensitive to power (Nicolaidis and Raymaker 2015).

\begin{tabular}{|l|l|}
\hline Principle & Description \\
\hline 1 & Acknowledge the community as a unit of identity. \\
\hline 2 & Build on strengths and resources in the community. \\
\hline 3 & Facilitate a collaborative, equitable partnership in all phases of the research. \\
\hline 4 & Foster co-learning and capacity building among all partners. \\
\hline 5 & Balance knowledge generation and intervention for the mutual benefit of all partners. \\
\hline 6 & Attend to both local relevance and ecological perspectives. \\
\hline 7 & Develop systems using a cyclical and iterative process. \\
\hline 8 & Disseminate results to all partners, and involve all partners in dissemination. \\
\hline 9 & Commit to long-term processes and group sustainability. \\
\hline
\end{tabular}

Table 4: Nine Principles of Community Based Participatory Research (extrapolated from Israel, 2003)

\subsubsection{Autism and Web Accessibility}

Although sharing many similar circumstances and goals, the population of people with disabilities is extremely diverse. Some groups of people with disabilities have been more effective in advocating for accommodations including web accessibility, either 
because they started sooner, are greater in number, began with greater privilege or community support, have disabilities that are easier to understand or accommodate, or achieved it among other reasons (Shapiro 1994, Charlton 2000, Jaeger 2011). Individuals on the autism spectrum, who likely comprise $1 \%$ of the population (Brugha, Meltzer et al. 2009, Centers for Disease Control and Prevention 2014), remain a particularly disempowered group, and their specific needs have rarely been considered in web accessibility discussions. There are currently no autism-specific guidelines for web accessibility published in the academic literature, and very few informal recommendations in professional literature (the National Autistic Society has provided one (The National Autistic Society 2013)). Despite lack of consideration of autismspecific web accessibility needs, a large number of autistic individuals likely use the Internet (Biever 2007, Robertson 2007, Jordan 2010), and Autistic community has developed largely through web-based interaction (Sinclair 2005, Chamak, Bonniau et al. 2008); the Internet has been called "to autistic people what ASL is to the deaf" (Blume 1997). Indeed, a recent online survey reported that the Internet helped autistic people communicate more than it helped non-autistic people because of its textual basis, provisioning of time to think, unique opportunities for practicing social interaction (including control of who to interact with and control of communication media), and facilitation of meeting similar people and expression of one's true self (Gillespie-Lynch 2014). 
Autism spectrum disorder is defined by differences in social communication and repetitive or restricted behavior or interests (American Psychiatric Association 2013), suggesting intellectual and social accessibility might be particularly important. Autistic individuals also often report differences in sensory perception and integration which can present barriers to technology use. Existing web accessibility guidelines for other types of disabilities do not address these particular areas, and may even increase barriers to access for autistic users. For example, while some aspects of the guidelines for individuals with intellectual disability (Mirchandani 2003, Friedman and Bryen 2007, Kennedy, Evans et al. 2011) such as consistent navigation may be helpful to autistic users, others can directly conflict, as is the case when simplifying vocabulary makes language pragmatics more difficult to understand (Raymaker 2011, Nicolaidis, Raymaker et al. 2014). Likewise with guidelines for making the web accessible to people with sensory disabilities; for example, captions may be helpful to autistic people who have difficulty processing auditory information, but high-contrast color schemes suitable for people with low vision may be painful or unreadable to autistic users with hypersensitive vision. "Universal design" (accessibility features that work for all) is not universal to meeting all needs and never can be due to conflicting needs (e.g., one person needs more light while another needs less light). Autism-specific guidelines for web accessibility are needed. 


\subsubsection{Project Context}

In response to the lack of accessible healthcare systems information on the World Wide Web, as well as the lack of resources targeted toward adults on the autism spectrum despite evidence of need for adult healthcare interventions (Nicolaidis, Raymaker et al. 2013), the Academic Autistic Spectrum Partnership in Research and Education (AASPIRE) initiated the AASPIRE Healthcare Toolkit web development project. AASPIRE is a community-academic partnership which uses a CBPR approach to conduct research with, and relevant to, the Autistic community (Nicolaidis, Raymaker et al. 2011). Our research group was founded on an emancipatory version of the learning organization model which uses feedback to generate "an organization that is continually expanding its capacity to create its future,"(Senge 1990) and incorporates ideas drawn from critical systems thinking, a critical theory-informed approach to inquiry into complex phenomena (Flood 1990, Jackson 1990, Flood and Jackson 1991, Jackson 2006). AASPIRE is comprised of a multi-disciplinary team of autistic persons, family members, healthcare professionals, academic researchers, and technology professionals. We operate with co-community/academic control at all organizational levels: community and academic co-Principal Investigators (co-PIs), community and academic councils which collaborate with the co-PIs during all phases of the research, and a steering committee (composed of the co-PIs, two community representatives, and one academic representative) to manage conflict-resolution and make decisions in rare cases when timing prohibits full group discussion. 
Since its inception in 2006, AASPIRE has conducted an ongoing series of healthcare studies (Nicolaidis, Raymaker et al. 2013, Nicolaidis, Raymaker et al. in press). In June 2010, we received an NIMH award to develop a web-based intervention for autistic adults and their healthcare providers. The intervention, the AASPIRE Healthcare Toolkit, consists of an informational web site and the Autism Healthcare Accommodations Tool (AHAT), an online form that converts user input into a customized accommodations report, translated and formatted to be amenable to healthcare professionals. Individuals can give the report to their healthcare providers and providers' staff.

\subsubsection{Objectives}

This paper focuses on our work using a CBPR approach to develop the content and user interface design of the informational web site, and the user interface design of the interactive AHAT tool. We present our methodology which included both our internal collaboration processes and a series of three end user engagement studies. We also present the results of the evaluation of the usability and acceptability of the full beta version of the AASPIRE Healthcare Toolkit to a larger sample of autistic and supporter end users. We then synthesize what we learned during the development process into 1) a set of recommendations for engaging end users in web development in similar settings and 2) a set of guidelines for making web sites accessible to autistic end users. It is our hope that others will use our methods for engaging with individuals with disabilities in technology development, as well as consider using our accessibility 
guidelines to create more approachable technology for individuals on the autism spectrum. We believe using a CBPR approach to technology development with people with disabilities can greatly improve equitable access to technology.

\subsection{CBPR Methods}

\subsubsection{General Methods}

Every CBPR partnership will operate uniquely, as it must incorporate the culture, values, resources, and needs of the community in developing its processes in accord with the principles of CBPR (Minkler and Wallerstein 2003, Israel, Eng et al. 2005, Nicolaidis and Raymaker 2015). AASPIRE has developed an infrastructure, communication and collaboration system, method for shared decision-making, and process for continual self-reflection and adjustment that accounts for the Autistic community's geographical dispersal, interest in Internet technology, and need for alternatives to real-time speech as a communication mode. (Nicolaidis, Raymaker et al. 2011)

\subsubsection{Collaboration Methods for Equitable, Iterative Involvement}

In order to involve Autistic individuals equitably at every stage of our work, AASPIRE has developed collaboration methods that enable and privilege the Autistic community's needs and culture, and help limit the advantage our non-autistic partners typically have in interactions. AASPIRE's day-to-day collaboration is conducted between meetings via our text-based listserve, and in group meetings via Skype text chat (Nicolaidis, Raymaker et al. 2011). During meetings, a facilitator guides attendees through the agenda, 
documents, and discussion points (sent to the listserve in advance) by pasting the information into the chat session. We have collaboratively developed guidelines for our meetings, including defining acronyms, prefixing text with initials if typing a direct response to that person's post, placing off-topic comments in parentheses, and providing a 30 to 90 second delay before switching topics to ensure everyone has had time to formulate and type a response. While our primary channel for meetings is the text chat, we offer multiple modes for collaboration to accommodate scheduling and communication needs, including one-on-one text chats, email, phone calls, or, for team members in the Portland, Oregon area, in-person meetings (Nicolaidis, Raymaker et al. 2011). This gives our Autistic partners more ability to influence and act (i.e., more power) in the collaboration than they would have had in fast-paced face-to-face meetings where some team members would have been disadvantaged or unable to participate at all (Nicolaidis, Raymaker et al. 2011). Other processes and policies for equitable collaboration include the "five finger" method for decision-making (described in detail elsewhere (Nicolaidis, Raymaker et al. 2011)), defined roles and responsibilities, financial compensation to all partners for their time on funded projects, and a private web site for archiving. In addition, the community and academic co-PIs meet weekly or more often to implement the group's decisions and conduct the work of the project. Methods for Self-Reflection and Process Adjustment

As part of our commitment to being a learning organization, as well as to the CBPR principle of developing systems via a cyclical and iterative process (i.e., cycles of 
critical self-reflection), we have mechanisms for continuously evaluating and improving our processes. We do explicit "CBPR check-ins" during meetings, re-evaluate processes when there is a perceived need, and encourage partners to provide unsolicited feedback. These mechanisms add reflexive practice and double-loop learning (the adjustment of underlying values and assumptions in addition to the adjustment of processes and procedures) (Lewin 1946, Argyris 1977) to our daily work, enabling us to constantly recalibrate our organizational practice to meet our team's and our projects' needs. During the AASPIRE Healthcare Toolkit project, we used these feedback mechanisms to adjust our usual research collaboration methods to fit the needs of web site development.

\subsubsection{Development Process, Co-Learning, and Power-Sharing}

Our usual CBPR methods for iterative research materials development--for example creating, reviewing, and refining recruitment materials, measures, and interview guides--for the most part fit with typical software development processes, with engineering staff taking on the roles typically done by research assistants and academic consultants. Roles throughout the toolkit technology development included the programmers (staff person/s with the engineering and technical skills to create the software and resources), a meeting facilitator, our team of community and academic partners, and the co-PIs. This paper's first author and community co-PI often occupied both the programmer and facilitator role; however additional staff also participated in the technology development and meeting facilitation. The co-PIs were directly involved 
at all stages of the software development process. Communication was often facilitated by team members who were able to "bridge the gap" for others between technical expertise and community expertise; in particular one of our community members is also a computer scientist and our lead programmer is also a community member.

The programmer prepared the web site and content for the group, for example by creating a new version of the software, setting up access to the secure development site, or compiling bug reports. The facilitator prepared materials by creating accessible review requests, agendas, and login instructions. The co-PIs helped prepare and review these materials prior to engaging with the team. After the team and co-PIs finished a portion of collaborative work, the programmer implemented the team's recommendations for the web site, and the facilitator implemented the team's recommendations for process modifications. As needed, changes were then fed back into the next iteration. We explicitly re-checked important or risky changes to the web site with the team, for example addressing a significant usability or accessibility issue, or cases where a fix for one issue had the potential to cause a problem in another area. We repeated this process of preparing materials, soliciting collaborative input, and implementing recommendations until converging on a product we felt able to release as an alpha or beta version.

CBPR's commitments to co-learning and power-sharing enabled us to find an equitable balance between the expertise of the programmers and the expertise of our academic and autistic team members. Team members respected decisions made by the 
programmers for technical reasons and the programmers respected decisions made by the team for scientific, functional, or cultural reasons; however, this rarely manifested as one group or the other "giving in." Instead it played out in dialogue with both parties explaining the reasons behind their thoughts, working back and forth to find a solution that took all reasons into consideration, and resulted in mutually agreeable solutions. For example, while underlines are standard for indicating hyperlinks and alternate methods present general usability issues, some autistic team members felt the underlines were visually distracting and compromised readability. Discussion from both the technical usability side and from the community accessibility side resulted in us keeping the underlines to indicate hyperlinks but implementing them as subtly colored bottom borders on the two lower contrast color themes. Both the learned expertise of the software professionals and the lived expertise of Autistic team members were equally respected as valid subject matter expertise, and everyone was able to learn from each other.

Our full team was involved with all stages of the development process including conceptualization, content development, user interface design, testing, and developing this manuscript.

\subsubsection{Adaptations for Web Development}

For most of the project, we successfully used our general methods for collaboration to accomplish the development cycle. However, at several stages our processes became infeasible and needed to be modified. Our methods for continual 
feedback and adjustment enabled us to flex the usual processes to fit the project needs and to continue to include our Autistic collaborators, enable them to share their subject matter expertise, and maintain the principles of CBPR.

As the AASPIRE team began reviewing an early version of the informational web site, it became clear that team members had different approaches to interaction with web technology; for example, some were exploratory users who clicked on everything, others zeroed in on a particular area of interest and ignored the rest. A guided walkthrough of the software and its features in our typical meeting format proved too restrictive. Through trial and error, we found reviewing software was more effective when the facilitator guided the group to a particular area of the site (e.g., "go to the home page") and then let individuals explore and share their thoughts in reference to that particular area.

With respect to collaborating on the drafts of the web site content, the enormous amount of information to be worked through made group discussion unfeasible: the final text of the site content comprised over 80,000 words and we made it through less than 3000 in our first two hour meeting due to the slowness of a largegroup format and the detailed comments by team members. At the end of that meeting, we discussed the need to change our process for content review and jointly agreed that each person would provide input via their own individually-preferred mode. For example, one team member opted to use track changes and comments in Word documents, another to set up one-on-one meetings via text chat to go over the 
documents with a developer or research assistant, and a third sent comments in email. I implemented the recommendations in collaboration with the academic co-PI and kept detailed change logs. Although we had originally intended to bring difficult or controversial edits back to the group for approval, the feedback given by team members, while substantive, ended up being straightforward and additional iterations prior to the beta release were not necessary.

\subsection{AASPIRE Healthcare Toolkit}

The AASPIRE Healthcare Toolkit consists of an informational web site and the Autism Healthcare Accommodations Tool (AHAT) interactive report generator. We developed these components separately and combined them in the final beta and public web-based toolkit. During the development process, we conducted four studies with autistic persons sampled from the online Autistic community and from the broader population of individuals on the autism spectrum. The first three studies were end user engagement studies designed to provide input and feedback on the components of the toolkit. Study 1: Recommendations used qualitative interviews to obtain stakeholder suggestions for the toolkit. We used information from Study 1 and our team's expertise to create the alpha version of the informational web site, both content and interface. We then conducted a small usability study, Study 2: Site Usability, of the alpha site. For the AHAT user interface, we conducted a brief survey Study 3: AHAT User Interface to help refine the tool. We used our collaboration methods, described earlier, to 
implement changes based on the findings of Study 2 and Study 3 to create the beta version of the toolkit product. As part of the larger healthcare intervention evaluation, we then conducted Study 4: Evaluation to gauge the usability and acceptability of the beta version of the complete toolkit product. See Figure 3 for the relationship between the studies, the toolkit components, and the full toolkit product.

We used our general CBPR collaboration methods to create the materials, collect the data, and perform the analysis and interpretation on all studies. All studies were approved by the Institutional Review Board (IRB) at Oregon Health \& Science University.

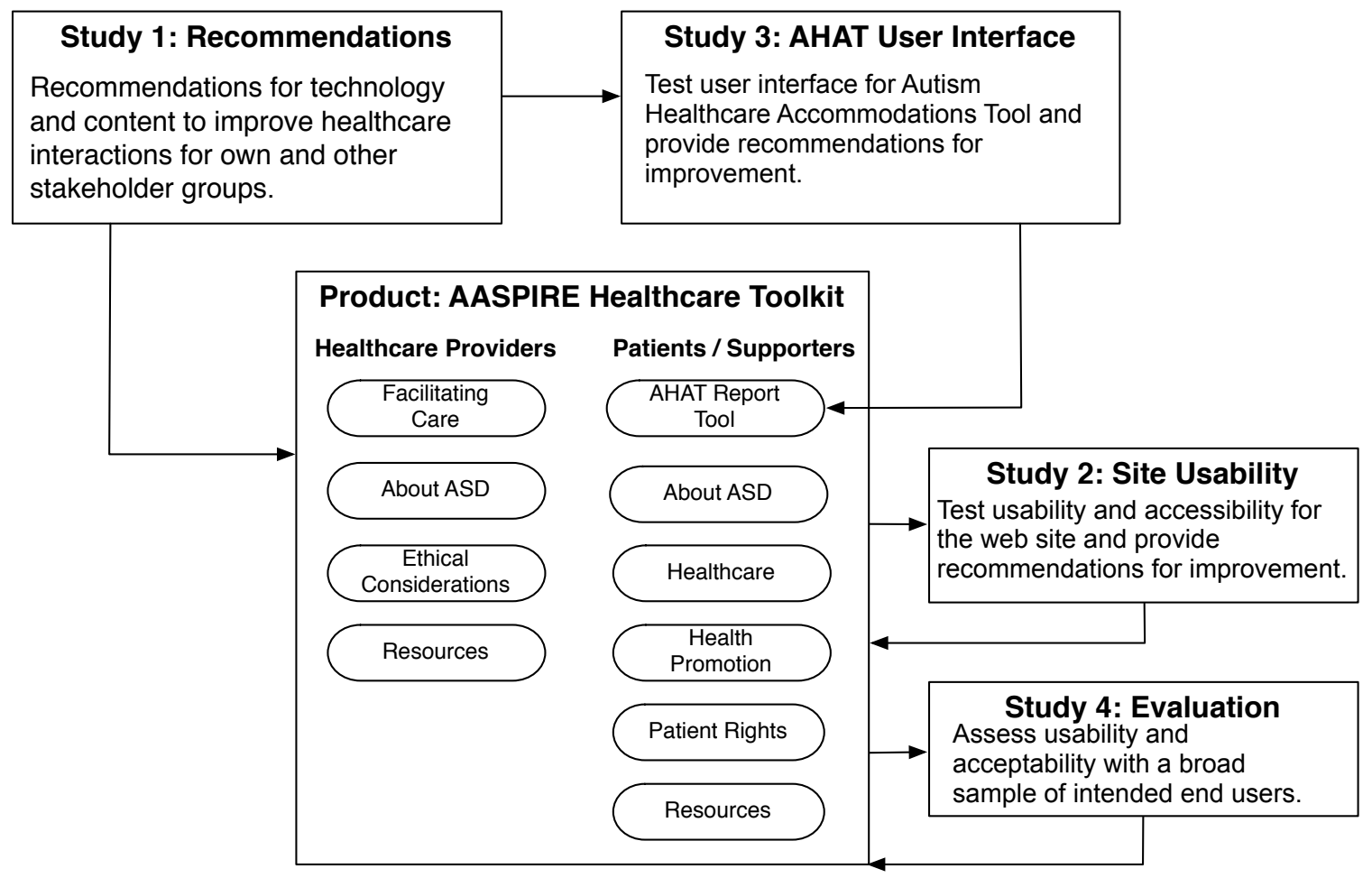

Figure 3: End User Engagement and Evaluation Studies 


\subsubsection{Informational Web Site Development}

We developed the informational web site using the expertise of our team, recommendations from end user engagement Study 1, our iterative CBPR methods, and usability feedback from end user engagement Study 3.

The original idea for the AASPIRE Healthcare Toolkit was generated by our team based on our own experiences--including our knowledge of healthcare-related discussions and concerns within the Autistic community and our knowledge of the healthcare system--and on preliminary findings from the first 20 participants in end user engagement Study 1, which began as part of a prior study (Nicolaidis, Raymaker et al. in press). We conceptualized the web-based toolkit with a section for patients and their supporters and a section for healthcare providers. The "patient side" would include the AHAT and the informational web site comprising the following resources: worksheets to assist in healthcare activities (e.g., preparing for a visit checklist); information about healthcare navigation, keeping healthy, and understanding patient's rights; and an "autism 101" section for people new to the diagnosis. The "provider side" would include information about how to understand autism and provide better care to patients on the autism spectrum. Although web-based, we wanted all content to also be available in print media for individuals who do not use the Internet, who prefer print media, or who would like to be able to engage with the material offline. While the web site as a whole is intended for multiple audiences (patients, their supporters, and healthcare providers), this paper focuses on the development and accessibility of the site for the patient 
audience only. Here in section 4 we discuss the "patient side" of the informational web site component of the toolkit.

\subsubsection{End User Engagement Study 1: Web Site Recommendations}

\section{Study 1 Methods}

The primary aim of Study 1 was to better understand the healthcare experiences of adults on the autism spectrum; primary findings are discussed elsewhere (Nicolaidis, Raymaker et al. in press). Secondarily, we were interested in soliciting end user recommendations for the web site. Qualitative questions relevant to this paper focused on technology that individuals had found helpful for improving their healthcare in the past, ideas they had for new technology that could improve their healthcare in the future, and what they thought should be available on an informational web site about healthcare for adults on the autism spectrum.

Our sample consisted of U.S. residents 18 and older who self-identified as being on the autism spectrum (i.e., autistic disorder, Asperger's disorder, pervasive developmental disorder - not otherwise specified, or autism spectrum disorder). We recruited a convenience sample via two channels. First, we recruited autistic adults who use the Internet from a larger quantitative survey comparing the healthcare experiences of autistic adults and non-autistic adults (Nicolaidis, Raymaker et al. 2013) purposefully sampled to represent as broad a demographic as possible (age, gender, race, ethnicity, educational attainment, living situation, need for assistance with healthcare visits, and communication mode used during healthcare visits). Second, we recruited an additional 
set of autistic adults in the local Portland, Oregon metro area via our off line networks and word-of-mouth, including through county disability services, group home staff, and self-advocacy groups, to further broaden the demographic to individuals with limited Internet access or lower educational levels, or who lived in supported housing. Participants had a choice of how to take part in the interview: email, text-based chat, telephone, or, if in the Portland metro area, in person.

I analyzed the qualitative data with TAMS Analyzer (Weinstein 2012) using thematic analysis with an inductive approach and an essentialist/realist paradigm (i.e., taking what participants said at face value rather than analyzing motivations behind their narratives) (Braun 2006). I verified my findings with peer debriefing by the academic PI and by member checking with the research team (i.e., sharing the findings with individuals who are similar to those we interviewed and asking if the interpretations seemed correct) (Marshall 2010). We used the findings from Study 1, along with our team's expertise, to create the alpha version of the toolkit.

\section{Study 1 Results}

We interviewed 35 adults on the autism spectrum. The group was $56 \%$ female, $70 \%$ non-Hispanic white, and had a mean age of 35 with a range of 19-64. Seventy percent had an education of high school or less, $21 \%$ a bachelor's degree, and $10 \%$ a graduate degree. Fifty-four percent received personal assistance in healthcare settings. Participants had a range of health statuses. See Table 5. The primary areas autistic participants said they would like to see addressed in the toolkit were: 
- navigating the healthcare system

- ways to facilitate communication with healthcare providers

- understanding and communicating symptoms

- health promotion (e.g., nutrition, exercise)

- reliable health and medical information

- software applications providing autism-friendly physician directories, patient/provider message boards, and an electronic system for communicating directly with their providers via writing.

We incorporated all of these participant recommendations into the alpha version of the web-based toolkit, with the exception of the software applications which were technologies outside of the scope of the project.

STUDY 1: RECOMMENDATIONS ( $\mathrm{N}=39$ )

\begin{tabular}{|c|c|c|c|}
\hline & $a v g$ & std.dev. & range \\
\hline Age & 35 & 13 & $19-64$ \\
\hline Sex (male) & $56 \%(22)$ & & \\
\hline Non-Hispanic White & $70 \%(27)$ & & \\
\hline \multicolumn{4}{|l|}{ Education } \\
\hline High school or less & $70 \%(27)$ & & \\
\hline Bachelor's Degree & $21 \%(8)$ & & \\
\hline Graduate Degree & $10 \%(4)$ & & \\
\hline Gets help with healthcare & $54 \%(21)$ & & \\
\hline \multicolumn{4}{|l|}{ Overall health status } \\
\hline Excellent & $5 \%(2)$ & & \\
\hline Very Good & $23 \%(9)$ & & \\
\hline Good & $36 \%(14)$ & & \\
\hline Fair & $28 \%(11)$ & & \\
\hline Poor & $8 \%(3)$ & & \\
\hline
\end{tabular}

Table 5: Study 1: Recommendations Demographics 


\subsubsection{Alpha Web Site Development}

\section{Content Development}

CBPR privileges community members as experts in their own lived experience. Thus in creating the alpha version of the content, community members on our team worked with staff technical writers as subject matter experts. We iterated through the content twice, first in broad topic areas and then in a finer-grained review of drafts.

Our initial discussion with respect to accessibility focused on making the health and healthcare recommendations on the web site intellectually and socially accessible. For example, most information about making an appointment assumes that patients can use the telephone for communication; our site needed to include information about what to do when one cannot use the telephone. Similarly, in the nutrition section, team members identified the need for information that attended to autism-specific sensory and organizational challenges related to shopping, alternatives to cooking, how to make a change in diet when someone else such as an adult foster care worker makes food decisions, and strategies for broadening diet when there are sensory difficulties with food--considerations missing from most comparable mainstream information. We also discussed whether or not to include a section on therapy. Therapy is a difficult issue within the Autistic community, as it has been both a source of increased quality of life and a source of harm or oppression (Giangreco 1996, Creal 1999, Ne'eman 2010). We decided that not only is therapy an important topic to the community, but we had the capability and expertise to treat the topic with suitable delicacy and cultural 
competence. It is unlikely that this degree of understanding of intellectual and social accessibility, as well as cultural sensitivity, would have been possible without the direct expertise and involvement of our Autistic community members.

In addition to implementing the broad items identified by the team, staff writers adhered to an eighth grade reading level, used specific and precise language and avoided idioms, minimized length as much as possible, and used a FAQ-formatted information architecture as intellectual accessibility considerations. For social accessibility, more explanation of social context was added than would be for other audiences--for example, including interaction scripts (e.g., for making an appointment, requesting accommodations from a healthcare provider, asking for a referral for a diagnosis).

After the programmers added the content to the informational web site, we reviewed the drafts and identified areas where accessibility could be improved. Key areas included the following.

Additions to the content based on lived experience: This included details such as using self-checkouts to avoid interaction at grocery stores and knowing that it is possible to be evaluated for autism even if there is no one available to give an early childhood report. It also included larger items such as adding a section on free clinics, and adding more social context, such as explaining why healthcare providers might be nonresponsive or antagonistic towards accommodation requests. 
Clarifications of ambiguities: Examples include instructions to communicate both medicine dosages to providers if two are listed; reinforcing that it's OK to leave blanks on intake forms; prefacing lists and recommendations with "not all of these items may apply to you".

Enhanced precision of language: This was done in some cases by simply being more specific (e.g., changed "contact" to "call or email"), in other cases by adding definitions (e.g. for "healthcare providers", "drug interactions", "in-network provider"), and in still other cases by providing examples ("advocating for accommodations in the waiting room--adjust the music, lights, etc.").

Clarifications due to community-specific context: For example, adding examples of special diet as "diabetic diet or low salt diet" to make it clear this wasn't a "special needs" or "cure-autism" diet; changing "wait in my car" to "wait outside" so as not to presume the person has a car.

Recommendations for restructures to reduce length or increase clarity: Examples include removing some items from a long list, moving any information that was repeated multiple times into a separate section and then referencing that section. Many small wording changes to simplify language/reduce reading level, or increase clarity.

These recommendations were implemented by the programmers and technical writers to complete the alpha version of the web site content used in end user engagement Study 3: Web Site Usability. 


\section{Web Design and User Interface}

As with the content development, we iterated through the site design first on a broader conceptual level and then by reviewing early versions of the site itself.

Programmers made mock-ups of the site using a low-contrast color theme, an accessible sans-serif font, and visual simplicity including plain, flat backgrounds for physical accessibility.

The team came to consensus on preferred layout quickly; however, the color palette for the site was difficult to arrive at. As a key aspect of physical accessibility, team members expressed particular preferences and noted that the "wrong" palette could lead to eye strain, migraines, and an inability to read the text. Further, while a low-contrast palette in general is an accessibility need for many autistic persons, it also presents a barrier to accessibility for individuals with low vision. This led to a decision to have multiple color themes and default to a palette similar to our aaspire.org web site, which everyone on the team likes. Two high contrast themes were developed to meet the WCAG guideline for contrast ratio (W3C 2013). We were unable to develop a theme with universal physical accessibility; that is, a palette that both met the contrast ratio guideline and was easy for community partners with sensitive vision to read comfortably (or at all).

I implemented the group's initial site design decisions. In addition to following the WCAG, I implemented physical accessibility features for user-controlled font sizes and color themes (including a "no CSS theme"), and intellectual accessibility features of 
a simple and clutter-free interface, predictable navigation and layout, and use of simple, meaningful icons to delineate and organize content areas and topics. We then held a series of group meetings to identify the following enhancements to accessibility. For intellectual accessibility:

- Decreasing clutter: remove or tone down use of horizontal rows as separators, increase use of white space.

- Reducing scrolling: layout tweaks so all navigation and key page elements (e.g., download content, AHAT link) can be seen at once in a standard-sized browser window to make it easier for users to understand the full context of each page.

- Increasing predictability: position elements in the same place on both the patient and provider sides of the site, add breadcrumbs even for shallow navigation.

- Integrating icons with information architecture: use visual cues to reinforce site structure. The team felt that the simple icons increased usability and accessibility, either because they provided an additional key to the nature of the content or because the visual delineation they created assisted with understanding how the information was organized (i.e., they functioned as a particularly effective bullet).

For social accessibility:

- Increasing explicitness: use words on the home page to make it very clear what the site is about and why someone might use it, replace "change skin" with 
"change theme", make key areas, such as the entry point for the AHAT, visually distinct from the surrounding layout.

- Neutralizing icons: be mindful of community-specific or cultural meanings of symbols. Though improving accessibility, the team found some initial icon choices problematic; in particular, the butterfly originally used to identify the patient side of the site held too many pre-existing connotations within the community, and some felt the lightning bolt originally used for the patient rights section communicated aggression. We worked together to come up with an icon set that was communicative of the site content without bringing in additional meanings.

For physical accessibility:

- Attending to accessible color: provide a dark background theme and a light background theme for both the low and high-contrast palettes (i.e., four themes were created in addition to the no CSS/print option) These recommendations were implemented by the programmers to complete the alpha version of the informational web site used in end user engagement Study 3: Web Site Usability.

\subsubsection{End User Engagement Study 2: Usability}

\section{Study 2 Methods}

We purposefully sampled participants for the usability study for proximity to the demographics and use cases of likely "real world" end users of the informational web 
site. Participants needed to be U.S. residents over the age of 18 , and fit one of the following criteria: 1) be diagnosed with an autism spectrum disorder; and/or 2) provide support to someone who has been diagnosed with an autism spectrum disorder; and/or 3) be a primary care provider; these three populations comprise the intended audiences for the web site. Additionally, participants were purposefully selected to represent a range of comfort with Internet technology, a range of educational levels, and multiple target use cases (task-oriented, exploratory, and proxy--using the site on behalf of a family member or client). Participants needed to live in the Portland, Oregon metro area as the study was administered in person.

We followed a typical protocol for software usability testing (US Department of Health and Human Services), where participants were asked to complete a series of tasks involving the web site functionality while I observed, asked follow-up questions, and recorded the results. Data recorded on the tasks were 1) whether or not the task could be completed; 2 ) how long the task took to complete; 3) researcher observations and; 4) participant comments. Tasks covered basic web functionality (e.g., search, navigation), accessibility functions (e.g., color theme switching, font size control), and functionality specific to the toolkit (e.g., downloading content for off line use, locating links to access the AHAT).

I met with participants in person. In cases where there appeared to be a problem with usability, I probed participants for what they thought might be the reason, and what they thought might remedy the problem. I created summary matrices of the 
results for site functionality and site content. I then aggregated problem areas in a third summary matrix indicating the number of participants who experienced the issue, the severity of the issue (i.e., degree to which the issue posed a barrier to key site functionality), and ideas for how the issue might be addressed. During the process, I referred to observational field notes and participant comments to gain a more in-depth understanding of issues. In my role as lead programmer, I made decisions about what to address from the aggregate issues matrix based on severity ranking and level of effort to correct the issue. The full team discussed the results of the usability study and reviewed the modifications using our regular CBPR methods.

\section{Study 2 Results}

Eight individuals participated in the usability study; participant characteristics are summarized in Table 6. While all participants were able to complete the primary site functionality tasks of navigating to their audience section, locating the main site content, and reading an article, they did identify several important usability and accessibility issues. Issues are summarized in Table 7. The highest priority issues were a consequence of the forms and worksheets displaying as the default page after entering the patient or provider side from the home page, and lack of clear labeling for the topic and outline navigation. These issues were remedied by adding, as default, a topic summary page, and by adding headers. The usability issues were not specific to autistic end users, nor were there any issues specific to only supporters or only primary care providers; in cases where an issue was reported by more than one person, those 
individuals spanned multiple stakeholder groups. This was important to us since all three audiences could conceivably be using the site.

STUDY 2: WEB SITE USABILITY

\begin{tabular}{lll} 
Stakeholder Group & N \\
& Autistic & 3 \\
Supporter & 3 \\
PCP & 2 \\
\hline Age & $\mathbf{N}$ \\
& $18-34$ & 2 \\
& $35-50$ & 2 \\
& $50+$ & 4 \\
\hline Technical Ability (observed) & $\mathbf{N}$ \\
& Low & 2 \\
& Medium & 3 \\
High & 3 \\
\hline Education & $\mathbf{N}$ \\
& gigh school or modified diploma & 2 \\
undergraduate degree & 3 \\
graduate degree & 3 \\
\hline Sex & Nale & 2 \\
& Female & 6
\end{tabular}

Table 6: Study 2 Web Site Usability Demographics

Participants were encouraged to "think out loud" as they performed the usability tasks. Several participants noted the accessibility features of the site during their dialogue. Autistic participants said they appreciated the ability to change the colors ("because some people may have a harder time seeing one...not many sites I know do that"); appreciated the icons and the simple, predictable navigation ("I like how you can go back to top from any place so you don't get lost"); the lack of clutter ("calming not to have the splashings and the fancies"); and the highly structured information architecture and FAQ-formatted content ("clear, categorical information in an accessible 
format is great and sorely needed. Most sites present information in the form of vague statements instead of a question...this is an intuitive web site...it's in question form so I know where to go").

The programmers revised the web site to address the issues brought out during the usability testing. We used the resulting beta site, along with the beta Autism Healthcare Accommodations Tool, in the evaluation study, Study 4 (described in section 4.3). 


\begin{tabular}{|c|c|c|c|c|}
\hline $\begin{array}{l}\text { \# of } \\
\text { reports }\end{array}$ & $\begin{array}{l}\text { sever- } \\
\text { ity }\end{array}$ & issue & actions & $\begin{array}{l}\text { stake- } \\
\text { holders** }\end{array}$ \\
\hline 1 & high & not clear site is about autism & add some identifiers & pcp \\
\hline 1 & high & $\begin{array}{l}\text { overwhelming and not clear what } \\
\text { would be relevant (PCP side) }\end{array}$ & $\begin{array}{l}\text { re-do the information } \\
\text { architecture for the PCP side }\end{array}$ & pсp \\
\hline 3 & high & topic and outline links not clear & $\begin{array}{l}\text { add "Topics" or "Outline" } \\
\text { header above the links }\end{array}$ & aut \\
\hline 3 & high & topics not clear & $\begin{array}{l}\text { change default to splash } \\
\text { page to description of topics }\end{array}$ & aut, sup \\
\hline 1 & med & $\begin{array}{l}\text { did not process right hand side of } \\
\text { main page where AHAT link is }\end{array}$ & $\begin{array}{l}\text { add AHAT link also to topic } \\
\text { list on left hand side }\end{array}$ & aut \\
\hline 1 & med & $\begin{array}{l}\text { not clear site is about primary } \\
\text { care only }\end{array}$ & add some identifiers & sup \\
\hline 1 & med & $\begin{array}{l}\text { font size adjuster hard to read for } \\
\text { someone with low vision }\end{array}$ & make high contrast always & $\mathrm{n} / \mathrm{a}$ \\
\hline 1 & med & $\begin{array}{l}\text { printed PDFs lack navigation and } \\
\text { branding }\end{array}$ & $\begin{array}{l}\text { add table of contents and } \\
\text { branded footer to PDFs }\end{array}$ & aut \\
\hline 1 & med & $\begin{array}{l}\text { close window button only } \\
\text { relevant in the popup print } \\
\text { version }\end{array}$ & $\begin{array}{l}\text { hide close window button } \\
\text { when "No CSS" used as } \\
\text { theme }\end{array}$ & aut \\
\hline 3 & low & slight crowding / narrow margins & $\begin{array}{l}\text { make whitespace a little } \\
\text { bigger, bullet links }\end{array}$ & aut, pcp \\
\hline $1 *$ & low & $\begin{array}{l}\text { could not find detail actions (print, } \\
\text { email, download) }\end{array}$ & $\begin{array}{l}\text { thought a special "tool" area } \\
\text { on the top bar might work }\end{array}$ & aut \\
\hline 3 & low & $\begin{array}{l}\text { looked for static content links on } \\
\text { bottom of page }\end{array}$ & $\begin{array}{l}\text { add static links to bottom in } \\
\text { addition to top }\end{array}$ & $\begin{array}{l}\text { aut, sup } \\
\text { pcp }\end{array}$ \\
\hline 5 & low & $\begin{array}{l}\text { graphic for switching sides not } \\
\text { effective; unclear what it will do }\end{array}$ & $\begin{array}{l}\text { change graphic to plain text; } \\
\text { consider other ideas }\end{array}$ & $\begin{array}{l}\text { aut, sup, } \\
\text { pcp }\end{array}$ \\
\hline 5 & low & $\begin{array}{l}\text { dropdown to change back to } \\
\text { layout hard to find on no css } \\
\text { theme }\end{array}$ & $\begin{array}{l}\text { place dropdown in same } \\
\text { place as on formatted layout }\end{array}$ & aut, sup \\
\hline 1 & low & $\begin{array}{l}\text { insufficient PDF identification and } \\
\text { resources }\end{array}$ & $\begin{array}{l}\text { add PDF indicator, link to } \\
\text { Acrobat, information for how } \\
\text { to get alternative format }\end{array}$ & aut \\
\hline $1 *$ & low & looked for email to on main page & $\begin{array}{l}\text { offer email option in a special } \\
\text { content area on the main } \\
\text { page }\end{array}$ & aut \\
\hline 1 & low & not sure what "No CSS" meant & change to "no layout" & aut \\
\hline
\end{tabular}




\subsubsection{Autism Healthcare Accommodations Tool}

The Autism Healthcare Accommodations Tool (AHAT) generates a customized accommodations report for autistic patients to give to their healthcare providers. Patients fill out an online form, and the software translates and formats patient answers into a PDF report suitable for primary care providers and their staff. For example, the patient form reads "press on" whereas the provider report reads "palpate," and patient responses appear on the report as bullets organized beneath headers indicating whether the accommodations would be made by office staff or healthcare providers. We built the AHAT as an extension to Portland State University's Audio Computer Assisted Self Interview (ACASI) platform, a web-based survey and teaching tool. The original ACASI was created in partnership with individuals with a wide range of disabilities to incorporate a number of accessibility features, using similar CBPR methods for technology development as those described here (Oschwald, Renker et al. 2009, Oschwald, Leotti et al. 2014). Accessibility features of the basic ACASI include a readaloud option, user-controlled font sizes, consistent and clutter-free navigation, the capacity to play ASL translations of text, and screen reader optimization. A detailed description of the original ACASI software, as well as another example of applying a CBPR approach to web development in collaboration with people with disabilities, can be found in our 2014 paper (Oschwald, Leotti et al. 2014).

Team members noted that they liked the neutral colors and the existing accessibility features, and no one reported difficulty using the form. The group 
identified one barrier to intellectual accessibility--the inability to go back to previous pages--and two barriers to physical accessibility. Those were: 1) dependence on Flash for the non-screen reader version, limiting cross-platform compatibility and compatibility with assistive technology (e.g., alternatives to keyboards or mice such as speech-to-text software or switches), and 2) lack of alternative color schemes.

Programmers addressed the no back button and Flash issues in the beta version of the tool; the alternative color scheme item was deferred until a later release due to time constraints.

\subsubsection{End User Engagement Study 3: AHAT Usability and Refinement}

Study 3 Methods

We conducted a two-week test-retest reliability study on the AHAT as part of its development as a healthcare intervention tool. After participants completed the AHAT the second time, we solicited feedback regarding their experiences with the user interface. We sampled U.S. residents age 18 or older who also met at least one of the following criteria: 1) diagnosed with an autism spectrum disorder and/or 2) providing support to an individual diagnosed with an autism spectrum disorder who would not be able to participate in the study themselves, even with accommodations and supports. We recruited participants through word of mouth and our personal networks, including community listserves, local developmental disabilities agencies, and social media. Multiple-choice items asked participants to rank their ease of understanding the content, the importance of the content, and whether or not they would share the AHAT 
report with a primary care provider. An open-ended item asked participants to offer suggestions for how to improve the AHAT. We analyzed the quantitative data with summary statistics using STATA (StataCorp LP 2013), and summarized the recommendations provided in the open-ended item. Decisions about which recommendations to address were made by the team using our usual collaboration methods.

Study 3 Results

Fifty-nine people (42 autistic and 17 support people) completed the study; see Table 8 for demographic information. In general, participants thought the information was very important ( $83 \% \mathrm{~N}=49)$, easy to understand $(97 \% \mathrm{~N}=59)$, and said they would like their providers to know the information ( $92 \% \mathrm{~N}=54)$.

STUDY 3: AHAT USER INTERFACE

\begin{tabular}{|c|c|c|c|}
\hline & $a v g$ & std.dev. & range \\
\hline Age & 34.6 & 11.5 & $18-64$ \\
\hline \multicolumn{4}{|l|}{$\mathbf{N}$} \\
\hline autistic & 42 & & \\
\hline supporter & 17 & & \\
\hline \multicolumn{4}{|l|}{ Sex } \\
\hline male & $32 \%(19)$ & & \\
\hline female & $59 \%(35)$ & & \\
\hline other & $8 \%(5)$ & & \\
\hline \multicolumn{4}{|l|}{ Education } \\
\hline$<$ high school & $5 \%(3)$ & & \\
\hline high school or modified diploma & $31 \%(18)$ & & \\
\hline undergraduate degree & $40 \%(23)$ & & \\
\hline graduate degree & $14 \%(24)$ & & \\
\hline Non-Hispanic White & $86 \%(50)$ & & \\
\hline
\end{tabular}


Qualitative suggestions for improving the user interface included the issues brought up already by our team. They also included the following suggestions for enhancing intellectual and/or social accessibility: 1) clarifying the reason for open-ended items; 2) adding a not sure or N/A option to reduce anxiety about not being able to answer exactly; 3) allowing people to write in their own answers instead of selecting from the checklists and; 4) correcting a confusing checkbox / write-in combo that was difficult to understand how to fill out. Participants also noted the need to reduce the font sizes to display more text per page and minimize scrolling. We made all these changes except allowing people to write in their own answers, as the main reason for the form was to restrict the type and quantity of information appearing in the report (healthcare providers respond better to smaller amounts of very concise information). No participants explicitly stated that the form was difficult to use or inaccessible.

We also analyzed statistics logged by the ACASI computer program to assess the amount of time it took participants to complete the form and the number of items they selected. Because the form is long--24 items shown one page at a time, most with 10-20 response options requiring self-reflection--we were concerned it might be too much of a burden for end users. We found, however, that participants took an average of 33 minutes to complete the AHAT (std.dev. 24, range 9-148). No participants commented on length. Problematically, though, we found that participants were endorsing on average 51 items (std.dev. 25, range 7-111). As healthcare providers interviewed in our 
larger study and on our team repeatedly stated the most important quality of the report was brevity, this finding presented a considerable concern.

To address the "too many answers" issue in the short-term, we added text crafted by our Autistic team members. The text included an instruction telling participants to select up to three options per item and an explanation of why endorsing a small number of options was important (social accessibility). We implemented this short-term solution for the beta version of the AHAT; however, it is not an ideal solution as it is not the number of options selected under each item that increases the length of the report but the total number of options selected across all items. Additionally, nothing prevents participants from endorsing large numbers of options. Long-term solutions are discussed later.

\subsubsection{Beta Toolkit and Study 4: Evaluation}

\subsubsection{Beta Toolkit}

The beta AASPIRE Healthcare Toolkit included the combined informational web site and AHAT report generation tool. Screen shots of the completed beta toolkit are depicted in Figures 6-9. We used this beta version in Study 4: Evaluation to assess the usability and accessibility of the full web-based toolkit. 


\section{AASPIRE Healthcare Toolkit}

Primary Care Resources for Adults on the Autism Spectrum and their Primary Care Providers

This web site has information and worksheets for adults on the autism spectrum, supporters, and healthcare providers. It focuses on primary healthcare, or healthcare with a regular doctor:

The resources on this site are meant to improve the healthcare of autistic adults. They were made by the Academic-Autistic Spectrum Partnership in Research and Education (AASPIRE) through a series of research studies funded by the National Institute of Mental Health. AASPIRE hopes that you will find these resources helpful.

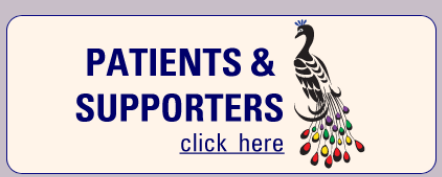

Make a Personalized Accommodations Report for your healthcare provider

This section also has information on:

- Healthcare

- Staying Healthy

- Your Rights in Healthcare

- Autism Information

- Medical Information

- Checklists and Worksheet

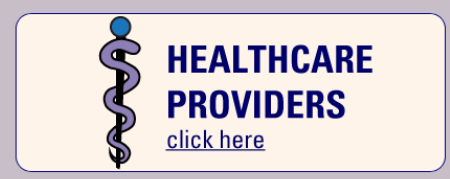

This section has information on

- Autism Information, Diagnosis, and Referrals

- Caring for Patients on the Autism Spectrum

- Legal and Ethical Considerations

- Associated Conditions

- Resources and Links

Healthcare providers also might want share our Autism Healthcare Accommodations Tool, and other checklists and worksheets with their patients on the autism spectrum.

Figure 4: Web Site Home Page

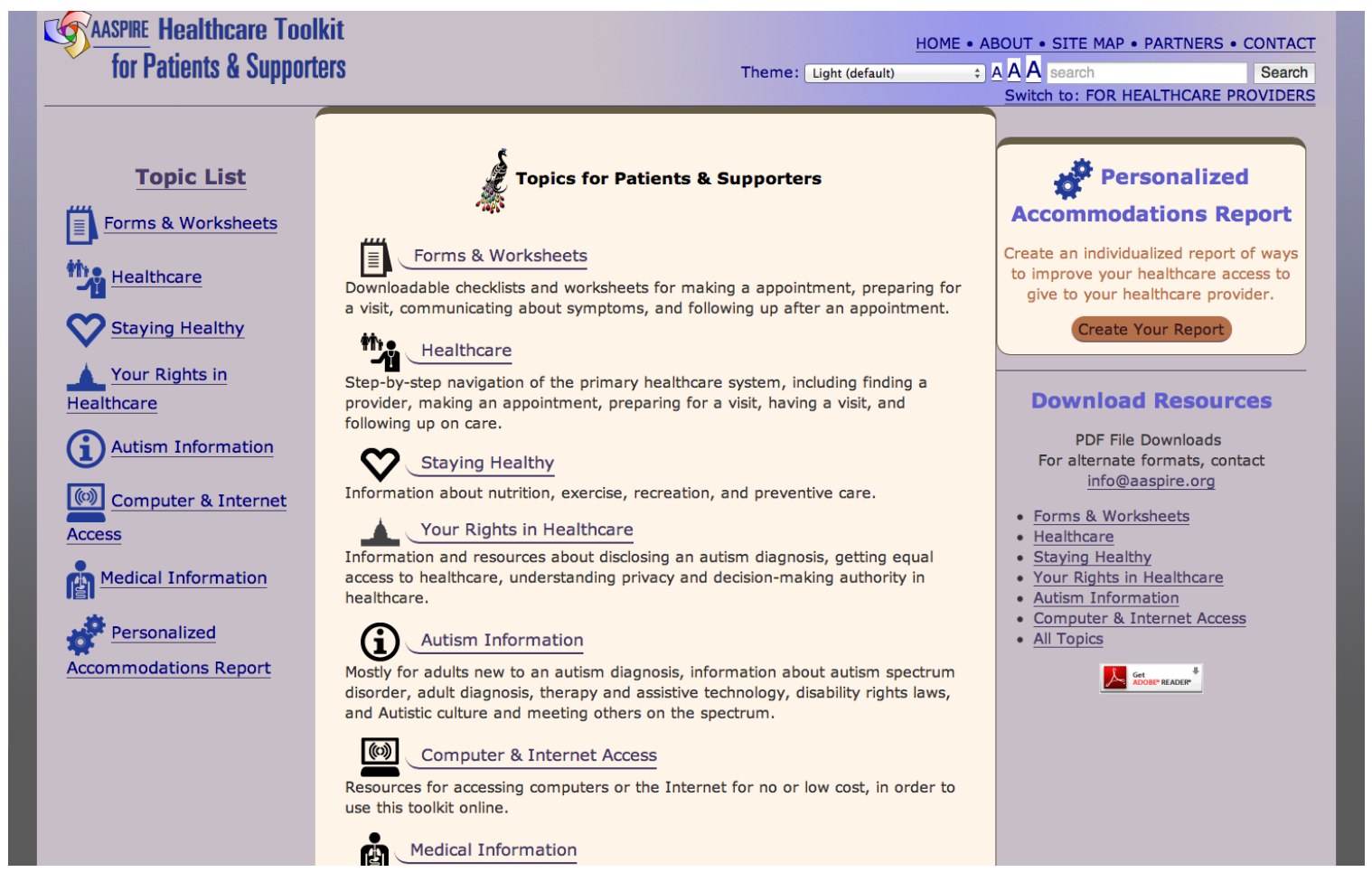




\section{Figure 5: Web Site Patient Main Page}

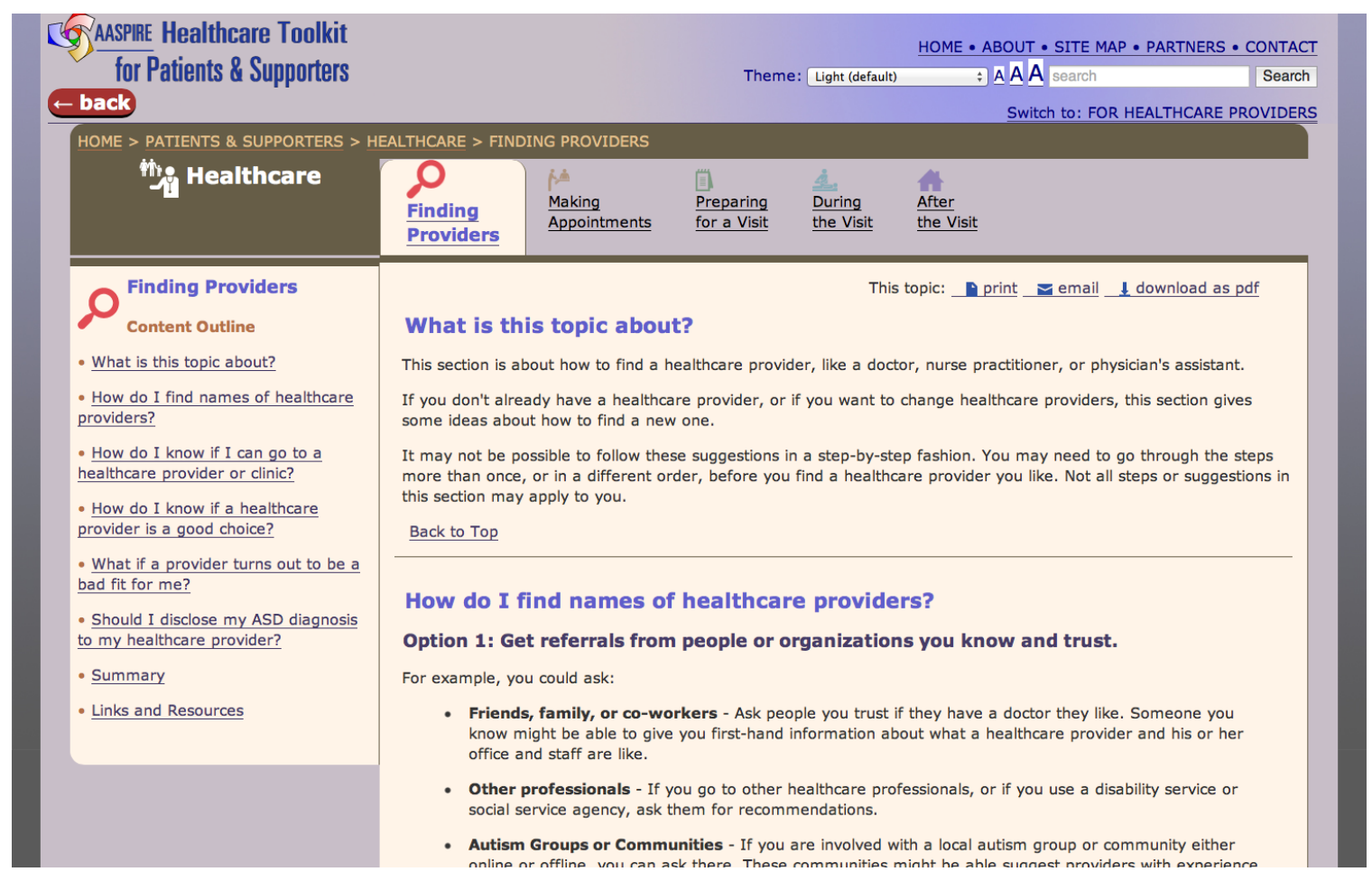

Figure 6: Web Site Patient Detail Page 


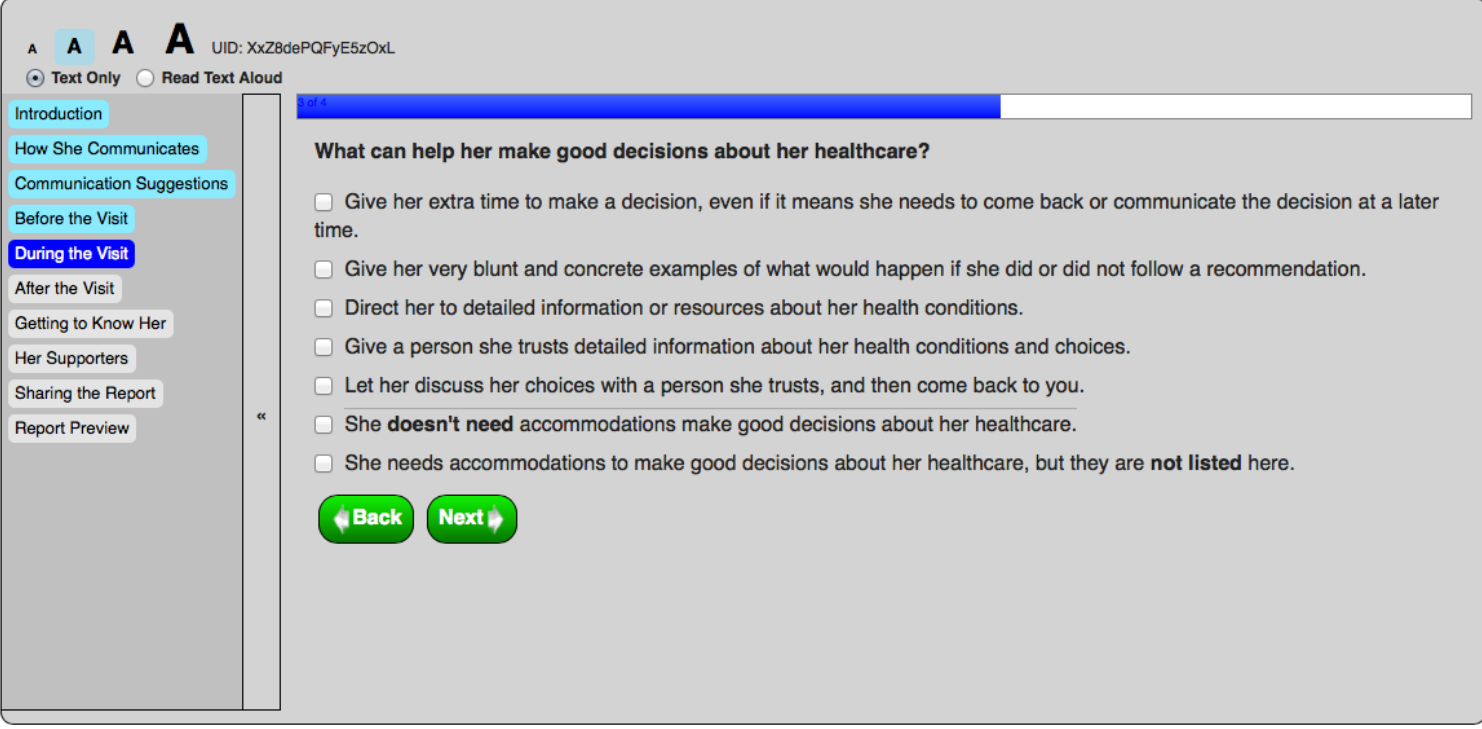

Figure 7: AHAT User Interface

\subsubsection{Study 4: Evaluation Methods}

We conducted an evaluation of the AASPIRE Healthcare Toolkit to determine its overall feasibility and acceptability as an intervention to improve healthcare for autistic adults; the details of the larger evaluation will be described elsewhere. Here we describe the results of the subset of evaluation items related to the usability and accessibility of the informational web site and AHAT user interface.

Our sample included U.S. residents age 18 or older who also met at least one of the following criteria: 1) diagnosed with an autism spectrum disorder (autistic disorder, Asperger's disorder, pervasive developmental disorder - not otherwise specified, autism spectrum disorder) and/or 2) providing support to an individual diagnosed with an autism spectrum disorder who would not be able to participate in the study themselves, 
even with accommodations and supports. We recruited a convenience sample of participants through word of mouth and our personal networks, including community listserves, local developmental disabilities agencies, and social media. We also recruited via broader online recruitment channels including the Interactive Autism Network (www.ianproject.org) and several general online study recruitment boards.

Participants took a pre-survey which directed them to the AHAT. The last screen of the AHAT then instructed participants to use the displayed URL and login information to access the web site. One month later, we sent participants a link to a post-survey which included the evaluation questions about the toolkit as a whole. Multiple-choice questions on the post-survey asked how easy the toolkit was to use and understand, how important and useful the information was, and whether or not participants would recommend it to friends or primary care providers. Open-ended items solicited information about what the participant liked most and least about the toolkit, what they thought was most useful, and recommendations for how to improve the toolkit. We analyzed quantitative data using STATA (StataCorp LP 2013) The primary analysis consisted of summary statistics for the combined patient and supporter populations. We conducted a secondary analysis using chi-squared tests for association between evaluation variables and the population, education level, and browser and device type used. We summarized the recommendations provided in the open-ended items. 


\subsubsection{Evaluation Results}

One hundred and seventy-seven patients enrolled in the evaluation study. Demographics are summarized in Table 9. The overwhelming majority of participants found the toolkit easy to use ( $97 \% \mathrm{~N}=120$ selected very easy or somewhat easy) and easy to understand ( $95 \% \mathrm{~N}=117$ selected all or most of the site). The majority also felt the information was important $(63 \% \mathrm{~N}=79$ selected very important and $43 \% \mathrm{~N}=42$ selected kind of important) and useful ( $53 \% N=63$ selected very useful and $43 \% N=53$ selected somewhat useful). Ninety-two percent ( $N=105)$ would recommend the toolkit to a friend and $95 \%(\mathrm{~N}=111)$ would recommend it to a healthcare provider. Evaluation statistics are presented in Table 10. There was no significant difference in results between autistic and supporter populations. There were no significant associations between usability or understandability and education level, having gotten help using the site, browser type, or device type. 
STUDY 4: EVALUATION ( $\mathbf{N = 1 7 7 )}$

\begin{tabular}{|c|c|c|c|}
\hline & $a v g$ & std.dev. & range \\
\hline Age & 36.5 & & 18-68 \\
\hline \multicolumn{4}{|l|}{ Sex } \\
\hline male & $44 \%(75)$ & & \\
\hline female & $55 \%(91)$ & & \\
\hline other & $2 \%(4)$ & & \\
\hline \multicolumn{4}{|l|}{ Education } \\
\hline$<$ high school & $5 \%(8)$ & & \\
\hline high school or modified diploma & $40 \%(67)$ & & \\
\hline undergraduate degree & $37 \%(63)$ & & \\
\hline graduate degree & $18 \%(31)$ & & \\
\hline Non-Hispanic White & $86 \%(142)$ & & \\
\hline \multicolumn{4}{|l|}{ Device Used } \\
\hline pc or laptop & $88 \%(111)$ & & \\
\hline tablet & $8 \%(10)$ & & \\
\hline smart phone & $4 \%(5)$ & & \\
\hline \multicolumn{4}{|l|}{ Browser Used } \\
\hline Chrome & $29 \%(38)$ & & \\
\hline FireFox & $33 \%(43)$ & & \\
\hline IE 9+ & $16 \%(21)$ & & \\
\hline IE 8- & $3 \%(4)$ & & \\
\hline Safari & $16 \%(21)$ & & \\
\hline Opera & $1 \%(1)$ & & \\
\hline Other & $2 \%(3)$ & & \\
\hline
\end{tabular}

Table 9: Study 4: Evaluation Demographics 
How easy was it to use the Healthcare Toolkit web site?

\begin{tabular}{|l|r|r|}
\hline & \multicolumn{2}{|c|}{$N$} \\
\hline very easy & $54 \%$ & 53 \\
\hline somewhat easy & $42 \%$ & 42 \\
\hline somewhat hard & $4 \%$ & 4 \\
\hline very hard & $0 \%$ & 0 \\
\hline & & 99 \\
\hline
\end{tabular}

How important is the information in the Healhtcare Tookit?

\begin{tabular}{|l|r|r|}
\hline \multicolumn{1}{|c|}{$\%$} & \multicolumn{1}{|c|}{ N } \\
\hline very important & $64 \%$ & 79 \\
\hline kind of important & $43 \%$ & 42 \\
\hline not important & $3 \%$ & 4 \\
\hline & & 125 \\
\hline
\end{tabular}

How much of the information in the Healthcare toolkit was easy to understand?

\begin{tabular}{|l|r|r|}
\hline \multicolumn{1}{|l|}{$\%$} & \multicolumn{1}{|c|}{ N } \\
\hline all or almost all & $63 \%$ & 77 \\
\hline most & $34 \%$ & 40 \\
\hline about half & $4 \%$ & 5 \\
\hline less than half & $1 \%$ & 1 \\
\hline & & 123 \\
\hline
\end{tabular}

How useful was the information in the Healthcare Toolkit?

\begin{tabular}{|l|r|r|}
\hline \multicolumn{1}{|c|}{$\%$} & \multicolumn{1}{|c|}{ N } \\
\hline very useful & $53 \%$ & 63 \\
\hline somewhat useful & $43 \%$ & 53 \\
\hline not useful & $5 \%$ & 6 \\
\hline & & 122 \\
\hline
\end{tabular}

Would you recommend the Healthcare toolkit...

\begin{tabular}{|l|l|l|r|}
\hline & $\%$ & $N$ & Total \\
\hline to a friend & $92 \%$ & 105 & 125 \\
\hline $\begin{array}{l}\text { to a healthcare } \\
\text { provider }\end{array}$ & $95 \%$ & 111 & 124 \\
\hline
\end{tabular}

Table 10: Study 4 Evaluation

Participants selected, on average, half as many items on the AHAT as they had in Study $3(M=25, S D=12$, range $0-101)$. While there is no way to directly relate this reduction in endorsement with our short-term solution of instructing people to select up to three items and reminding them that healthcare providers respond better to shorter lists, the added verbiage may have been helpful.

Qualitative comments were minimal. As had occurred at other stages of the process, many participants expressed a need for alternative color schemes on the AHAT. A few participants felt the AHAT user interface was too cluttered, possibly due to some items having a large number of possible options. Some participants noted the accessibility and usability as what they appreciated about the site: "the questions aren't vague and they are easy to understand," "it was easy to navigate and it was free," "very well organized and easy to use." 
Future releases will add user-controlled color themes to the AHAT user interface and consider ways to minimize the clutter of pages with a large number of options. We will also implement a more effective long-term solution regarding the number of options individuals can select on the AHAT by tracking the total number selected, supplying warnings at 25 options and 35 options, and limiting the number of options appearing on the report to 35. The current, public production release of the toolkit can be found at http://autismandhealth.org.

\subsection{Recommendations}

\subsubsection{Methods for Community-Engaged Web Development}

Although it was developed as a branch of action research within the healthcare field, and most commonly used in healthcare research settings, we have found methods used in community based participatory research applicable to a web development project. Further, we found these methods to facilitate the co-creation of accessible web technology that attended to both good web design practices and to the physical, intellectual, and social needs of autistic end users. The resulting product was usable and acceptable to a broad sample of adult web users on the autism spectrum, as well as to a sample of non-autistic end users. Although the end user engagement studies were helpful in corroborating accessibility points related by our community partners, new information was minimal, meaning that having community co-developers alone may be sufficient to pick up on most accessibility issues. Community based participatory research provided us with the means to equitably engage a community which is 
frequently left out of web technology conversations, even conversations about disability-related accessibility. We offer the following recommendations for communityengaged web development to others who may be interested in co-creating accessible web spaces with individuals with disabilities.

\section{Respect people with disabilities as subject matter experts on their own web}

accessibility needs. CBPR is an approach to research that equally privileges the respective expertise of community members and academics (Israel, Schulz et al. 2003, Nicolaidis and Raymaker 2015). The lived experience of community members constitutes legitimate knowledge as much as the learned expertise of academics. Throughout this project, our Autistic team members were considered the subject matter experts on making web sites accessible to individuals on the autism spectrum. Accessibility requests are not edge cases; they are legitimate barriers to participation in online activities. The same dynamic between community members and academics can translate between community members and engineers or other technology professionals.

\section{Involve people with disabilities equitably at every stage of the web}

development process. In CBPR, community partners are involved in every stage of the research process, from idea development, through implementation, and including dissemination (Israel, Schulz et al. 2003, Nicolaidis and Raymaker 2015). During our web development process, our community partners were involved in every aspect: user interface design, information architecture, topic generation, and content creation. Note, 
however, that while community partners were involved in all aspects of the web development process, they were not asked to become programmers, learn W3C standards, etcetera. Equitable involvement does not mean to "do the same work as," but to contribute expertise and participate in joint decision-making with equal weight and respect.

Adjust the development process as needed to attend to power-sharing and equitable end user engagement. Community co-developers have likely experienced substantial marginalization; it may be necessary to adjust standard operating procedures to balance power. For example, meetings may need to be held in a different way, new processes for shared decision-making may need to be implemented, or development cycles may need to be modified to allow for co-developer feedback, as was the case when we needed to modify our usual processes to fit the needs of the project. It is critical to work in the way that is easiest for the community co-developers, not in the way that is easiest for the more privileged engineers. While this will manifest uniquely for each group of people, being aware of it and letting the community codevelopers define what will work best for them is generalizable across settings (Nicolaidis and Raymaker 2015). Openness and mechanisms for feedback regarding the team's processes are essential for recognizing process issues and correcting them before they become barriers to authentic collaboration (Nicolaidis and Raymaker 2015).

Consider the emancipatory aims and general methodological approach of CBPR as a functional foundation for developing effective co-development methods. The nine 
principles of CBPR (Table 4) were developed to facilitate the generation of methods for equitable co-creation of work between marginalized communities and academics or scientists, who typically have more social, political, and economic power. Research conducted in concord with these principles has been found to produce at least equivalent results to traditional studies in similar settings (Agency for Healthcare Research and Quality 2003). Further, CBPR takes a broad systems perspective that includes deep consideration of context when applying the principles, meaning they can be modified to some degree if needed for a particular instance (Israel, Schulz et al. 2003). Applying the principles of CBPR to collaborative web site development means cocreating methods that attend to power-sharing, co-learning, social and cultural context, holistic thinking, and human emancipation. Drawing this into practice means collaboratively creating a group infrastructure, means of joint decision-making, means of communicating and performing the day-to-day work of the project, and mechanism for internal reflection, feedback, and adjustment (Nicolaidis and Raymaker 2015). The extensive literature on methods in CBPR, particularly from CBPR projects involving partners with disabilities, can suggest a variety of approaches to equitable codevelopment (Israel, Eng et al. 2005).

Leverage existing CBPR groups to create more accessible sites. The efficacy of CBPR does not come without cost. Finding community partners, building trust, finding ways to work effectively together--these things and more can take a lot of time and effort. It is for this reason, among others, that one of the principles of CBPR is long-term 
commitment. Although a full-blown CBPR approach may not be necessary to apply the methods described in this paper, it may make sense for web developers to approach an existing CBPR group to see if the team would be interested in working with them on making their project more accessible.

While our work has been focused on web development, it is likely that these recommendations would also apply with respect to other types of technology development.

\subsubsection{Accessibility Guidelines for End Users on the Autism Spectrum}

The guidelines presented below represent the full set of those we identified and implemented throughout our iterative development process with our experienced team of autistic web users and technology professionals, and the participants in our end user engagement and evaluation studies. The beta site which followed these guidelines was usable and acceptable to a sample of autistic end users. Some of the items we identified are not typically included in guidelines; for example, providing low-contrast color schemes. Others are part of existing guidelines (e.g., plain sans-serif fonts) but they may have greater relative importance to autistic end users. Regardless of whether each individual item is unique to autistic end-users, the items together as a whole are unique to autistic end users. None of these items were difficult or expensive to implement. They did not require any special expertise beyond basic web programming skills and a familiarity with W3C standards, or intermediate technical communications / information architecture skills. We recommend following the AASPIRE Web Accessibility Guideline, 
in addition to the WCAG, to make web sites more accessible to end users on the autism spectrum.

Physical Accessibility

- Provide a least one low-contrast, neutral color palette to accommodate sensitive vision.

- Provide a selection of color palettes, including one with a dark background and one with a light background, again to accommodate color and contrast sensitivity.

- Provide a no-style option (i.e., no CSS) to accommodate browser customization.

- Provide simple, consistent navigation and highly consistent site behavior for increased ease of operation.

- Avoid textured backgrounds, moving images, decorative elements that do not convey information, and other visual and/or sonic "clutter;" these types of elements may make the site impossible to comprehend.

- Provide smaller font sizes in addition to larger ones; large font sizes may make the page appear cluttered and difficult to read.

- Use a plain, accessible sans-serif font for ease of readability.

Intellectual Accessibility

- Use the simplest interface possible for ease of understanding.

- Use simple, concrete icons or images to communicate similar information as text and accommodate multiple ways of understanding information. 
- Clearly label site elements with their purpose everywhere on the site, even if it seems redundant, to make navigation and site functionality easier to follow.

- Provide concrete examples where applicable to accommodate difficulties understanding abstractions or generalizations.

- Minimize scrolling so the user does not need to rely on assumptions about content to guess what might be on the page.

- Show all important features and site navigation (as opposed to within dropdowns) so the user does not need to rely on assumptions to guess whether the item exists and how to access it.

- Make content as short as possible without sacrificing precision and specificity in order to reduce cognitive burden.

Social Accessibility

- Be specific and precise in language use; avoid colloquialisms, idioms, and ambiguity in order to accommodate difficulties with language pragmatics.

- Explain the reason behind any non-standard instructions or unusual information; provide additional pragmatic context to accommodate difficulties with language pragmatics.

- Provide alternatives to absolutes on surveys and forms, for example, "do not know," "do not wish to say," "not applicable" to reduce frustration over not being able to produce an exact answer. 
- Use FAQ formats to organize complex information to enhance clarity as to why the information might be useful to the user and how it connects to their life.

- Define terms that might have different meanings depending on social context, or which might have specialty meanings (e.g., "drug interactions", "healthcare providers") to accommodate difficulties with language pragmatics.

\subsection{Discussion}

\subsubsection{General Discussion}

Community based participatory research has been effective in multiple research contexts with marginalized communities (Minkler and Wallerstein 2003, Israel, Eng et al. 2005), including communities of people with disabilities (Nicolaidis, Raymaker et al. 2011, Nicolaidis, Raymaker et al. 2014). As far as we know, our project is the first to apply this approach in an engineering context, engaging members of the Autistic community as co-developers in all phases of the web development process. Our project provides an example of the ability of CBPR to effectively translate into technology development.

Our project provides both support for the already large literature on the necessity of direct end user engagement in creating accessible web sites (Mirchandani 2003, Federici, Micangeli et al. 2005, Friedman and Bryen 2007, Jaeger 2008, Adam and Kreps 2009, Kelly, Sloan et al. 2009, Brajnik, Yesilada et al. 2011, Kennedy, Evans et al. 2011), and a unique, new approach to achieving this engagement. By attending to power-sharing and co-learning, and respecting the lived experience related to web 
accessibility held by people with disabilities, they can be directly involved in all stages of web development without compromising the technical integrity of the work.

Direct engagement with people with disabilities as equals in web development has multiple advantages. It assists in the identification and effective implementation of accessibility features to remove functional barriers to web-based content. It can help technology professionals who do not experience a particular disability become conscious of 1) their assumptions about accessibility, 2) areas in which accessibility needs may run counter to traditionally taught best practices, and 3) stereotypes they may hold about people with disabilities. One of our academic partners whose area of expertise is medical informatics stated that through the process of working together he "learned that many of my assumptions about users' preferences were incorrect." It also provides developers with insight into the reason for end users' accessibility recommendations; the literature and standards on accessibility often omit the reasons behind guidelines, leaving developers to potentially implement non-optimal solutions. The ability to engage in dialogue with end users enabled us to find solutions to accessibility issues that balanced the needs of individuals on the autism spectrum with best practices for web design (e.g., our experience with underlined links). With codevelopers who have the expertise of lived experience, and a willingness on the part of technology professionals to engage in equitable dialogue with them, the opportunity for a richer understanding of the creation of a more universally approachable product is present. This could, in turn, start breaking down the barriers to an accessible Internet 
that contribute to broader inequities experienced by people with disabilities in technology use (Jaeger 2011).

For all its benefits, taking a CBPR approach to web development requires lot of time and genuine commitment to the principles of CBPR to do right. It is critical that anyone wishing to use the methods described in this paper commit to a long-term process of finding authentic, representative community partners, building trust, cocreating and implementing processes that support equitability and empowerment, and adjusting engineering operating procedures to include co-creation at all stages of the development process. It may be possible to have some of the benefits of taking a CBPR approach to web development without needing to commit to as much work by partnering with existing CBPR groups. Alternately, models which include community members but don't use the full-blown CBPR approach may be appropriate for some projects (e.g., hiring several community members as accessibility consultants).

\subsubsection{Limitations}

Throughout this project, the community co-PI was also the lead programmer. How much, and in what ways, her intersectional positioning as an Autistic person and engineer affected the project is not known; thus, what would have happened with an outsider in the lead development role is unknown. Ideally the CBPR approach to inquiry, with its methods for power-sharing and feedback and its commitment to equitability, is designed to enable successful work between insiders and outsiders. We did have a nonautistic assistant developer and his outsider status did not impact his ability to work 
with the team or his ability to create accessible materials. It is likely that while having an Autistic lead engineer enabled us to operate more efficiently at times, we do not believe it is not a necessary criterion for a successful application of CBPR methods in web development with communities defined by disability. On the other hand, employing engineers who also experience disability could be a valuable strategy for increasing technology accessibility.

The ACASI platform on which we built the AHAT was tested prior to the start of this project by a cross-disability group, thus evaluating the accessibility of the software to people with a wide range of physical, sensory, and cognitive disabilities, and the operability of the software via assistive technology (e.g., JAWS screen reader, keyboardonly navigation, etc.), but the resource web site was not. While we adhered to W3C standards including the WCAG, and added some universal features beyond the recommendations in the WCAG, the resource web site may need further work to make it as accessible to individuals with a broad range of disabilities, or to autistic individuals with other types of disabilities. Likewise, while the ACASI platform, and thus the AHAT, provides a "read aloud" feature for individuals for whom an eighth grade reading level would be a barrier to access, the primary web site content is only available as written text. The toolkit was not tailored to any other minority, and is English language only. While the ACASI provides the ability to include American Sign Language (ASL) translations, we did not record ASL translations for the AHAT. A future version of the AASPIRE Healthcare Toolkit might include bringing the main web site to the same level 
of universal access as the AHAT, as well as adding ASL or other non-English translations of the AHAT and resources.

Even given our attention to power and process, there were still some items and recommendations made during team discussions with respect to the main site content that were not implemented. For some items, the reason was due to lack of time, and the team intends to implement them in a later version of the toolkit (e.g., health section on relaxation, visual versions of key materials); other items were not implemented due to difficulty figuring out how to fit them into the larger product (e.g., an autism myths section for providers); still other items were simply missed in the complexity of the development process (e.g., adding some links and resources recommended by the team). In future versions of the toolkit, we hope to address some of these items.

\subsubsection{Implications}

We present here the first set of systematically derived guidelines for web accessibility for end users on the autism spectrum. This list was created via AASPIRE's collective expertise and our iterative engagement with end users on the autism spectrum in the context of a larger research study. These guidelines add to the growing literature of disability-specific accessibility recommendations that go beyond what the WCAG supports, such as those for people with intellectual disability (Mirchandani 2003, Friedman and Bryen 2007, Kennedy, Evans et al. 2011). We strongly support the implementation of accessible web sites for all people; implementing our accessibility recommendations could improve access to information and technology for the $1 \%$ of 
the population on the autism spectrum, as well as to others who may not be autistic but who have similar or overlapping accessibility needs. Accessibility matters and has real impact on reducing the significant inequities experienced by people with disabilities in the world today.

The AASPIRE Healthcare Toolkit-a web-based information technology geared toward improving health education and patient-provider communication for individuals on the autism spectrum-illustrates the potential for Web accessibility to improve medical care. Since communicating and managing information are fundamental to every medical specialty, facilitating these functions could help autistic patients and their providers clarify goals and engage in more effective shared decision-making, improve patients' follow-up on care, and improve patients' and providers' satisfaction with receiving and providing health care. This might, in turn, lead to improved clinical outcomes including safety, costs of care, injuries, and outcomes of common chronic diseases such as diabetes and hypertension (Greenfield, Kaplan et al. 1985, Greenfield, Kaplan et al. 1988, Kaplan, Greenfield et al. 1989, Stewart 1995, Tierney 2001, Weiner and Biondich 2006, Street, Makoul et al. 2009). Better health education can more broadly be linked to valued vocational outcomes, processes of healthcare delivery, and quality of life. Further investigation could test hypotheses about these factors.

Our work shows that people with disabilities--including those which affect communication and interaction or who have been particularly marginalized--can be key co-developers in technology creation. A community co-development approach to web 
technology is not only necessary for building accessible web sites, but can be an empowering and enriching process for everyone involved, which in turn can give people with disabilities greater capacity to effect change or take action (i.e., greater power). Enhanced access to web-based technology is a key component of reducing some of the inequities experienced by people with disabilities, as it helps to break the status quo of marginalization, oppression, and disempowerment. We recommend anyone interested in improving the accessibility of their web-based technology consider co-development with people with disabilities using methods derived from community based participatory research.

\section{Acknowledgments}

We would like to thank the AASPIRE team members and everyone else we have worked with, past and present, who have greatly influenced the ideas in this paper. AASPIRE is based at Portland State University and collaborates with other academic and community institutions and organizations, including Syracuse University, Oregon Health \& Science University, University of Indiana, Autism Society of Oregon, and the Autistic Self-Advocacy Network, as well as with the Autistic community at large. The content of this paper is solely the responsibility of the authors and does not necessarily represent the official views of the National Institute of Mental Health or the National Institutes of Health. 
This project was funded by the National Institute Of Mental Health, Award Number R34MH092503. 


\section{Article 3 - Reflections of a Community Based Participatory Researcher from the Intersection of Disability Advocacy, Engineering, and the Academy}

Keywords

autoethnography, insider-researcher, community based participatory research, critical systems thinking, autism, intersectionality

\section{Abstract}

This article uses an evocative autoethnographic approach (Ellis, Adams et al. 2011) to explore the experience of being an insider-researcher in a community based participatory research setting. Taking a holistic perspective and using the form of narrative story-telling, I examine the dynamics between the typically marginalizing (but sometimes empowering) experience of being an Autistic woman and the typically privileging (but sometimes oppressive) experience of being an engineering professional, during a time of career upheaval. Themes of motivations and mentors, adversity from social services and the academy, belonging, the slipperiness of intersectional positioning, feedback cycles of opportunity, dichotomies of competence and inadequacy, heightened stakes, and power and resistance are explored through the narrative. While primarily leaving the narrative to speak for itself per the qualitative approach taken, the article concludes with a discussion of how the personal experiences described relate both to the broader work of insider-researchers within disability- 
related fields, and to misconceptions about self-reflection and capacity for story-telling in individuals on the autism spectrum.

\subsection{Introduction}

It's winter, 2015, and my dissertation manuscript is complete sans this article. I'd forgotten, until a committee member reminded me today, that I am a student. I am--of course I am--I'm working on my dissertation manuscript. But how could a thin, transient identity like "student" compete with the blaring lighthouse-glare of the rest of me? I've filled senior engineering roles for two decades, worked as an academic scientist for one, and been an Autistic woman my whole life. Plus I'm fixated right now on that very crossroads of scientist/self-advocate/engineer because it's the experience I'm exploring in this article. From that crossroads, I co-direct a community based participatory research group, the Academic Autism Spectrum Partnership in Research and Education (AASPIRE). I co-founded AASPIRE from the community side nine years ago, angry about how poorly autism and autistic people are represented in research, angry about oppression in my own life, and wanting to leverage science for social change. But my positioning is complex. With my MS in systems science, current career in academic research, and previous career in software engineering, I also exist as a part of the academy and am used to the relative respect and privilege afforded senior technology professionals--even if they happen to be female and disabled. As I work deeper into my 
doctorate and deeper into the academy, these intersections of marginalization and privilege shift, dance, and, at times, assault each other.

My dissertation topic is on building an interactive web site with the Autistic community using a hybrid critical systems thinking (Flood and Jackson 1991) and community based participatory research (Israel, Schulz et al. 2003) approach. Both of these approaches to inquiry draw heavily on critical theory and are philosophically and pragmatically rooted in concerns of power, resistance, and emancipation (Flood and Jackson 1991, Minkler and Wallerstein 2003). Therefore engaging in critical selfreflection, exploring non-reductive / holistic methods of analysis, and challenging dominant discourse are key components of my work. Of holism from within the context of critical systems thinking, Jackson writes, "Holism puts the study of wholes before that of the parts. It does not, therefore, try to break organizations, or other entities, down into parts in order to understand them.... (Jackson 2006)" On intersectionality, Hulko writes,

"Researching and writing about intersectionality and interlocking oppressions often require a blurring of any remaining lines of distinction between the personal and the professional because identity, oppression, and privilege are not solely abstract concepts; they have real, complex, and often-disputed meanings in our daily lives. Moreover, it can be difficult to comprehend what these meanings may be and the dialectical relationship between the personal and the political from a purely structural level analysis. Consequently, feminist, antiracist, 
and disabilities scholars have urged researchers and practitioners to engage in explorations of the subjective realm of oppression to gain a better understanding of the personal impact of structural relations of domination (Hulko 2009)."

Regarding autoethnography (Ellis, Adams et al. 2011), the method of holistic inquiry with which I have chosen to explore my intersectionality, Ellis writes in a dialogue with a friend, "Autoethnography shows struggle, passion, embodied life, and the collaborative creation of sensemaking in situations in which people have to cope with dire circumstances and loss of meaning. Autoethnography wants the reader to care, to feel, to empathize, and to do something, to act...." and "Instead of being obsessively focused on questions of how we know, which inevitably leads to a preference for analysis and generalization, autoethnography centers attention on how we should live and brings us into lived experiences in a feeling and embodied way....We take people into these ethical domains through story, characters, emotion, and dramatic and narrative plot (Ellis and Bochner 2006)."

\subsection{Motivations and Mentors}

Winter, 1986. It's Maine, so it's cold. The ground is so frozen they have to stash the dead in crypts until the spring thaw, and that won't come till April. I'm on the floor again, knees tucked under me as a stack of books slough over. Index cards scatter, unnoticed, my disorderly attempt to conform to the teacher's instructions long- 
abandoned; keeping track of a chaos of index cards is more work than an entire research paper four times over. Do the real work first, then make it look like I did what the teacher wanted after the paper is written. Hide the evidence that I just can't do anything the normal way.

The Underground Railroad. Civil Rights in America. Segregation in the 60's. I thread through the story of oppression and resistance as though it were my own. Which is ridiculous, I'm a white, Italian-American from a recently-immigrated family; there's no reason for it to resonate. Yet in my bedroom a half-assembled robot and a Commodore 64 co-exist with the Civil Rights Movement. Cool mathematics and flaming social justice. Private rebellions and mental malfunctions. "Am I strong to live with these difficulties I have, or am I weak to have them at all?" I trace the question with obsessive precision in my journals beside suicide dreams and blueprints for systems change.

Passion keeps me going most days, but when it's not enough I continue on because of Mrs. G, the English teacher who taught me how to write, and Miss. $\mathrm{H}$ the history teacher who yells, "IT ALL INTERRELATES," isn't allowed in Congress because of past civil disobedience, and slips me Anatomy of a Revolution (Brinton 1965) on the side. Mrs. $\mathrm{G}$ and Miss. H don't care if I use index cards when I write my research papers. They care that I learn something. Their caring makes me cry. I do not want to let them down.

Some days mentors aren't enough either. Glass breaks, the world fragments, the shrapnel of peer-abuse and functional impairment piles into a rage of self-hate, and 
nothing makes sense. There are no anchors here. Always too loud, too bright, eyes and mouths I don't recognize, and no matter what I do it's never the right thing--and I never know why. Senses scrambled. Word salad. Communication disconnect, static on the radio. Some days I can keep organized within the mess; other days I can't. I'm labeled "disturbed," but no one knows why.

Winter, 2014. It's Oregon, so it's raining. The ground is so wet it can steal your boot. I'm on the floor again, knees tucked under me as I try to extract the book I want without toppling the stack. Power/Knowledge (Foucault 1980). Disability and the Internet (Jaeger 2011). Critical Systems Thinking (Flood and Jackson 1991). Social justice stacked beside books on programming languages, dynamical systems, and fuzzy logic-plus a healthy collection of robot parts. My passion for narratives of oppression and resistance makes sense to me now; doesn't matter how white or educated I am, I don't pass for non-disabled any more than I pass for a man. Being different makes me marginalized, especially in male-dominated engineering fields. Being marginalized makes me angry. Anger I can channel into social justice.

Or self-destruction.

I am savvy about self-destruction too these days. When hope isn't enough hate will have to do. They both get the job of systems change done. For the past three years I've combined my dual passion for engineering and social justice into building an interactive online healthcare tool kit for autistic adults, supporters, and healthcare 
providers (AASPIRE 2014). There are still no anchors in my sense-scrambled world, but at least now I have a diagnostic term--autism--for why I fail at basic things.

Other days neither hope nor hate is enough, so I continue on because of $\mathrm{CN}, \mathrm{KM}$, and LP. They are my friends, peers, mentors, challengers, and champions. They have given me opportunities I must honor. I would not be on the floor working on my dissertation without them, nor would I have written in my reflexive journal the previous autumn, "Midgely's sacred and profane systems boundaries (Midgley 1992) is really interesting for this paper too, since my intersectionality places me in both the sacred and profane categories simultaneously. What comes of the margins when one occupies space in the entire system?"

\subsection{Adversity from Social Services and the Academy}

Winter, 2008. I am desperate for work. I'd let myself be lulled into a false sense of privilege. I thought I could have a house and a future and a modicum of respect; the delusion came easily during my decade as a senior engineer. I was in charge of a department, responsible for the company's internal information systems, respected, gifted with a beefy paycheck. Of course the fantasy fell apart when my office moved five miles south because difficulty coping with change one of the criteria that can define autism (American Psychiatric Association 2013). Now the loss of my daily routine has taken with it most of my functional speech and I can't find all the rooms in my house, 
but I've been denied disability benefits because I can bend and lift and have a work history. Naturally I can clean toilets along with the rest of my kind.

Except I can't. Cleaning toilets, like most "simple" things, is something I've never been able to manage.

So what can I manage? I can program computers. I can write well. I can learn almost anything that doesn't involve navigating the sensory world. I'm clever with science, particularly in nonlinear or "wicked problem" (Churchman 1967) areas that don't yield well to traditional analytical methods, such as human-computer interaction, process analysis, and communications. I need a career that builds on my engineering skills, gives me control over my schedule and environment, and is willing to ignore the double-whammy of sex and disability (in 2010 and 2011 white women comprised only $18 \%$ of scientists and engineers, women more generally only $15 \%$ of engineers and $23 \%$ of computer scientists, and, in addition to experiencing higher rates of unemployment, only $65 \%$ of scientists and engineers with a disability were employed compared with 83\% of non-disabled peers (National Science Foundation 2013)). Perhaps I could do something in academic research?

I think my posse of social workers would be happier with the toilet-cleaning plan. I sit with my mouth shut, eyes on the spaces between the tiles, as they tell me I am expensive and difficult, and roll their eyes in joint sympathy over having to endure me. But my Individual Employment Plan includes a master's degree in Systems Science with a focus in computational intelligence and modeling, which I've nearly completed. 
It's clear they are not going to help me find a job. Anything I can do is so outside of what they understand that they don't even know how to start. My past professional privilege bites me on the throat again.

I find a researcher working with assistive devices for autistic people.

"Why would I want to talk to people with autism about my work?"

"Well, first because it's important to involve end-users in technology development," (Mirchandani 2003, Federici, Micangeli et al. 2005, Friedman and Bryen 2007, Jaeger 2008, Adam and Kreps 2009, Kelly, Sloan et al. 2009, Brajnik, Yesilada et al. 2011, Kennedy, Evans et al. 2011) I say, "but second, I'm not coming to you as a 'person with autism' but as an engineer with relevant expertise looking for a research internship. My lived experience is simply added value."

A long, uncomprehending stare.

I find another researcher, and this one wants me! She wants me to apply cuttingedge technology to problems of accessibility. Yes!

A month idles by. I remind, "You're paying me. I have a wide range of skills, programming, databases, user interface design, technical communications--"

"Check this research assistant's paperwork for mistakes."

I'm disappointed there's no technology component, but at least it's something to do. I finish fast, it's a trivial task.

"Actually, I don't need you right now," the researcher confesses. "Perhaps you can help my colleague make her web site more accessible." 
"Sure, that's one of my specialties." A week later, I present my assessment. "To meet accessibility standards, we need to make these interface changes, plus add laylanguage summaries for the legal information. Here are some options..."

"No."

"No?"

"The navigation and layout stuff is great, but leave the text alone."

"I'm not suggesting we modify the legal documents. Just supplement them."

"No."

"But the purpose of the site is to help people obtain assistive devices. They can't do that when the information is at a post-graduate reading level and the concepts completely abstract. You're shutting out the very people you're trying to benefit!"

"Good bye."

Maybe I am setting my sights too high. Maybe I am letting the privilege I once enjoyed get in the way of whatever dues I need to pay to the academy before it will have me. "I will do this work you need without pay," I offer to another researcher. He accepts, and is thrilled with my product.

"Maybe you could pay me for future projects?" I whisper.

He coughs around the offense I have just given. "You're an autistic self-advocate, not a member of my research team. Paying you would be unethical.

"But," he adds, "feel free to continue to volunteer." 
I stare down the barrel of a group home. No money for the mortgage. Freedom lost.

\subsection{Belonging}

Fall, 2009.

"We got the OCTRI grant!"

I co-founded AASPIRE in 2006 because of social justice, writ large. Not everything about the crisis that cost me my engineering job was bad; it encouraged me to connect with the large, international community of Autistic people. For the first time, I met others who knew the dissonance of feeling stupid and smart at the same time. Who knew what it was like to experience the world through a whirl of sensory chaos, to be pushed to the margins by ableist oppression--and to delight in and leverage a unique cognitive-sensory experience too. As social workers and academics destroyed my selfconfidence, my peers taught me to take back my power. It was through engagement with the Autistic community, too, that I met CN. We met to discuss autism research, segued swiftly into how science contributes to oppression, and ended up discussing ways community based participatory research (CBPR) can address these issues. A form of action research developed within public health, CBPR seeks to create equitable partnerships between marginalized communities and academic institutions to conduct research desired by the community (Israel, Schulz et al. 2003, Minkler and Wallerstein 2003, Nicolaidis and Raymaker 2015). We--CN, myself, and founding members from the 
Autistic community--formulated AASPIRE's mission as science for social justice with the Autistic community (Nicolaidis, Raymaker et al. 2011, Raymaker 2013).

But the universal social justice issues experienced by the Autistic community are also the personal social justice issues of my daily life. As Hulko pointed out in her earlier quote, the dynamic between identity, oppression, and privilege plays out as messily as anything in the real world (Hulko 2009). There is no easy delimiter between the personal and the universal, between the political and the scientific.

AASPIRE was a love-labor, a gamble. It was the safe space I had carved with mentors and peers I trusted where I could belong. It was the one thing I cared about enough to do for free--although it was also my last hope for employment before I passed into the murk of no return.

"We got the OCTRI grant!" CN and I jump and clap, giddy and grinning.

We got funding to collect preliminary data for our healthcare intervention plan. And I got a pay check and an opening into academia as the community Principal Investigator $(\mathrm{PI})$.

\subsection{Slipperiness of Intersectional Positioning}

Fall, 2011.

"We got the healthcare toolkit grant!" Another cause for jumping and grinning, this time higher and broader. AASPIRE got its intervention funding; we are going to create an interactive, online toolkit of healthcare resources for adults on the autism 
spectrum and I am going to be community $\mathrm{PI}$, project director, and lead web developer. Occupying intersectional space makes me economical--I am self-advocate, scientist, and engineer all-in-one. Academics like working with me as a community voice because I am easy and save time. (Although KMD remarks, "I think 'we' like working with you because you are also smart, and willing to collaborate (McDonald 2015);" like any model, storytelling necessarily oversimplifies.)

On the other hand, I am not representative. Sure, I know the sick lurch-and-grind as the social worker blackmails me by withholding my bus pass and I am forced to hand her all my power. But I also know the satisfaction of walking into a room of highpowered professionals and having them listen to, and act upon, my recommendations. I do not know the oppression without the privilege. Which is why AASPIRE includes a whole team of autistic people with different experiences from mine.

As the project opens, those collaborators push back. Who is doing the work? Who made these decisions? Where is the transparency? Why did I not get a say in X? Comfortable in my Autistic identity, my foot in the community, I forget that I am made suspect by my intersection with the professional and scientific. This hurts; I withdraw, unsafe in my own community space.

But really, do I not have the same reaction to people in authority? They have blackmailed me with bus passes, denied me needed services, pushed me into poverty, and dismissed the idea that an autistic person could have anything of value to contribute to a research project. 
I unbristle, swallow, and acknowledge I need to re-earn trust in this new context. I reveal: this is the work I do, here is a $F A Q$, these are the important decisions we make together and these are the boring, busy, techy decisions that are a waste of your time. I do my job of implementing the team's decisions and recommendations, and take deep breaths into the passage of time where actions can prove the sincerity of words. In a confidential check-in conducted by KMD in spring, 2012, team members overall say they trust the process of working together, enjoy the project, and feel they are contributing at a desired level (McDonald 2012).

\subsection{Opportunity Begets Opportunity (or Privilege Begets Privilege?)}

Summer, 2012, I travel to Autreat, one of the Autistic community's oldest and biggest cultural events. I've always wanted to go and this project is what gives me the resources to get there. Friends online become friends at the lunch table; we blow bubbles and I spin and trill in their iridescent fairy-shine. I present on AASPIRE's work and get important feedback about the web site's accessibility. Most importantly, for three days, I am somewhere I belong.

I return and get back to work. I program the web application, work with the AASPIRE team on content and design, and work through the end-user engagement studies to test the intervention's usability and acceptability (Raymaker, Nicolaidis et al. in review). I write oceans about health and healthcare (AASPIRE 2014). CN encourages me to go for my doctorate. The project has given me enough financial stability, and 
enough of a meaty study with aspects under my direction, to make that possible. I feel the feedback between my community status, my professional background, and these academic opportunities like an unstoppable machine. If I hadn't had professional skills, I wouldn't have been trusted with these project roles; if I hadn't been an Autistic person, I wouldn't have been privileged as a co-PI with only a master's degree; if I hadn't been given that first co-PI opportunity, I wouldn't have this project to carve out a section for my dissertation work. One of the basic systems archetypes--a generalized model of nonlinear feedback in a particular class of situations--is "success to the successful" (Senge 1990). I think uncomfortably about my friends who were never given an opportunity for that initial success.

I pass my comprehensive exams in spring, 2013. My dissertation will consist of three papers on intersections of CBPR, critical systems thinking, and the techier aspects of the toolkit web site development. In order to meet the requirement of at least one sole-authored paper (AASPIRE's CBPR process requires an offer of co-authorship to all partners), I plan to conduct an autoethnography of my experience as an intersectional researcher working on the project. I begin a reflexive journal.

\subsection{Dichotomies of Competency and Inadequacy}

In spring, 2014, my mentors nominate me for the student award from the American Association of Intellectual and Developmental Disabilities, and I receive it. In my reflexive journal I write, "Intersectionally, I co-exist as all of these identities, as a 
whole person with overlapping facets. But sometimes the overlays separate and...none of the pieces fit. I've won an award for my research but am incapable of executing any of the steps to attend the ceremony to accept it [because of my disabilities]. I'm doing work that should see me involved in a professional organization, but...being totally unable to execute any steps to make use of a membership or attend any of the conferences [because of my disabilities], there's little point.... haven't been paid since December because my necessarily job-carved world doesn't fit with what the academic administration can cope with....My ability to do anything besides the core of the research work is dependent utterly on colleagues [due to my social and communication limitations]. On tagging along with them to a conference, on them introducing me to others and facilitating the conversation, on their kindness in hiring me even though I have no real position, no legitimate claim to the work I do....I can manage to succeed at the science, but I can't manage anything that being successful brings with it."

A week later, I add, "But realistically, there's a ton of ways in which my intersectionality makes things hella [lot] easier and stronger than they would have been otherwise. I don't have to go to consultants to check something about the community or about what having an autistic perspective is like. I don't run as much of a risk of making faulty assumptions and erroneous conclusions. In many ways being a member of the community/population of interest removes a degree of bias because I'm not having to work with a mental model of an alien culture/experience. Insider status might introduce some biases like knee-jerk responses about power, but it also relieves other biases like 
around what the community/population 'should' be like or do. It also helps me to properly contextualize the community/population without having to do a ton of anthropological study. There are tons of benefits."

Someday, maybe, I will have an office in which to hang that award. (At which point, reading an early draft, KM reminds me I'm a student and students do not get offices (McDonald 2015). Which leads me to acknowledge the entitlement I feel because my first career privileged me with offices, so less is a step back--unlike traditional students who have yet to begin.)

\subsection{Heightened Stakes of Success or Failure}

Winter, 2014. My dataset stares icily. I wish it would give me a hint as to what it contains, some means to brace myself against failure. Back in December, someone in the community called the project "silly," amongst other hurtful things. In my journal, I wrote, "If people don't like something, I listen carefully, ask questions, and then make determinations about whether or not I feel the comment requires action.... where that breaks down--but for a different reason [than ego]--is when people within the community reject...the work that...me and my team actively tried really, really hard to account for. That type of thing hits me hard...because I care so much about 1) helping my community and 2) my peers in my research team. It's not just my hard work that's getting thrashed, it's THEIR hard work too. The community side of my work has an entirely different investment in it than the academic/professional sides, and I really 
struggle there." Later I wrote, "I sometimes feel like I hide in my academics because I can't cope with what I really care about on the community level." Research results have loaded meanings when acceptance and rejection by one's own community hinges on them. Botching this project could mean loss of social support, friendship, access to the comfort of shared culture and belonging; I've an ethical obligation to report the truth. When I look at the results of the toolkit web site evaluation, will I find vitriol?

Not to mention I've few sustainable options for a fall-back career. Where else would I go, what else would I do? Back to begging at the feet of academics who see little point in working with someone like me? Back to a corporate office where any change could send me into catatonia again, like when I lost my engineering job because of a minor office move (assuming a corporation would have me)? I can't let down the people who believed in me either, who gave me this opportunity--what if I find I acted irresponsibly with their trust in my skills when no one else would touch me? This data represents the edge between maintaining professional privilege and being pushed further into the margin.

My palms prickle. I run the statistics first. Good, old, friendly quantitative numbers; perhaps my data can give me a hint as to what it contains after all.

Easy to use: $97 \%$. Easy to understand: $95 \%$. Useful: $96 \%$. Would recommend to a friend: $92 \%$. Would recommend to a healthcare provider 95\% (Raymaker, Nicolaidis et al. in review). Deep breath. It's safe to dig deeper. 
The qualitative data is spare but encouraging. There is no hate. The suggestions for improvement make sense. People really liked the online toolkit. I am going to be OK.

\subsection{Power and Resistance}

Late spring, 2014, I write,

"Engaging in the academic system as a peer makes me feel powerful in a way that's never been open to me as an advocate. I can rant all I want about stigmatizing research, about lack of focus on whatever area I care about, etc. And on a policy-level sometimes it does get through a bit, shifting focus here, encouraging someone to include the community in their work there. But that is not the same type of power at all as when I review a paper or a grant proposal, or publish a paper that gets cited and used in classrooms, or discuss something with a student, and know that what I have done has shifted whether something gets published, funded, or considered by others when s/he goes back out into the world or develops his/her career. It's a top-down vs. bottom-up impact/influence on science. Am I the outsider urging people to change the structure of their system to produce different behavior? Or am I the insider restructuring the system with my own hands...?... As an advocate I often leave situations frustrated even if they have been successful, having banged up against the enormity of something that may or may not implement [systems change] in a way that makes a difference. As a scientist I leave the situations satisfied; even 
if my recommendations are not taken I was a part of a larger process that, for all its flaws, was set up exactly to allow for new voices, new discoveries, and change in the landscape of knowledge....As a systems person, I've always felt more comfortable finding and fingering the leverage points myself than asking someone else to influence them for me."

In retrospect, I recognize that it's easier to get things done from the privileged position of a scientist than the marginalized position of a self-advocate.

10 December, 2013, two days before my dissertation proposal defense, I write:

"The very act of you doing this research is an act of resistance vs. Foucault's normalizing power (Foucault 1980). It is a small subversion from within."

10 December, 2014, as I prepare my final manuscript I find that quote next to a photograph of a page from a CBPR textbook: "'Doing research' is not, in itself, a goal. Research is only a method to achieve these broader goals [of systems change]." (Minkler and Wallerstein 2003)

I will be ashamed of neither my marginalization nor my privilege.

May they make the way easier for researchers with disabilities to come.

\subsection{Loose Ends and Broader Implications}

Before starting this manuscript, I re-read my $\mathrm{PhD}$ research log, which spanned January 2012 through January 2015. Copying the reflexive passages into a separate document, I rearranged them under themes. I thought about the events of my 
dissertation work, and about the events that got me to those events. I paired the themes from my reflections with the events of my life and began writing this narrative, modifying identifying details to protect confidentiality where needed. Although presented somewhat linearly through time and organized under themes, the lived experience itself can only be understood non-reductively, as a whole. Themes simultaneously influence each other much as the personal and the universal, the political and the scientific, and the intersection of privilege and marginalization; the whole is a restless dynamic.

I shared my findings with the AASPIRE research team and with four similarly intersectional researchers for member checking and verification (Rossman and Marshall 2010). Not only did they triangulate my experiences, they brought up other ways in which intersectionality has played a similar role in their lives along lines of ethnicity, sexuality, and belonging to a religious minority. While my experiences are uniquely mine, the broader themes and narratives may have transferability to other settings. I have avoided presenting too much explicit analysis of my experience in an effort to both avoid reductionism and to stay true to Ellis' approach to autoethnography as a means to "open up conversations about how people live, rather than close them down with a definitive description and analytical statements about the world as it 'truly' exists (Ellis and Bochner 2006)," and story-telling as "an 'activity which reveals meaning without committing the error of defining it' (Arendt 1973)" (Ellis and Bochner 2006). However, there are two broader implications I wish to make explicit. First, this article 
has connections to the larger body of work examining the experiences of researchers with disabilities in academia. Lack of inclusion of insider perspectives in scientific inquiry has been criticized as presenting significant ethical problems, a situation CBPR aims to address (Oliver 1992, Israel, Schulz et al. 2001, Minkler and Wallerstein 2003, Israel, Eng et al. 2005, Raymaker 2013, Raymaker and McDonald 2013). Disability studies also calls for individuals with disabilities to work within the field (Oliver 1992, Linton 1998, Raymaker and McDonald 2013). However, the topic of insider-researchers is not without dilemmas, such as potential for harm via the research process itself or by rejection from the larger academy (Vernon, Mogendorff 2013, O'toole 2013, Rinaldi 2013), or via rejection by one's own disability or advocacy communities. The decision to "out" oneself as a disabled disability researcher (in so much that remaining hidden is avoidable to those of us who do not "pass" or who have established political identities) is a political act in itself which may ultimately shift ableism within the academy (O'toole 2013). On the other side, being an "out" researcher within a community which is suspicious of researchers may help to build trust toward scientists. I hope that my experience, as well as AASPIRE's longevity and success, reinforces the value of insider-researchers within disability-related fields, contributes to the growing body of work about our experiences, and that the risks I take, along with those taken by others of my generation, push that political shift forward.

The second implication is with respect to the characterization of autism as involving impaired capacity for story-telling and self-reflection (e.g., Goldman, 2008; 
Kennedy, 2006). One of AASPIRE's early attempts to fund the toolkit received the following comment from a reviewer with respect to including autistic people as coresearchers and study participants: "It is assumed that high-functioning individuals on the spectrum have the ability to reflect on their own experience and that they can give a valid assessment of what they need. Yet there are studies which indicate that lack of self-reflection is one of the limitations of those individuals. In short, there is not adequate evidence that the self-reports of individuals on the autism spectrum are valid or reliable. (anonymous 2010)." This notion likely comes from a large body of work led by autism researcher Firth and her students, which postulates that lack of "theory of mind" is at the core of autistic behavior (Firth 1993), and has permeated the broader social consciousness; for example, one BBC news article titled "People with autism have 'problem with self-awareness'" states "Sophisticated scans showed the brains of people with autism are less active when engaged in self-reflective thought" and "research has shown the problem is people with the condition have trouble thinking about, and making sense of, themselves." (BBC News 2009)

Autistic individuals, however, frequently tell a different story. Sinclair writes, "I have an interface problem, not a core processing problem. I can't always keep track of what's happening outside myself, but I'm never out of touch with my core. Even at worst, when I can't focus and I can't find my body and I can't connect to space or time, I still have my own self. That's how I survive and how I keep growing..." (Sinclair 1993) This is echoed in the documented lived experience of many of us, and has led to a strong 
critique of the prevalent literature (Lindsay 2012). Conceptualizing people on the autism spectrum as incapable of self-reflection is of great concern within the Autistic community, because it risks dehumanization or dismissal of our thoughts and opinions. If nothing else, let the fact that my reflexive writing exists at all play some small role in changing that dangerous discourse.

\section{Acknowledgements}

Foremost, I thank my AASPIRE team members, past and present, for doing the work, reading this paper, and being there for me. In particular, I thank Katherine McDonald for letting me ramble to her about this article despite it being Christmas break; Christina Nicolaidis and Laurie Powers for their mentorship, friendship, and support in dark and bright times; and my chair Wayne Wakeland who, along with Katherine, Christina, and Laurie, showed enthusiasm for reading my reflections even when I got scared.

AASPIRE's work is supported by the National Institute of Mental Health [grant number R34MH092503], by the Oregon Clinical and Translational Research Institute (OCTRI), [grant number UL1 RR024140 from the National Center for Research Resources (NCRR), a component of the National Institutes of Health (NIH), and NIH Roadmap for Medical Research], Portland State University, and the Burton Blatt Institute. 


\section{Synthesis}

\subsection{Evaluation Question}

I now focus on the synthetic question the theoretical, practical, and selfreflective articles have probed in depth. How, if at all, did taking a hybrid CST/CBPR approach to developing information technology impact the quality of the project as evidenced by

1. the ability of our team to operate equitably as a learning organization and

2. the perceived quality of the web site product to autistic people?

\subsection{Logic and Change Models}

In order to answer the synthetic evaluation question, it is first necessary to ask 1) How did I select the indicators (operation as an emancipatory learning organization, perceived quality of the web site to its intended audiences), and 2) Why did I hypothesize that a combined CBPR/CST approach might positively influence them? Also, why did I choose the data sources I have selected, particularly with respect to the institutional ethnography? This section describes the logic and change models for the web site development. 


\begin{tabular}{|c|c|c|c|c|}
\hline Inputs & Activities & Outputs & Outcomes & Impact \\
\hline $\begin{array}{l}\text { - Autistic community } \\
\text { expertise } \\
\text { - Healthcare } \\
\text { professional } \\
\text { expertise } \\
\text { - Academic expertise } \\
\text { - Supporter expertise } \\
\text { technormation } \\
\text { techy expertise }\end{array}$ & $\begin{array}{l}\text { - Project planning } \\
\text { - Team meetings } \\
\text { - Online discussion } \\
\text { - Team processes } \\
\text { - Feedback integration } \\
\text { processes } \\
\text { - Web design and } \\
\text { development } \\
\text { - Usability study }\end{array}$ & $\begin{array}{l}\text { - Project documentation } \\
\text { - Team feedback } \\
\text { - Content drafts } \\
\text { - Web site drafts } \\
\text { - Usability data } \\
\text { - Change logs } \\
\text { - Process } \\
\text { documentation } \\
\text { - Personal field notes } \\
\text { and reflexive journal } \\
\text { - Evaluation questions }\end{array}$ & $\begin{array}{l}\text { - Final content } \\
\text { - Final web site } \\
\text { - Collection and analysis } \\
\text { of end user } \\
\text { engagement and } \\
\text { evaluation studies } \\
\text { - Equitable and effective } \\
\text { collaboration }\end{array}$ & $\begin{array}{l}\text { - Accessible web site } \\
\text { and content (autistic } \\
\text { people can use it) } \\
\text { - Usable web site and } \\
\text { content (people can } \\
\text { perform necessary } \\
\text { tasks on it) } \\
\text { - Acceptable web site } \\
\text { and content (people } \\
\text { like it) } \\
\text { - AASPIRE as a learning } \\
\text { organization }\end{array}$ \\
\hline $\begin{array}{c}\text { (stakeholder } \\
\text { expertise) }\end{array}$ & $\begin{array}{c}\text { (CBPR/CST } \\
\text { processes) }\end{array}$ & $\begin{array}{c}\text { (artifacts for } \\
\text { ethnographic } \\
\text { analysis) }\end{array}$ & $\begin{array}{c}\text { (artifacts for } \\
\text { web site } \\
\text { analysis) }\end{array}$ & $\begin{array}{c}\text { (quality/success } \\
\text { indicators) }\end{array}$ \\
\hline & Team Level & & Product Level & Synthesis \\
\hline
\end{tabular}

Logic Model for AASPIRE Healthcare Toolkit Web Site Development (with explicit relationships to dissertation components)

Figure 8: Logic Model for AASPIRE Healthcare Toolkit Web Site Development

In the logic model (Figure 8), inputs are stakeholder expertise. Activities involve the work of developing the web site, including internal feedback processes. The outputs are the project artifacts including both process and product artifacts. These three aspects of the logic model feed into the team-level analysis of the synthesis, providing the artifacts for the institutional and auto-ethnographies. The outcomes are the final web site product and the web site evaluation data, which comprise the artifacts for the web site analysis. Also in the outcomes on a team level is equitable and effective collaboration. The impact of the project, explicit in the quality or success indicators in the synthesis research question, is an accessible, usable, acceptable web site and the 
operation of AASPIRE as an emancipatory learning organization (see background on learning organizations). Note that these impacts are the indicator outcomes of the synthetic evaluation question.

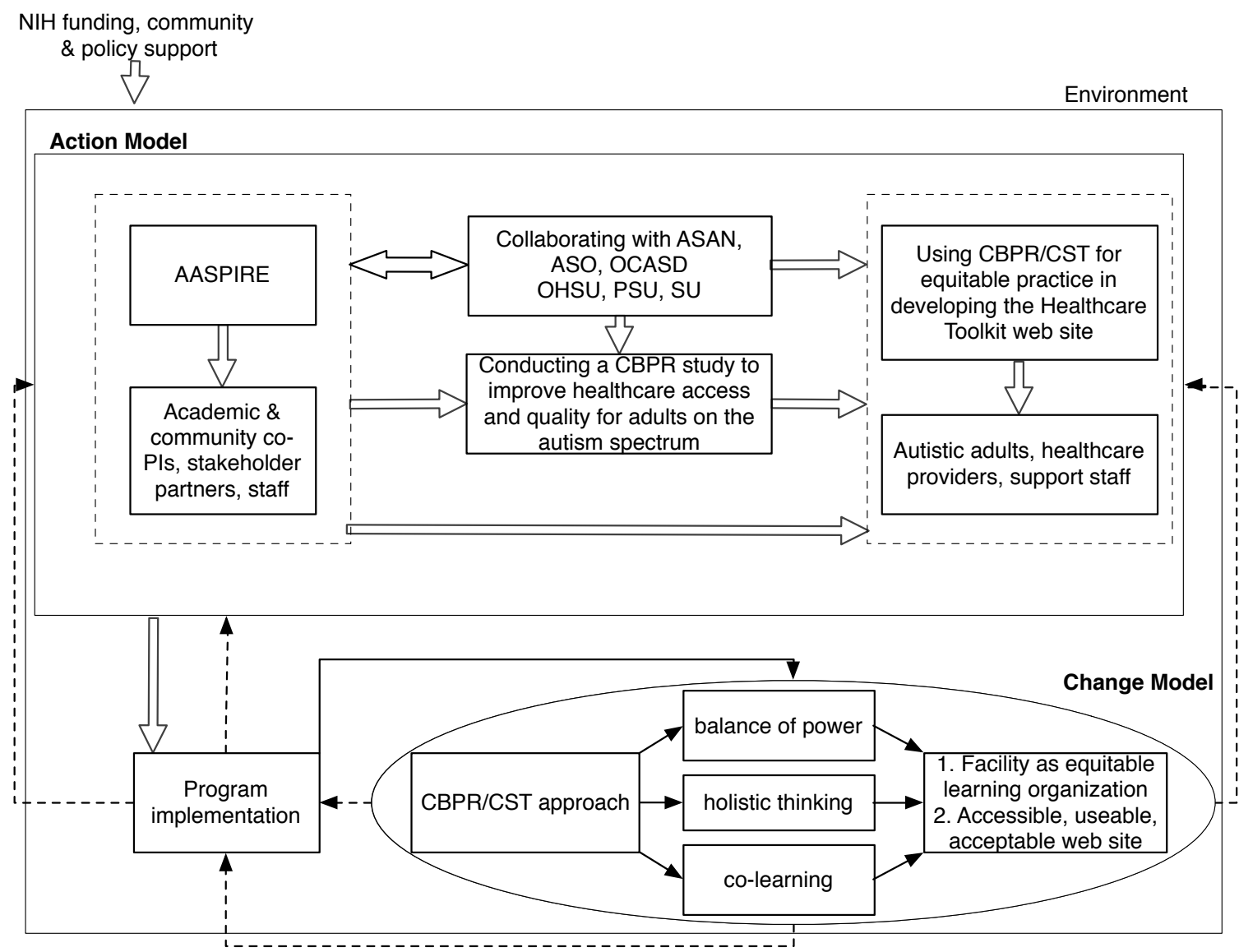

Figure 9: Action and Change Models for AASPIRE Healthcare Toolkit Web Site Build

The action and change models (Chen 2004, Kellogg Foundation 2004) for the project are shown in Figure 9. The action model (upper part of the diagram) shows the broader context for the project: AASPIRE's team of community, academic, and other stakeholder partners, our academic and community connections, and the broader project for improving healthcare access and quality of which the web site development 
was a part. The model also shows the specific intervention that this dissertation is addressing: the use of a CBPR and CST approach to develop a web site for autistic adults, their healthcare providers, and their supporters.

The change model (lower part of the diagram) shows my hypothesis for why a combined CBPR/CST approach may be an effective way to generate the desired outcomes of an emancipatory learning organization and an accessible, usable, and acceptable web site (i.e., the impacts in the logic model, which are the indicator outcomes). In particular, the determinants activated by CBPR/CST in the change model are those explicitly shared by both CBPR and CST approaches:

1. Attendance to, and balance of, power (via the explicit emancipatory commitments of both approaches (Jackson 1990, Minkler and Wallerstein 2003))

2. Encouragement of thinking holistically (via systems thinking in CST (Jackson 1990) and ecological perspectives in CBPR (Israel, Eng et al. 2005))

3. Facilitation of co-learning (explicitly in the CBPR principle of co-learning (Israel, Eng et al. 2005) and implicitly in CST's criticism of learning in traditional systems thinking (Cavaleri 2005, Caldwell 2012)).

\subsection{Methods}

\subsubsection{Data Sources}

The data used in this synthesis is the same data used for the theory, practice, and reflection articles. See Figure 2 for a map of how the data from each article's 
analyses informs the synthesis. In particular, the data sources for each evaluation question are:

Did the team operate equitably as a learning organization? The data came from the institutional ethnography used in the theory and practice papers (articles 1 and 2) and my personal observations from the autoethnography in the reflexive paper (article 3), as well as from the findings in all three papers.

\section{Were we able to create a web site that is perceived as high-quality to autistic}

people? This is the data from the AASPIRE Healthcare Toolkit evaluation described in detail in the practice paper, article 2.

\subsubsection{Reinterpretation of Analysis}

As described in the Methods Summary regarding the AASPIRE institutional documents, I reviewed a number of artifacts related to AASPIRE's organizational practices in general and AASPIRE's work on the AASPIRE Healthcare Toolkit web site in particular during the course of developing the three levels of inquiry. In article 1 (theory), I focused my analysis on exemplars of our conjoined CBPR/CST approach with particular attention to exemplars of the five disciplines (shared vision, team learning, mental models, personal mastery, systems thinking). In article 2 (practice) , I focused my analysis on data describing the processes we used for web site development, as well as the recommendations made by the team with respect to web site usability. I reviewed my research log for article 3 (critical self-reflection) and described additional events, 
both personal and with respect to AASPIRE's operations during the healthcare toolkit project.

For this evaluation analysis in the synthesis, I reinterpreted the findings from those three analyses with respect to the learning organization evaluation question (Q1) as a whole, and included the seven barriers to learning in my frame. The learning organization concept does not imply that these seven identified barriers to implementing a learning organization cease to exist when one has successfully operationalized the five disciplines; instead it sees a successful operationalization of the five disciplines as enabling an organization to dynamically manage the barriers to learning in day-to-day practice; the disciplines are, Senge says, "an antidote" (Senge 1990) for the barriers to learning. So the question became, how did we experience these barriers to learning--or avoid them--and how did we respond to them if they occurred? If they occurred, do they persist?

To assess the idea of an "emancipatory learning organization," I also looked for where power (operationalized and defined as control over decision-making and actions) was centered throughout the web development project. In other words, were decisions and actions directed by the project leaders or privileged members of the group (e.g., healthcare providers, non-autistic academics), or by the Autistic community partners and people in non-leadership roles? Which types of decisions were made by whom? I pulled the findings from each article and organized them in a matrix indicating the perspective of each article and, as a-priori categories, the discipline and the barrier 
to learning. I further coded items based on locus of power with respect to stakeholder group (autistic, scientist, clinician, supporter). While there is not always a perfect match and many items overlap, I have chosen categories into which there is a most illustrative fit (e.g., there are elements of seeing one's self in isolation present in the story of how I believed my community identity would engender trust without acknowledging my connection to a leadership role on the project; however, it fit better as part of a larger story about correcting the damaging reactionary response I had to people's pushback). The matrix is shown in Table 11. I also pulled some additional examples and points not present in the articles into the discussion, particularly in seeking instances of the barriers to learning which did not come up in the article narratives.

Table 11: Synthesis Results Matrix

\begin{tabular}{|c|c|c|c|c|c|}
\hline $\begin{array}{l}\text { Disc- } \\
\text { ipline }\end{array}$ & $\begin{array}{l}\text { barrier to } \\
\text { learning }\end{array}$ & power & theory & practice & $\begin{array}{l}\text { critical self- } \\
\text { reflection }\end{array}$ \\
\hline $\begin{array}{l}\text { systems } \\
\text { thinking }\end{array}$ & 1. isolation & Joint & $\begin{array}{l}\text { joint decision- } \\
\text { making } \\
\text { processes }\end{array}$ & $\begin{array}{l}\text { description of joint } \\
\text { decision-making } \\
\text { processes }\end{array}$ & \\
\hline $\begin{array}{l}\text { systems } \\
\text { thinking }\end{array}$ & 1. isolation & Joint & & $\begin{array}{l}\text { intersectionality of } \\
\text { leadership }\end{array}$ & $\begin{array}{l}\text { blurring of } \\
\text { boundaries } \\
\text { and roles, } \\
\text { perspective } \\
\text { spans autistic, } \\
\text { scientist, } \\
\text { engineer }\end{array}$ \\
\hline $\begin{array}{l}\text { team } \\
\text { learning }\end{array}$ & 1. isolation & Joint & $\begin{array}{l}\text { joint operating } \\
\text { processes }\end{array}$ & $\begin{array}{l}\text { involvement of all } \\
\text { stakeholders in all } \\
\text { stages }\end{array}$ & \\
\hline $\begin{array}{l}\text { systems } \\
\text { thinking }\end{array}$ & 1. isolation & Aut & $\begin{array}{l}\text { political aims of } \\
\text { CBPR / CST }\end{array}$ & $\begin{array}{l}\text { policy implications: } \\
\text { recommendations } \\
\text { for co-development } \\
\text { and accessibility } \\
\text { guideline }\end{array}$ & $\begin{array}{l}\text { blurring of } \\
\text { universal and } \\
\text { personal }\end{array}$ \\
\hline $\begin{array}{l}\text { mental } \\
\text { models }\end{array}$ & $\begin{array}{l}\text { 2. blaming } \\
\text { externalitie } \\
\text { s }\end{array}$ & Aut & $\begin{array}{l}\text { awareness of } \\
\text { political } \\
\text { landscape }\end{array}$ & $\begin{array}{l}\text { inclusion of } \\
\text { stakeholders } \\
\text { outside our value }\end{array}$ & $\begin{array}{l}\text { use of insider } \\
\text { mental models } \\
\text { helps to }\end{array}$ \\
\hline
\end{tabular}




\begin{tabular}{|c|c|c|c|c|c|}
\hline & & & & $\begin{array}{l}\text { system as } \\
\text { participants, co- } \\
\text { learning internally }\end{array}$ & $\begin{array}{l}\text { minimize some } \\
\text { types of errors } \\
\text { and biases }\end{array}$ \\
\hline $\begin{array}{l}\text { shared } \\
\text { vision }\end{array}$ & 3. reactive & Aut & $\begin{array}{l}\text { mission } \\
\text { statement with } \\
\text { emancipatory } \\
\text { aims }\end{array}$ & $\begin{array}{l}\text { long game, whole } \\
\text { system approach to } \\
\text { systems change is } \\
\text { proactive }\end{array}$ & $\begin{array}{l}\text { AASPIRE was } \\
\text { founded to turn } \\
\text { a reaction into } \\
\text { a "proaction" } \\
\text { with respect to } \\
\text { autism } \\
\text { research }\end{array}$ \\
\hline $\begin{array}{l}\text { team } \\
\text { learning }\end{array}$ & 3. reactive & Aut & $\begin{array}{l}\text { implementing } \\
\text { community } \\
\text { decisions } \\
\text { (building trust) }\end{array}$ & $\begin{array}{l}\text { description of } \\
\text { implementing } \\
\text { community } \\
\text { decisions }\end{array}$ & $\begin{array}{l}\text { description of } \\
\text { listening to } \\
\text { people and } \\
\text { implementing } \\
\text { their decisions } \\
\text { over time to } \\
\text { build trust }\end{array}$ \\
\hline $\begin{array}{l}\text { mental } \\
\text { models }\end{array}$ & $\begin{array}{l}\text { 4. isolated } \\
\text { events }\end{array}$ & Joint & $\begin{array}{l}\text { compromising } \\
\text { but not caving to } \\
\text { dominant views- } \\
\text { e.g., use of } \\
\text { person first vs. } \\
\text { identity first vs. } \\
\text { politics-neutral } \\
\text { language }\end{array}$ & $\begin{array}{l}\text { compromising but } \\
\text { not caving to } \\
\text { dominant views - } \\
\text { e.g., finding a way } \\
\text { to underline } \\
\text { hyperlinks without } \\
\text { introducing } \\
\text { accessibility issues }\end{array}$ & \\
\hline $\begin{array}{l}\text { personal } \\
\text { mastery }\end{array}$ & 6. nonlinear & Aut & $\begin{array}{l}\text { stories of } \\
\text { capacitation }\end{array}$ & $\begin{array}{l}\text { details of how } \\
\text { capacitation played } \\
\text { out during the } \\
\text { toolkit development }\end{array}$ & $\begin{array}{l}\text { my story, as a } \\
\text { whole, is one } \\
\text { of capacitation; } \\
\text { also, the } \\
\text { theme of } \\
\text { success to the } \\
\text { successful }\end{array}$ \\
\hline $\begin{array}{l}\text { systems } \\
\text { thinking }\end{array}$ & 6. nonlinear & Aut & $\begin{array}{l}\text { playing the long } \\
\text { game vs. stigma }\end{array}$ & $\begin{array}{l}\text { makes headway } \\
\text { into the long game - } \\
\text { community has } \\
\text { most to gain from } \\
\text { recommendations \& } \\
\text { guidelines; strong } \\
\text { case for inclusion of } \\
\text { all stakeholders }\end{array}$ & $\begin{array}{l}\text { theme of } \\
\text { subversion and } \\
\text { resistance }\end{array}$ \\
\hline $\begin{array}{l}\text { team } \\
\text { learning }\end{array}$ & $\begin{array}{l}\text { 7. ignorant } \\
\text { leadership }\end{array}$ & Joint & $\begin{array}{l}\text { co-creating } \\
\text { organizational } \\
\text { materials }\end{array}$ & $\begin{array}{l}\text { description of co- } \\
\text { created materials }\end{array}$ & \\
\hline $\begin{array}{l}\text { team } \\
\text { learning }\end{array}$ & $\begin{array}{l}\text { 7. ignorant } \\
\text { leadership }\end{array}$ & Joint & $\begin{array}{l}\text { knowledge } \\
\text { translation and } \\
\text { sharing }\end{array}$ & $\begin{array}{l}\text { description of } \\
\text { knowledge } \\
\text { translation \& } \\
\text { sharing, process of } \\
\text { co-learning } \\
\text { between engineers, } \\
\text { scientists, autistics }\end{array}$ & $\begin{array}{l}\text { me doing the } \\
\text { knowledge } \\
\text { translation \& } \\
\text { sharing, } \\
\text { awareness I } \\
\text { am not } \\
\text { immune to }\end{array}$ \\
\hline
\end{tabular}




\begin{tabular}{|l|l|l|l|l|l|}
\hline $\begin{array}{l}\text { systems } \\
\text { thinking }\end{array}$ & $\begin{array}{l}\text { 7. ignorant } \\
\text { leadership }\end{array}$ & Joint & $\begin{array}{l}\text { internal } \\
\text { feedback }\end{array}$ & $\begin{array}{l}\text { description of } \\
\text { internal feedback } \\
\text { and processes, } \\
\text { using it to adapt to } \\
\text { new tasks, } \\
\text { contexts; roles } \\
\text { defined by the } \\
\text { feedback processes } \\
\text { between them }\end{array}$ & $\begin{array}{l}\text { story of how } \\
\text { feedback } \\
\text { course- } \\
\text { corrected me } \\
\text { as a leader } \\
\text { when I } \\
\text { assumed trust } \\
\text { that didn't exist }\end{array}$ \\
\hline $\begin{array}{l}\text { team } \\
\text { learning }\end{array}$ & POWER & Aut & $\begin{array}{l}\text { communication } \\
\text { methods } \\
\text { privilege } \\
\text { autistics }\end{array}$ & $\begin{array}{l}\text { description of } \\
\text { communication } \\
\text { methods }\end{array}$ & $\begin{array}{l}\text { privileging } \\
\text { strengths-based } \\
\text { models of } \\
\text { disability }\end{array}$ \\
\hline team & POWER & Aut & $\begin{array}{l}\text { strengths-based } \\
\text { framework is } \\
\text { implicit }\end{array}$ & $\begin{array}{l}\text { my own } \\
\text { strengths as } \\
\text { an autistic } \\
\text { person } \\
\text { described }\end{array}$ \\
\hline $\begin{array}{l}\text { systems } \\
\text { thinking }\end{array}$ & POWER & Aut & $\begin{array}{l}\text { CBPR brings the } \\
\text { margins into the } \\
\text { center }\end{array}$ & $\begin{array}{l}\text { implemented all } \\
\text { community } \\
\text { recommendations, } \\
\text { and found them } \\
\text { effective }\end{array}$ & $\begin{array}{l}\text { increased } \\
\text { power given to } \\
\text { me via the } \\
\text { CBPR } \\
\text { framework }\end{array}$ \\
\hline
\end{tabular}

The results from web site evaluation study, used in this synthesis with respect to the product evaluation question (Q2), are reinterpreted without further analysis from that already described in article 2.

\subsection{Results}

5.4.1. Q1: Did the team operate equitably as a learning organization?

\subsubsection{The Barriers to Learning and the Five Disciplines}

Seeing one's position in isolation from the big picture - This issue occurs when individuals fail to see how their positions connect to other positions and the larger organization, project, or world. With the exception of the need for more transparency to 
enable everyone in the group to understand each other's roles and to avoid this issue (discussed under reactivity), I could think of no clearly identifiable instances of seeing one's position in isolation in internal operations during the course of the web development project. This may be because we have multiple components in place to avoid compartmentalization. These include our joint decision-making and development processes (articles 1 and 2), processes designed to include all team members in every stage of the research process (article 2), intersectionality of many of our team members in addition to of our co-PIs (articles 2 and 3), and comfort with the way CBPR and CST intrinsically blur the lines between the scientific and the political, the margin and the center (all articles).

Blaming individuals or externalities for systems problems - Described by Senge as "the enemy is out there," (Senge 1990) this issue happens when individuals or external contexts are blamed for problems that are in reality generated by the larger system in which they have occurred. As a team of individuals who have a perhaps atypically systems-focused world-view, on a day-to-day basis I could only think of instances in which leadership (myself included) spent too long looking for, and trying to correct, systemic causes for problems which ended up resting in individuals. Perhaps this is a cautionary lesson that systems thinking can be as hurtful as reductionism if applied unconsidered. Sometimes the enemy really is "out there."

Broadening the view, in a political sense it can be easy to blame external enemies (family members, professionals, bullies, employers, politicians, autism 
researchers, charity leaders, etc.) for stigma against people on the autism spectrum. While some of these externalities may be responsible for the continuation of the institutionalized oppression we experience, AASPIRE has taken a more systems thinking approach to the problem. The co-learning that occurs between community partners and team members from dominant groups both recognizes the systemic roots of oppression and offers a means to gradually change that system from within (e.g., a clinician team member with the courage to make mistakes in terms of community culture has made changes based on--sometimes strongly worded--community feedback; quoted in article 2). Because of our broad stakeholder inclusion, we are able to make use of insiders' perspectives to better understand mental models within the larger political landscape in which we operate. This is useful in identifying points of leverage.

\section{Mistaking reactivity for proactivity - This issue occurs when a "proactive"}

correction is really a reactive response to an issue, unconsidered and disconnected from the generative or systemic source of the problem. This was exemplified when I assumed I would be awarded a level of trust at the start of the project that I had not yet earned (article 3). When the community pushed back, I reacted by over-compensating, scrabbling to place a different person in the facilitator role of our team meetings, and purposefully giving up my own power--including necessary leadership structure that no one had wanted me to abdicate. This caused equally reactionary responses in others, and an event that might have been a small learning experience turned into a painful start to the project for me. This issue was fixed by rethinking what happened, providing 
greater transparency around my role, and allowing the natural effect of actions over time to build a more stable foundation of trust. Key actions over time were listening to feedback from team members, respecting and implementing their ideas and recommendations, and doing my best to not be reactionary again, even when my knee jerked.

On a more global level, AASPIRE began when $\mathrm{CN}$ and I moved past our reactionary response to stigmatizing autism research and decided to take a proactive approach of modeling the type of research we felt should be happening, using an approach (CBPR) with a systems change and social justice agenda. AASPIRE's mission statement reflects a proactive course.

Fixating on isolated events instead of seeking patterns - It would have been easy to fixate on small points like the tension between people who prefer person-first and our preference for identity-first language (article 1), or between software best practices and stated community accessibility needs like with the debate over underlining hyperlinks (article 2). However, our team has always been exceptional at looking for, and understanding, larger patterns to find satisfying solutions. As with blaming externalities, our inclusion of multiple stakeholders and processes for co-learning may help facilitate a broader understanding of the mental models behind the tension (the organization that preferred person-first language was connected to the intellectual disabilities self-advocacy movement, which advocates for person-first language for civil rights reasons; the reasons behind the user interface best practice and the 
accommodation request, once explained on both ends, did not conflict) helped us to find a solutions of compromise without sacrificing anyone's values, culture, or needs.

Not recognizing change because it happens too slowly - Using the parable of the "boiled frog," (Senge 1990) this issue is about harmful changes happening so slowly as to go unnoticed. Given the three-year time frame of the project and the close proximity in time to its events at the time of this writing, whether or not this happened is difficult to gauge, and I found no direct evidence of us experiencing it (although if it's currently happening too slowly to detect, I wouldn't). I hope that the frequent CBPR "check-ins" and group feedback processes and general openness (articles 1 and 2) have helped us-and may continue to help us--to avoid this.

Not understanding nonlinear effects - As noted in the introductory sections of this dissertation on systems thinking, complex, nonlinear, real-world systems and "wicked problems" can be extremely difficult to predict and understand. Nonlinear feedback is hard to trace, change over time may not be predictable from short term behavior, etcetera. Continuously mindful of this from the CST aspects of our approach and the influence of my systems science background on operations, having an understanding of nonlinearity is why we play a long game of influencing science, society, and policy through our work (article 1). I take a personal role in this as my presence in the academy plays has a normalizing impact with respect to the presence of people with disabilities within its ranks (article 3). Community capacitation--one of the CBPR principles--plays a role in this long game as well (all articles). We know we can't erase 
stigma against autistic people with a single study but we can chip away at it over time with multiple acts of subversion and resistance, effective interventions, and sound science. However, to trouble the idea of capacitation, the "success to the successful" archetype (article 3) has non-emancipatory implications (i.e., those with privilege tend to be granted additional privileges, leaving those with little unable to gain more). Even given all the reasons to open opportunities for those who have been denied them, many times I decided to just do something myself instead of spending the time to coach a novice. At the end of the day, the work simply needed to get done, and with tight research deadlines made tighter by the additional time required by our iterative processes, I often found myself prioritizing task completion over capacitation. This is an issue that I am aware needs a better framework to manage in the future.

\section{Leading in a top-down, willfully ignorant or opaque manner to obscure issues -}

This issue is exemplified by top-down management, and management doing whatever it can to preserve an image of things running well, no matter the damage. During the web development project, I was in a position of management. While AASPIRE's management in general has avoided top-down approaches--neither CBPR nor systems thinking are particularly compatible with such, our group is tiny and almost entirely flat in structure, and we co-create all of our organizational documents with the entire team using our iterative processes--I have been guilty of making poor and ignorant decisions out of fear. Senge speaks of this in connection with egos and competition (Senge 1990); however my experience has largely been around the increased stakes of my intersectional role 
(article 3). I have a dual desire to "protect" people I care about from harm as well as to "protect" myself from loss of community and financial support. A situation not covered in the articles exemplifies this. During a team meeting about study recruitment strategies, a community member suggested reaching out to organizations with opposing ideologies to ours. I panicked, and nearly shut the conversation down. What would people think of us if we were associated with these groups? We'd lose all our credibility within the community! People would hate us and never trust us again! It was at this point that I realized I'd been making many decisions, for a long time, without consulting anyone, for fear of retaliation. At this point, multiple Autistic team members called me on my fear, and we had a supportive, productive dialogue about the situation. My peers helped me to examine my mental models in a safe space and realize that not only had I been making decisions about where to send recruitment materials without consulting anyone, I had been manipulating events to avoid having to reveal my fear. Because of the openness and trust that our group had built by the time this incident occurred, it ended up affirming my sense of belonging in the community and empowering me to be more effective in my leadership role. Interestingly, Senge relates that Argyris (founder of action research) observes "most managers find collective inquiry inherently threatening" due to fear of being wrong (Senge 1990). It was collective inquiry, a cornerstone of action research, that helped me out a destructive pattern, and improved both the project and my relationship with the community and team. A less dramatic example, but one I am more proud of, is when we used our internal feedback processes 
to adjust our means of working together during the web site development, and thus avoided "ignorant management" entirely.

In summary, based on this information, while we were unable to fully avoid the barriers to learning, we were able to use our mastery of the five disciplines as an "antidote" to identify and remedy them. We were able to operate as a learning organization during the web development project.

\subsubsection{Locus of Power}

If considering my positioning as a member of the marginalized community, my involvement in all of these activities as co-PI, project director, and web developer means that there was always an autistic person with control over decisions and activities. This would, however, overlook my intersectional position and the fact that I was in a privileged management / leadership role throughout the project. Thus I occupied the position of authority under criticism in Cavaleri's and Caldwell's articles on the oppressive potential of the learning organization (Cavaleri 2005, Caldwell 2012). ("...who will openly sacrifice knowledge as power for knowledge as learning (Caldwell 2012) ?") Therefore, when labeling the locus of power in my matrix, I considered primarily the decisions and actions made by regular (i.e., non-leadership, non-student, non-support staff) members of the team, leaving aside for a moment those activities in which only leadership or support staff was involved.

At first I was surprised that the power was either jointly held, or it was weighted on the side of the Autistic community, with no instances of the power resting with the 
academics or other stakeholder groups on the team (supporter, healthcare provider). Thinking about this further, the reason seemed obvious. While CBPR seeks to be emancipatory, it also seeks to share power equitably between the academy and the community (Nicolaidis and Raymaker 2015), thus jointly-held power should be clearly evident in a CBPR project. AASPIRE's processes are set up to facilitate co-learning and joint decision-making, not to privilege the community at all costs. However, equalizing power also means giving more privilege to those who had less (i.e., the Autistic community members). Additionally, AASPIRE's mission statement and emancipatory aims further privilege the community's values, needs, and resources over the needs of the academy. Researcher and other stakeholder input into the joint decision-making process is to ensure scientific rigor and acceptability to relevant stakeholder groups, not to tell the community what it "should" do. Does the locus of power, generally, rest with the Autistic community when it comes to the decisions made by the group as a whole? Yes, it does.

Looking now at the other dimension of power--management versus the rest of the group--first a distinction must be made between leadership (myself and co-Director / co-PI CN) and support staff comprised of student interns and research assistants. For the purposes of this analysis, I leave out the latter group; further discussion around this is provided in the Limitations section. Examining the management/team dimension of power, some insight may be found in examining the internal FAQ leadership created to start addressing the trust issues at the start of the project. In answer to the question 
about what leadership does between engagements with the rest of the team, the first three items are:

- Implement the decisions made by the group.

- Draft materials to bring to the group for review and then making the desired changes.

- Translate the researchy stuff to lay language so that everyone can understand it and give their input.

Reviewing the iterative process used to create the web site content and user interface detailed in the CBPR sections of article 2, I feel that leadership was able to be true to these points.

The first point privileges the decisions made by non-leader members of the team (community and academic partners without leadership roles). This was maintained throughout the process, although not all decisions were implemented (article 2). Anything deliberately not implemented was, however, documented transparently in the change logs and shared with the group for further discussion if needed.

The second point includes regular members in the product revision process. Although this does not place regular members in control of initial product creation, the intention of our iterative review process (article 2) is to balance that power. For example, I shared several web site color palettes which the group vetoed; I did not develop those palettes further (though it is worth noting I did not implement a number of editorial suggestions made by academics which I felt would have decreased the 
intellectual accessibility of the web site content, and did not open a dialogue with them, reflective of the balance of power toward the autistic partners).

The third point I feel--perhaps more keenly as an individual who struggles with communication--is particularly important to balancing power because without knowledge, there is no way to make informed decisions or to take controlled action. Leadership--in this case primarily me--hold a tremendous amount of power in translating the technical aspects of the project for everyone else. While I can't speak to the personal experience of team members, people were forward in their requests to me for more information or better explanations when those presented were inadequate, and the depth and breath of ideas, decisions, direction, and criticisms contributed by team members throughout all stages of the project would not have been as rich had no one understood the more technical and scientific aspects of the project, as evidenced in the team's deep contributions to the web site usability and accessibility (article 2). Knowledge translation is also an area in which my intersectional positioning may have been particularly helpful, as my simultaneous placement in both the community and the academy gives me access to the culture, vocabulary, values, and concerns of both groups.

Triangulation with respect to this idea of equitability in our learning organization can also be found in a small but growing literature examining the inclusion of autistic people in research (Jivraj, Sacrey et al. 2014, Pellicano, Dinsmore et al. 2014). Jivraj in particular gave AASPIRE a nice review stating, "The two reports by Nicolaidis et al. 
(Nicolaidis, Raymaker et al. 2011, Nicolaidis, Raymaker et al. 2013) demonstrate how PR [participatory research] research should be completed, allowing for a feeling of authenticity and relevance of the research and exemplifying the necessity of adults with ASD or other neurodevelopmental disorders to be included as partners in PR."

There is evidence that 1) power is shared between academic and Autistic partners; 2) power is shared between leadership and non-leader community and academic team members; and 3) the Autistic community is privileged in terms of shared vision, value system, important decisions, and other key organizational characteristics. Therefore, I would consider AASPIRE as able to operate as an emancipatory learning organization.

\subsubsection{Q2: Was the web site perceived as high-quality by autistic people?}

As described in article 2, the overwhelming majority of participants in the web site evaluation found the toolkit easy to use and easy to understand. The great majority also felt the information was important and useful, and would recommend the toolkit to a friend or healthcare provider. Evaluation statistics are presented in Table 10. There was no significant difference in results between autistic and supporter populations. There were no significant associations between usability or understandability and education level, having gotten help using the site, browser type, or device type, suggesting the acceptability, accessibility, and usability of the site was is applicable to a broad range of intended users and devices. 
Qualitative comments about the web site were largely positive, with some specifically acknowledging the accessibility and usability as reasons why they liked the site. Participants did provide recommendations for improvement; these recommendations were largely ones we were already aware of and planning to address in a later release.

In so much as our evaluation study was able to determine, the web site is accessible, usable, and acceptable to adults on the autism spectrum, the primary intended audience, as well as to their supporters. Usability study results (see 3.4.1.3. End User Engagement Study 2: Usability) additionally suggest that healthcare providers, the other primary intended audience, found the site at least usable (accessibility taking a less important role because the concept only applies to people with disabilities, and assessing the acceptability to these other stakeholders was outside of the scope of the dissertation).

Thus the web site was perceived to be high quality to autistic people as indicated by accessibility, usability, and acceptability.

\subsubsection{Synthesis: How did a hybrid CST/CBPR approach impact the quality of the project} as indicated by Q1 and Q2?

Based on the synthesis of findings in articles 1, 2, and 3 there is evidence for balance of power, holistic thinking, and team learning (the determinants in the change model, Figure 9). AASPIRE was able to operate as an emancipatory learning organization, and able identify and correct barriers to operating as such. A sample of 
intended end users of the web site found it to be accessible, usable, and acceptable. Taking a hybrid CST/CBPR approach to a web development project enabled us to conduct a quality project by both internal (team) and external (product) indicators.

\subsection{Conclusion}

\subsubsection{Summary}

In this dissertation, I explored the intersections of critical systems thinking and community based participatory research in the context of developing a web site for autistic end users. I explored these ideas on three levels: theory, practice, and critical self-reflection. On the theory level, I examined the common philosophical and historical roots of the two approaches, ways in which they intersect and complement, and proposed a hybrid CST/CBPR approach to inquiry, exemplified by AASPIRE's experience. On the practice level, I explored AASPIRE's web site development process and evaluated the accessibility, usability, and acceptability of the web site for autistic end users; from that exploration, we produced a set of recommendations for working with people with disabilities in technology development and a set of guidelines for making accessible web sites for individuals on the autism spectrum. On the critical self-reflection level, I inquired into my own intersectional experiences as an insider-researcher spanning multiple stakeholder groups during the web site development. I then synthesized these three levels to evaluate whether or not taking a CST/CBPR approach to the web site development was effective, as indicated by the team's ability to function as an 
emancipatory learning organization (an indicator of effective employment of systems thinking at an organizational level), and the overall usability and accessibility of the web site to autistic end users. The result of the synthesis suggests a hybrid CST/CBPR approach was successful on our web development research project.

The implications and limitations that follow should be considered in addition to those already covered in the context of the three articles, and are largely synthetic.

\subsubsection{Implications and Recommendations}

As a whole, this dissertation has the potential to advance the field of Systems Science by expanding the critical systems thinking literature. Specifically, it has the potential to enhance CST's commitment to emancipation with principles and practices drawn from CBPR, particularly with respect to how to operationalize its emancipatory aim. Indeed CST has already begun looking at similar intersections with feminist theories (Stephens, Jacobson et al. 2010). While outside of the scope of this dissertation, the synthesis may be reworked into a manuscript format as a case study of using an emancipatory approach to creating a learning organization.

Although the learning organization has been criticized for not attending to power, in so far as such a thing can be evaluated in a small, largely qualitative project such as this one, my experience with AASPIRE indicates that it is possible to create a learning organization which is attentive to power. If the five disciplines are the "antidote" for the seven barriers to learning, then perhaps the CBPR principles and considerations for creating emancipatory processes--or a similar formalism--are the 
"antidote" for the power inequities identified in the learning organization (Cavaleri 2005, Caldwell 2012). Individuals wishing to create a more power-balanced learning organization may want to consider a similar hybrid CST/CBPR approach.

In general, a more formal background in, and deliberate application of, systems thinking in our CBPR setting was useful to us in transparently and effectively implementing feedback processes and other systems-related mechanisms. These tools aided us in accomplishing our web development project, as well as in communicating complex ideas. As CBPR practitioners have already noted, systems thinking has much to offer the approach (Trochim, Cabrera et al. 2006, Dick 2010, Trickett 2011, BeLue, Carmack et al. 2012); CST may provide a particularly compatible entry into the field as its aims and philosophical foundations are so closely aligned with those of CBPR.

Lastly, the ability of a group of individuals, the majority of whom are Autistic, to work effectively together to create a high quality piece of technology and conduct sound research has wide-reaching implications to science, society, and the advancement of rights for people with disabilities, including disrupting stereotypes that people on the autism spectrum are unable to work collaboratively due to social and communication impairments, or that people with developmental disabilities are not able to succeed at technical or skilled work. I strongly recommend anyone developing interventions or technology for, or conducting research on, people on the autism spectrum find a way to work directly and equitably with those of us with lived experience. 


\subsubsection{Limitations and Future Directions}

The evaluation question is intended to be holistic and synthetic. It is not intended to reduce or tease out components of applying a CST/CBPR approach to web development and evaluate them individually, but to assess and model the task of building the AASPIRE Healthcare Toolkit web site holistically. This analysis has focused on CST and CBPR in AASPIRE's operation, but there are other factors which may have had a significant role in the evaluation outcomes. For example, if the people involved on the project had been less willing to communicate, persist, compromise, and reach consensus, then team learning and shared decision-making may have suffered (e.g., our ability to come to quick consensus over site design detailed in article 2). Or, if the co-PIs had not been intersectionally positioned, leadership may have had different challenges than those noted here (e.g., my erroneous assumption that people would trust me based on my community status in article 3). Instead of trying to find ways to remove such confounders, I hope that this holistic approach to analysis both horizontally (across operational, technological, sociological, critical, and political domains) and vertically (from high-level theory, through the mid-level of practice, to the low-level of critical-self reflection) (Lendaris 1986), will honor the inevitable presence of such factors while at the same time highlighting the core CST/CBPR ideas within the larger whole. Future work to better understand contextual factors could come from taking a realist evaluation approach to examine the dynamics of context, mechanisms, and outcomes (Henry 2005). 
In the analysis of the equitability of our learning organization, I deliberately placed students and research assistants outside the boundary of inquiry. The relationship between the core AASPIRE team (leadership and community stakeholders), and students and support staff is complicated by the existing structures of academic mentorship and research project roles, and we have not attempted to promote equitability for students and support staff. Further, we have left this dimension of power largely unexamined. With respect to our own students and research support, we may want to take a more conscious look at how existing hierarchical models inherent in the academy (e.g., the student-mentor relationship, positionality of research support as people with skills and training who are in a role which is by definition subservient) fit with our organizational model, including being more clear in explaining distinctions to these individuals; for example, to avoid confusion around being treated differently from community team members. In the other direction, intersectional complications with team members who are also students or who are occasionally hired to perform support staff functions (as when we hired a community partner to draft some of the web site content) need to be explored more consciously (e.g., do we inadvertently set up false expectations in student partners by teaching them to expect co-learning from senior academics, only to be upset when academics in their own programs don't privilege them with such?). In terms of AASPIRE's future directions, more clarity around how a CST/CBPR approach and the model of the learning organization relates to the broader group involved in AASPIRE's work could be beneficial. 
This dissertation presents an exploration of a single case of using a hyrid critical systems thinking / community based participatory research approach. Whether or not a similar approach would work in other domains (i.e., not information technology), other organizational contexts (e.g., within a community-based organization), or other populations (e.g., racial minorities) is yet to be explored. Also unexplored are alternative approaches which may function as well or better than the one examined here.

Resolving some of these limitations, as well as those noted in the individual articles, suggests areas for future work. Additionally, feedback from my member checking for article 3 was so rich and encouraging as to suggest a qualitative study looking at the experiences of disabled academics, or intersectionally positioned academics more broadly, could be fruitful. As for my own future work, I will continue to weave the intersections of CST and CBPR, the political and the scientific, the personal and the universal, the center and the margins, and use my increased privilege as I advance within the academy to continue to conduct science for social justice. 


\section{References}

AASPIRE. (2013). "Academic Autism Spectrum Partnership in Research and Education: Home." Retrieved 29 January, 2013, from http://aaspire.org.

AASPIRE. (2014). "AASPIRE Healthcare Toolkit." Retrieved May 3, 2014, from http://autismandhealth.org.

Ackoff, R. and R. Sheldon (2003). Redesigning Society, Stanford Business Books.

Adam, A. and D. Kreps (2009). "Disability and discourses of web accessiblity." Information, Communication \& Society 12(7): 1041-1058.

Agency for Healthcare Research and Quality (2003). Community-Based Participatory Research: Assessing the Evidence. Evidence Report/Technology Assessment, Agency for Healthcare Research and Quality: 8.

American Psychiatric Association (2013). Diagnostic and statistical manual of mental disorders, fifth edition (DSM-5). Washington, DC, American Psychiatric Association.

anonymous (2010). 2010 Autism research program: Peer review panel summary statement, Department of Defense.

Arendt, H. (1973). Men in dark times. New York, Penguin.

Argyris, C. (1977). "Double loop learning in organizations." Harvard Business Review 55(September/October): 115 - 125.

Arrow, K. J. (1950). "A difficulty in the concept of social welfare." Journal of Political Economy 58(4): 328-346.

BBC News. (2009). "People with autism 'have problem with self-awareness'." Retrieved 30 November, 2013, from http://news.bbc.co.uk/2/hi/health/8407857.stm.

BeLue, R., C. Carmack, K. R. Myers, L. Weinreb-Welch and E. J. Lengerich (2012). "Systems thinking tools as applied to community-based participatory research: a case study." Health Educ Behav 39: 745-751.

Biever, C. (2007). "Web removes social barriers for those with autism." New Scientist(2610): 26 - 27. 
Bigirimana, S. (2011). "Changing paradigms in the information society: From analysis to systems thinking." International Journal of Interdiciplinary Social Sciences 5(11): $1-12$.

Blume, H. (1997). Autistics, freed from face-to-face encounters, are communicating in cyberspace. The New York Times. 30.

Brajnik, G., Y. Yesilada and S. Harper (2011). "The expertise effect on web accessibility evaluation methods." Human-Computer Interaction 26(3): 246-283.

Braun, V., Clarke V. (2006). "Using thematic analysis in psychology." Qualitative Research in Psychology 3: 77-101.

Brew-Parrish, V. (1997). "The wrong message." Awareness Days Retrieved 16 November, 2013, from http://www.raggededgemagazine.com/archive/aware.htm.

Brew-Parrish, V. (2004). "The wrong message still." Retrieved 16 November, 2013, from http://www.raggededgemagazine.com/focus/wrongmessage04.html.

Brinton, C. (1965). The Anatomy of Revolution, Vintage.

Brugha, T., H. Meltzer, J. Smith, F. J. Scott, S. Purdon, J. Harris and J. Bankart (2009). Autism spectrum disorders in adults living in households throughout England: Report from the adult psychiatric morbidity survey 2007, Information Center for Health and Social Care.

Caldwell, R. (2012). "Leadership and Learning: A critical reexamination of Senge's learning organization." Systemic Practice and Action Research 25(1): 39-55.

Campbell, M. (1998). "Institutional ethnography and experience as data." Qualitative Sociology 21(1): 55-73.

Campbell, M. and F. Gregor (2004). Theory "in" everyday life. Critical Strategies for Social Research. W. Caroll. Toranto, ON, Canadian Scholars Press: 170-180.

Cavaleri, S. (2005). "Systems thinking for knowledge." World Futures 61: 378-396.

Center for Plain Language. (2013). "What is plain language?" Retrieved 10 October, 2013, from http://centerforplainlanguage.org.

Centers for Disease Control and Prevention. (2014). "Facts About ASDs." Retrieved 8 April, 2014, from http://www.cdc.gov/ncbddd/autism/data.html. 
Chamak, B., B. Bonniau, E. Jaunay and D. Cohen (2008). "What Can We Learn about Autism from Autistic Persons?" Psychotherapy and Psychosomatics 77(5): 271279.

Charlton, J. I. (2000). Nothing About Us Without Us: Disability Oppression and Empowerment, University of California Press.

Checkland, P. (1999). Systems Thinking, Systems Practice: Includes a 30-Year Retrospective, Wiley.

Chen, H. T. (2004). A conceptual framework of program theory for practitioners. Practical Program Evaluation: Assessing and Improving Planning, Implementation and Effectiveness. Thousand Oaks, CA, Sage Publications: 15-44.

Churchman, C. W. (1967). "Guest editorial: Wicked problems." Management Science 14(4): B141-B142.

Churchman, C. W. (1979). The Systems Approach and Its Enemies, Basic Books.

Coleman Institute for Cognitive Disabilities. (2013). "The rights of people with cognitive disabilities to technology and information access." Retrieved Dec. 24, 2014, from http://www.colemaninstitute.org/declaration-text.

Córdoba, J.-R. (2009). "Critical reflection in planning information systems: a contribution from critical systems thinking." Information Systems Journal 19(2): 123-147.

Córdoba, J.-R. and G. Midgley (2008). "Beyond organisational agendas: using boundary critique to facilitate the inclusion of societal concerns in information systems planning." European Journal of Information Systems: 125-142.

Creal, D. L. (1999). "The "disability of thinking" the "disabled" body: Course paper for ambiguous bodies: Studies in contemporary sexuality, masters level English course (6994.06)." Retrieved October 4, 2012, from http://www.normemma.com/advocacy/artcreal.htm.

Dick, B. (2010). "Action research literature 2008-2010: Themes and trends." Action Research 9(2): 122-143.

Ellis, C. S., T. E. Adams and A. P. Bochner (2011). "Autoethnography: An overview." Forum: Qualitative Social Research 12(1).

Ellis, C. S. and A. P. Bochner (2006). "Analyzing analytic autoethnography: An autopsy." Journal of Contemporary Ethnography 35(4): 429-449. 
Federici, S., A. Micangeli, I. Ruspantini, S. Borgianni, F. Corradi, E. Pasqualotto and M. Olivetti Belardinelli (2005). "Checking an integrated model of web accessibility and usability evaluation for disabled people." Disability and Rehabilitation 27(13): 781-790.

Firth, U. (1993). "Autism." Scientific American 268: 108-114.

Flood, R. L. (1990). "Liberating systems theory: Toward critical systems thinking." Human Relations 43(1): 49-75.

Flood, R. L. (2013). "The relationship of 'systems thinking' to action research." Systemic Practice and Action Research 23(4): 269-284.

Flood, R. L. and M. C. Jackson (1991). Critical Systems Thinking: Directed Readings. Chichester, England, Wiley.

Foucault, M. (1980). Power/Knowledge: Selected Interviews and Other Writings, 19721977. New York, Vintage.

Friedman, M. G. and D. N. Bryen (2007). "Web accessibility design recommendations for people with cognitive disabilities." Technology and Disability 19(4): 205-212.

Fuenmayor, R. (1991). Between systems thinking and systems practice. Critical Systems Thinking: Directed Readings. R. L. F. M. C. Jackson. Chichester, Wiley: 227-244.

Gaventa, J., Cornwall, A. (2004). Power and knowledge. Critical Strategies for Social Research. W. K. Carroll. Toronto, ON, Canadian Scholars Press: 320-333.

Giangreco, M. (1996). "'The stairs don't go anywhere!": A self-advocate's reflections on specialized services and their impact on people with disabilities." Physical Disabilities: Education and Related Service 14(2): 1-12.

Gillespie-Lynch, K., Kapp, Steven K., Shane-Simpson, C., Smith, D.S., Hutman, T. (2014). "Intersections between the autism spectrum and the Internet: perceived benefits and preferred functions of computer-mediated communication." Intellectual and Developmental Disabilities 52(6): 456-469.

Greenfield, S., S. Kaplan and J. E. Ware, Jr. (1985). "Expanding patient involvement in care. Effects on patient outcomes." Ann Intern Med 102(4): 520-528.

Greenfield, S., S. H. Kaplan, J. E. Ware, Jr., E. M. Yano and H. J. Frank (1988). "Patients' participation in medical care: effects on blood sugar control and quality of life in diabetes." J Gen Intern Med 3(5): 448-457. 
Hall, A. D. (1989). Metasystems Methodology: A New Synthesis and Unification. Oxford; New York, Pergamon Press.

Henry, G. T. (2005). Realist evaluation. Encyclopedia of Evaluation. S. Mathison. Thousand Oaks, SAGE Publications, Inc.: 360-363.

Holian, R. and D. Coghlan (2013). "Ethical issues and role duality in insider action research: Challenges for action research degree programmes." Systemic Practice and Action Research 26(5): 399-415.

Hulko, W. (2009). "The time- and context-contingent nature of intersectionality and interlocking oppressions." Journal of Women and Social Work 24(1): 44-55.

Ison, R. L. (2008). Systems thinking and practice for action research. The Sage Handbook of Action Research Participative Inquiry and Practice (2nd Edition). P. W. Reason, Bradbury, Hillary. London, UK, Sage Publications: 139-158.

Israel, B., Eng E, Schulz AJ, Parker EA (2005). Methods in community-based participatory research for health. San Fransisco, John Wiley \& Sons, Inc.

Israel, B. A., E. Eng, A. J. Schulz and E. A. Parker (2005). Methods in Community-Based Participatory Research for Health. San Fransisco, John Wiley \& Sons, Inc.

Israel, B. A., A. J. Schulz, E. A. Parker and A. B. Becker (2001). "Community-based participatory research: policy recommendations for promoting a partnership approach in health research." Education for Health 14(2): 182-197.

Israel, B. A., A. J. Schulz, E. A. Parker, A. B. Becker, A. J. I. Allen and J. R. Guzman (2003). Critical issues in developing and following community based participatory research principles. Community-Based Participatory Research for Health. N. W. Meridith Minkler. San Fransisco, CA, John Wille \& Sons, Inc.: 53-73.

Jackson, M. C. (1990). "The origins and nature of critical systems thinking." Systems Practice 4(2): 131-149.

Jackson, M. C. (2006). "Creative holism: a critical systems approach to complex problem situations." Systems Research and Behavioral Science 23(5): 647-657.

Jaeger, P. T. (2008). "User-centered policy evaluations of Section 508 of the Rehabilitation Act." Journal of Disability Policy Studies 19(1): 24-33.

Jaeger, P. T. (2011). Disability and the Internet: Confronting a Digital Divide. Boulder, CO, Lynne Rienner Pub. 
Jivraj, J., L.-A. Sacrey, A. Newton, D. Nicholas and L. Zwaigenbaum (2014). "Assessing the influence of researcher-partner involvement on the process and outcomes of participatory research in autism spectrum disorder and neurodevelopmental disorders: A scoping review." Autism 18(7): 782-793.

Jordan, C. (2010). "Evolution of autism support and understanding via the world wide web." Intellectual and Developmental Disabilities 48(3): 220-227.

Kaplan, S. H., S. Greenfield and J. E. Ware, Jr. (1989). "Assessing the effects of physicianpatient interactions on the outcomes of chronic disease." Med Care 27(3 Suppl): S110-127.

Kaufman, J. (2007). "Campaign on childhood mental illness succeeds at being provocative." New York Times Retrieved 6 September, 2010, from http://www.nytimes.com/2007/12/14/business/media/14adco.html?_r=1\&ref= business.

Kellogg Foundation (2004). Logic Model Development Guide. Battle Creek MI, W.K. Kellogg Foundation.

Kelly, B., D. Sloan, S. Brown, J. Seale, P. Lauke, S. Ball and S. Smith (2009). "Accessibility 2.0: Next steps for web accessibility." Journal of Access Services 6(1 \& 2): 265294.

Kennedy, H., S. Evans and S. Thomas (2011). "Can the Web Be Made Accessible for People with Intellectual Disabilities?" The Information Society 27(1): 29-39.

Lendaris, G. (1986). "On systemness and the problem solver: Tutorial content." IEEE Transactions on Systems, Man, and Cybernetics 16(4): 603 - 610.

Levin, M. (1994). "Action research and critical systems thinking: Two icons carved out of the same log?" Systems Practice 7(1): 25-41.

Lewin, K. (1946). "Action Research and Minority Problems." Journal of Social Issues 2(4): 34-46.

Lindsay (2012). "Autism, alexithymia, and empathy." Autism and Empathy: Dispelling Myths and Breaking Stereotypes http://www.autismandempathy.com/?p=1108 2013.

Linstone, H. (1999). Decision Making for Technology Executives: Using Multiple Perspectives to Improve Performance. Boston, Artech House.

Linton, S. (1998). Claiming Disability: Knowledge and Identity. NYC, NYU Press. 
Lukes, S. (2005). Power: A Radical View. Great Britain, Palgrave Macmillan.

Marshall, C., Rossman, G.B. (2010). Trustworthiness and ethics. Designing qualitative research. C. Marshall, Rossman, G.B., Sage Publications.

McDonald, K. E. (2012). AASPIRE Healthcare Toolkit summary of evaluation findings. unpublished work.

McDonald, K. E. (2012). "'We want respect": adults with intellectual and developmental disabilities address respect in research." American Journal on Intellectual and Developmental Disabilities 117(4): 263-274.

McDonald, K. E. (2015). personal communication.

McDonald, K. E. and C. B. Keys (2008). "How the powerful decide: Access to research participation by those at the margins." American Journal of Community Psychology 42(1): 79-93.

McDonald, K. E., C. A. Kidney, S. L. Nelms, M. R. Parker, A. Kimmel and C. B. Keys (2009). "Including adults with intellectual disabilities in research: Scientists' perceptions of risks and protections." Journal of Policy and Practice in Intellectual Disabilities 6(4): 244-252.

Midgley, G. (1992). "The sacred and profane in critical systems thinking." Systems Practice 5(1): 5-16.

Midgley, G. (2001). Systemic Intervention: Philosophy, Methodology, and Practice (Contemporary Systems Thinking). New York, New York, Springer.

Midgley, G. (2006). "Systemic intervention for public health." American Journal of Public Health 96(3): 466-472.

Miles, M. B. and A. M. Huberman (1994). Qualitative Data Analysis: An Expanded Sourcebook (2nd Edition). Thousand Oaks, CA, SAGE Publications, Inc.

Minkler, M. and N. Wallerstein (2003). Community-Based Participatory Research for Health. San Fransisco, CA, John Wille \& Sons, Inc.

Mirchandani, N. (2003). "Web accessibility for people with cognitive disabilities: Universal design principles at work!" Research Exchange Vol.8, No.3. Retrieved 27 September, 2013, from http://www.ncddr.org/products/researchexchange/v08n03/8_access.html. 
Mogendorff, K. (2013). "The blurring of boundaries between research and everyday life: Dilemmas of employing one's own experiential knowledge in disability research." Disability Studies Quarterly 33(2).

National Science Foundation (2013). Women, minorities, and persons with disabilities in science and engineering: 2013, National Center for Science and Engineering Statistics, Directorate for Social, Behavioral and Economic Sciences.

Ne'eman, A. (2007). "Victory! The end of the ransom notes campaign." Retrieved 6 September, 2010, from http://www.autisticadvocacy.org/modules/smartsection/item.php?itemid=23.

Ne'eman, A. (2010). "The future (and past) of autism advocacy, or why the ASA's magazine, The Advocate, wouldn't publish this piece." Disability Studies Quarterly 30(1).

Nicolaidis, C. and D. M. Raymaker (2015). Community based participatory research with communities defined by race, ethnicity, and disability: Translating theory to practice. The SAGE Handbook of Action Research. H. Bradbury, SAGE: in press.

Nicolaidis, C., D. M. Raymaker, E. Ashkenazy, K. E. McDonald, W. C. Boisclair, A. E. V. Baggs, S. Kapp, M. Weiner and S. Dern (in press). ""Respect the way I need to communicate with you": Healthcare experiences of adults on the autism spectrum." Autism.

Nicolaidis, C., D. M. Raymaker, M. Katz, M. Oshwald, R. Goe, S. Leotti, L. Grantham, E. Plourde, J. Salomon, R. B. Hughes and L. E. Powers (2014). "Participatory research to adapt measures of health and interpersonal violence for use by people with developmental disabilities." Progress in Community Health Partnerships: Research, Education, and Action in press.

Nicolaidis, C., D. M. Raymaker, K. E. McDonald, S. Dern, E. Ashkenazy, W. C. Boisclaire, S. M. Robertson and A. Baggs (2011). "Collaboration strategies in non-traditional CBPR partnerships: lessons from an academic-community partnership with autistic self-advocates." Progress in Community Health Partnerships: Research, Education, and Action 011:5(2): 143-150.

Nicolaidis, C., D. M. Raymaker, K. E. McDonald, S. Dern, W. C. Boisclair, E. Ashkenazy and A. Baggs (2013). "Comparison of healthcare experiences in autistic and nonautistic adults: A cross-sectional online survey facilitated by an academiccommunity partnership." Journal of General Internal Medicine 28(6): 761-769. 
O'toole, C. (2013). "Disclosing our relationships to disabilities: An invitation for disability studies scholars." Disability Studies Quarterly 33(2).

O'toole, T. P., K. F. Aaron, M. H. Chin, C. Horowitz and F. Tyson (2003). "Journal of General Internal Medicine: Special issue on community-based participatory research." Journal of General Internal Medicine 18(7).

Oliver, M. (1992). "Changing the social relations of research production?" Disability, Handicap, and Society 7(2): 101-114.

Oschwald, M., S. Leotti, D. M. Raymaker, M. Katz, R. Goe, M. Harviston, A. Wallington, L. Howard, L. Beers, C. Nicolaidis, S. Robinson-Whelen, R. B. Hughes, L. E. Powers and the Partnering with People with Disabilities to Address Violence Consortium (2014). "Development of an Audio-Computer Assisted Self-Interview to investigate violence and health in the lives of people with developmental disabilities." Disability and Health Journal.

Oschwald, M., P. R. Renker, R. B. Hughes, A. Arthur, L. E. Powers and M. A. Curry (2009). "Development of an accessible audio computer-assisted self-interview (A-CASI) to screen for abuse and provide safety strategies for women with disabilities." J Interpers Violence 24(5): 795-818.

Pellicano, E., A. Dinsmore and T. Charman (2014). "Views on Researcher-Community Engagement in Autism Research in the United Kingdom: A Mixed-Methods Study." PLoS ONE 9(10): e109946.

Pew Internet and American Life Project. (2011). "Internet adoption over time." Retrieved 18 November, 2013, from http://pewinternet.org/Reports/2012/Digital-differences/Main-Report/Internetadoption-over-time.aspx.

Pew Internet and American Life Project. (2013). "Who's online: Internet user demographics." Retrieved 30 October, 2013, from http://pewinternet.org/Trend-Data-(Adults)/Whos-Online.aspx.

Progress in Community Health Partnerships. (2013). "Progress in Community Health Partnerships: Research, Education, and Action: Author Guidelines." Retrieved 21 November, 2013, from http://www.press.jhu.edu/journals/progress_in_community_health_partnership s/guidelines.html.

Raymaker, D. M. (2011). Unpublished database and notes on Partnering ACASI usability study. 
Raymaker, D. M. and K. E. McDonald (2013). "Paradigm shifts in disability and health: Toward more ethical public health research." American Journal of Public Health 103(12): 2165-2173.

Raymaker, D. M., C. Nicolaidis, W. C. Boisclair, K. E. McDonald, M. Wiener, S. Kapp and E. Ashkenazy (in review). "Community based participatory research methods in codeveloping an accessible web site for end users on the autism spectrum." Human Computer Interaction.

Raymaker, D. M., Nicolaidis, C. (2013). Participatory research with autistic communities: Shifting the system. Worlds of Autism. J. Davidson, Orsini, M. Minneapolis, University of Minnesota Press.

Reason, P. and H. Bradbury (2006). Handbook of Action Research, Sage.

Rinaldi, J. (2013). "Reflexivity in research: Disability between the lines." Disability Studies Quarterly 33(2).

Robertson, S. M. (2007). Information technology \& the autistic culture: Influences, empowerment, \& progression of it usage in advocacy initiatives. Autreat. Johnstown, Pennsylvania.

Rossman, C. and G. Marshall, B. (2010). Designing Qualitative Research. Thousand Oaks, CA, SAGE Publications, Inc.

Senge, P. (1990). The Fifth Discipline: The Art and Practice of the Learning Organization. New York, Doubleday/Currency.

Senge, P. (1990). The fifth discipline: The art and practice of the learning organization. New York, Doubleday/Currency: 174-204.

Shapiro, J. (1994). No Pity: People with Disabilities Forging a New Civil Rights Movement. New York, Three Rivers Press.

Sinclair, J. (1993). "Bridging the gaps: An inside-out view of autism (Or, do you know what I don't know?)." Retrieved 30 November, 2013, from http://web.archive.org/web/20080919074006/http://web.syr.edu/ jisincla/brid ging.htm.

Sinclair, J. (1999). "Why I dislike "person first" language." Retrieved February 26, 2008, from http://web.syr.edu/\%7Ejisincla/person_first.htm.

Sinclair, J. (2005). "History of ANI." Retrieved 2 January, 2014, from http://www.autreat.com/History_of_ANI.html. 
St. Denis, V. (2004). Community-based participatory research: Aspects of the concept relevant for practice. Critical Strategies for Social Research. W. K. Carroll. Toronto, Canadian Scholars' Press: 292-302.

StataCorp LP. (2013). "Stata: Data analysis and statistical software." Retrieved 15 November, 2013, from http://www.stata.com/.

Stephens, A., C. Jacobson and C. King (2010). "Towards a feminist-systems theory." Systemic Practice and Action Research 23(5): 371-386.

Sterman, J. D. (1994). "Learning in and about complex systems." System Dynamics Review 10: 291-330.

Sterman, J. D. (2000). Business Dynamics: Systems Thinking and Modeling for a Complex World. Boston, Irwin McGraw-Hill.

Stewart, M. A. (1995). "Effective physician-patient communication and health outcomes: a review." CMAJ 152(9): 1423-1433.

Street, R. L., Jr., G. Makoul, N. K. Arora and R. M. Epstein (2009). "How does communication heal? Pathways linking clinician-patient communication to health outcomes." Patient Educ Couns 74(3): 295-301.

The National Autistic Society. (2013). "Designing websites suitable for people with autism spectrum disorders." Retrieved 16 November, 2013, from http://www.autism.org.uk/working-with/leisure-and-environments/designingwebsites-suitable-for-people-with-autism-spectrum-disorders.aspx.

Tierney, W. M. (2001). "Improving clinical decisions and outcomes with information: a review." Int J Med Inform 62(1): 1-9.

Trickett, E. J. (2011). "Advancing the science of community-level interventions." American Journal of Public Health 101(8): 1410-1419.

Trochim, W. M., D. A. Cabrera, B. Milstein, R. S. Gallagher and S. J. Leischow (2006). "Practical challenges of systems thinking and modeling in public health." American Journal of Public Health 96(3): 538-546.

U.S. Department of Labor. (2014). "U.S. Department of Labor - Office of Disability Employment Policy." Retrieved 2 January, 2014, from http://www.dol.gov/odep/.

Ulrich, W. (1995). Critical Heuristics of Social Planning: A New Approach to Practical Philosophy. Bern, Wiley. 
Ulrich, W. (2005). A brief introduction to critical systems heuristics (CSH). Web site of the ECOSENSUS Project, Open University.

Ulrich, W. and M. Renolds (2010). Critical systems heuristics. Systems approaches to managing change: A practical guide. M. Renolds and S. Holwell. London, Springer: 243-292.

United Nations (2006). Some facts about persons with disabilities. United Nations. New York, United Nations.

United Nations. (2013). "Making web sites accessible for the Unitied Nations." Retrieved 5/25, 2013, from http://www.un.org/webaccessibility/index.shtml.

United Nations Human Rights Council (2011). Thematic study by the Office of the United Nations High Commissioner for Human Rights on participation in political and public life by persons with disabilities, United Nations.

United States Government. (2013). "Section 508." Retrieved 25 May, 2013, from https://www.section508.gov/.

US Department of Health and Human Services. "Usability testing." Retrieved 5 November, 2012, from http://usability.gov/methods/test_refine/learnusa/index.html.

Vernon, A. (1997). Reflexivity: The dilemmas of researching from the inside. Doing Disability Research. C. B. G. Mercer. Leeds, The Disability Press: 158-176.

W3C. (2008). "Web content accessiblity guidelines (WCAG) 2.0." Retrieved 16 November, 2013, from http://www.w3.org/TR/UNDERSTANDINGWCAG20/intro.html\#introduction-fourprincs-head.

W3C. (2013). "Introduction to understanding WCAG 2.0." Retrieved 16 November, 2013, from http://www.w3.org/TR/UNDERSTANDINGWCAG20/intro.html\#introduction-fourprincs-head.

W3C. (2013). "Web Accessiblity Initiative (WAI)." Retrieved 5/25, 2013, from http://www.w3.org/WAl/.

Wallerstein, N. and B. Duran (2003). The conceptual, historical, and practice roots of community based participatory research and related participatory traditions. Community-Based Participatory Research for Health. N. W. Meridith Minkler. San Fransisco, CA, John Wille \& Sons, Inc.: 27-52. 
Wallis, C. (2009). "'I am autism': An advocacy video sparks protest." Time Retrieved 6 September, 2010, from http://www.time.com/time/health/article/0,8599,1935959,00.html.

Weiner, M. and P. Biondich (2006). "The influence of information technology on patientphysician relationships." J Gen Intern Med 21 Suppl 1: S35-39.

Weinstein, M. (2012, 15 May, 2012). "TAMS Analyzer for Macintosh OS X: The native open source, Macintosh qualitative research tool." Retrieved 17 May, 2012, from http://tamsys.sourceforge.net/.

World Health Organization (2011). World report on disability, World Health Organization.

World Health Organization. (2013, 2013-09-11 10:28:03). "WHO | Disability and health." WHO Retrieved 2 January, 2014, from http://www.who.int/mediacentre/factsheets/fs352/en/index.html. 